\title{
Investigation of Particulate Matter Size Distribution and Concentration During Low Temperature Combustion
}

\author{
Ramamoorthy Balakrishnan \\ West Virginia University
}

Follow this and additional works at: https://researchrepository.wvu.edu/etd

\section{Recommended Citation}

Balakrishnan, Ramamoorthy, "Investigation of Particulate Matter Size Distribution and Concentration During Low Temperature Combustion" (2011). Graduate Theses, Dissertations, and Problem Reports. 4687.

https://researchrepository.wvu.edu/etd/4687

This Thesis is protected by copyright and/or related rights. It has been brought to you by the The Research Repository @ WVU with permission from the rights-holder(s). You are free to use this Thesis in any way that is permitted by the copyright and related rights legislation that applies to your use. For other uses you must obtain permission from the rights-holder(s) directly, unless additional rights are indicated by a Creative Commons license in the record and/ or on the work itself. This Thesis has been accepted for inclusion in WVU Graduate Theses, Dissertations, and Problem Reports collection by an authorized administrator of The Research Repository @ WVU. For more information, please contact researchrepository@mail.wvu.edu. 
Investigation of Particulate Matter Size Distribution and Concentration During Low Temperature Combustion

Ramamoorthy Balakrishnan

Thesis submitted to the College of Engineering and Mineral Resources

at West Virginia University

in partial fulfillment of the requirements

for the degree of

Master of Science

in

Mechanical Engineering

Dr. Mridul Gautam, Chair

Dr. Benjamin C. Shade

Dr. Gregory J. Thompson

Dr. John P. Nuszkowski

Department of Mechanical and Aerospace Engineering

Morgantown, West Virginia

2011

Keywords: Low Temperature Combustion, Particulate Matter, Emissions, Advanced Combustion

Copyright 2011 Ramamoorthy Balakrishnan 


\title{
Investigation of Particulate Matter Size Distribution and Concentration During Low Temperature Combustion
}

\author{
Ramamoorthy Balakrishnan
}

\begin{abstract}
Stringent emissions regulations imposed by US EPA on diesel engine manufacturers have shifted the focus towards development and implementation of in-cylinder emissions reduction strategies. In order to simultaneously achieve low oxides of nitrogen $\left(\mathrm{NO}_{\mathrm{x}}\right)$ and particulate matter (PM) emissions, along with high thermal efficiencies, advanced combustion concepts, such as low temperature combustion (LTC), have been identified as promising approaches. Furthermore, fuel properties, such as cetane number $(\mathrm{CN})$ have been known to critically affect the combustion process and hence exhaust emissions.
\end{abstract}

The primary objective of this study was to investigate the impacts of LTC on PM size distribution and number concentration for two different fuels - one a low and other a high CN. A 1.9l turbocharged diesel engine equipped with a common rail injection system and cooled high pressure EGR was employed for this work. Additionally, the OEM engine control unit (ECU) was replaced by an independent controller, allowing open access to control a number of ECU parameters. The engine was instrumented with an in-cylinder pressure transducer to calculate the in-cylinder bulk temperature as a function of crank angle position. Gaseous brake specific emissions were measured from a full-flow CVS tunnel system following the procedures outlined in 40 CFR, 1065. The study was aimed at characterizing the size distribution and concentration of solid accumulation mode particles, as these reflect the in-cylinder PM formed during LTC operation. Due to an expected increase in hydrocarbon emissions, the PM sampling setup was designed to remove the volatile fraction by means of a two stage dilution system, with a hot first stage and cold second stage dilution. A scanning mobility particle sizer (SMPS, 3936) was employed to measure number concentrations and size distributions of PM emissions. A design of experiment (DOE) technique, making use of orthogonal arrays and ANOVA, was employed in order to simplify the process of achieving LTC by varying only four engine parameters, namely variable geometry turbocharger (VGT) vane position, exhaust gas recirculation (EGR) rate, start of pilot injection and fuel rail pressure.

Low temperature combustion was achieved at an engine speed of $2100 \mathrm{rpm}$ and a target brake mean effective pressure (BMEP) of 3.5 bar by employing a split fuel injection strategy, increasing the EGR rates and fuel injection rail pressures, and advancing fuel injection timing. A unique combination of all these four parameters was identified to simultaneously produce low NOx, low soot, and low in-cylinder bulk temperatures. The identified optimal parameter setting for both fuels showed a reduction in the NOx-PM trade-off, compared to conventional combustion. PM emissions decreased by over $84 \%$ during operation of the low CN fuel, along with a $51 \%$ increase in the NOx emissions, when compared to the high CN fuel. Although the low CN fuels exhibited zero soot characteristics, there was a drastic increase in the THC and CO emissions when compared to the high CN fuels. Advancing SOI timing resulted in an increase in nanoparticle emissions for both the fuels supporting the hypothesis. Finally, a comparison of PM 
size distribution between conventional combustion and LTC during the operation of a low CN fuel revealed a significant shift towards nucleation mode particles thus suggesting a strong impact of CN property on exhaust emissions. 


\section{Table of Contents}

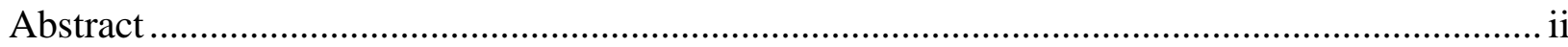

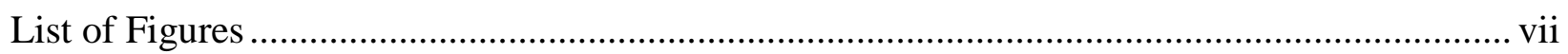

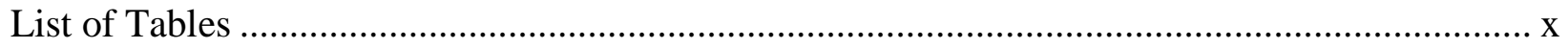

Nomenclature.

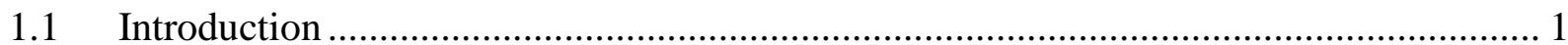

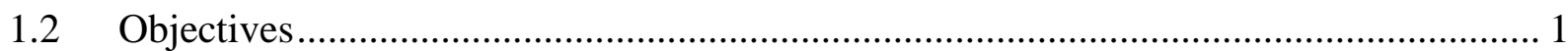

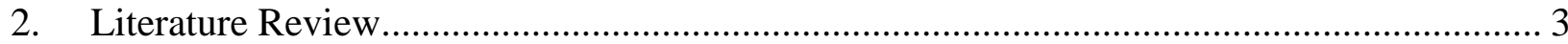

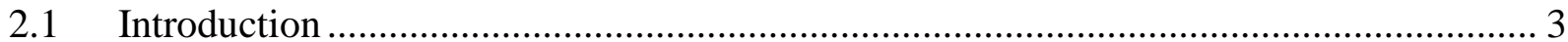

2.2 Advanced Combustion Vs. Conventional Combustion ...................................................... 3

2.3 Advantages of Advanced Combustion.............................................................................. 5

2.4 Disadvantages of Advanced Combustion .................................................................. 5

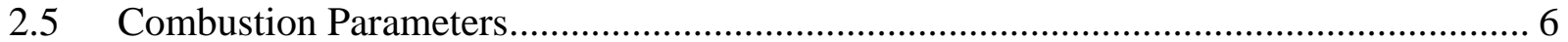

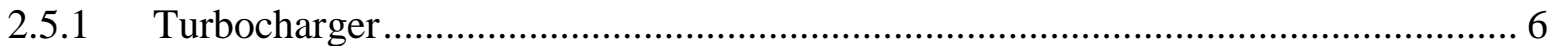

2.5.2 Exhaust Gas Recirculation ................................................................................... 8

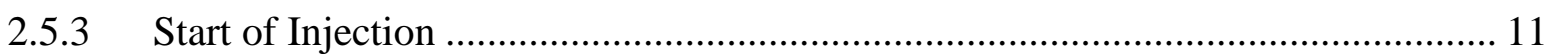

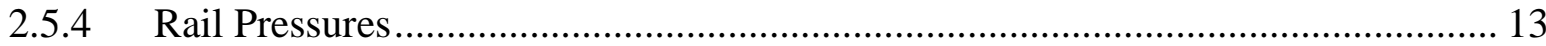

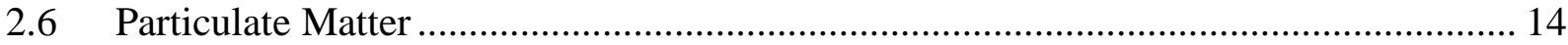

2.6.1 Composition of Particulate Matter...................................................................... 16

2.6.2 Formation of Particulate Matter.......................................................................... 16

2.7 Factors Affecting Nanoparticle Formation ............................................................ 18

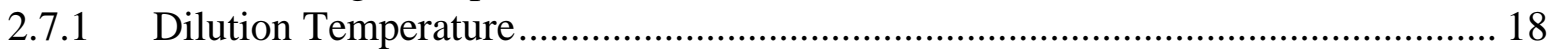

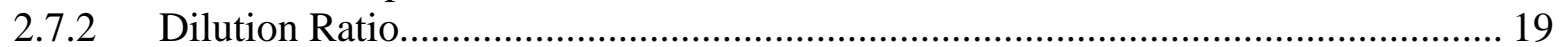

2.7.3 Residence Time and Humidity................................................................................. 19

2.8 PM in Advanced Diesel Combustion ...................................................................... 20

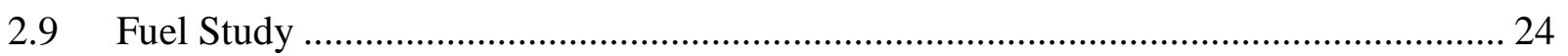

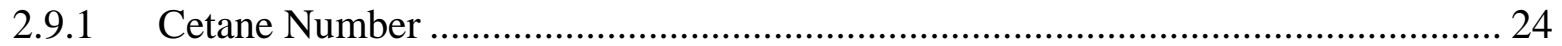

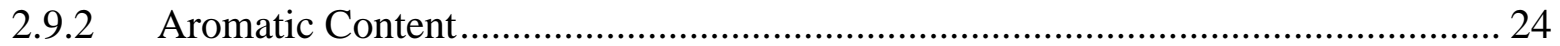

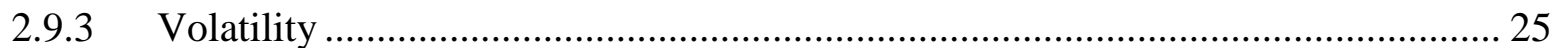

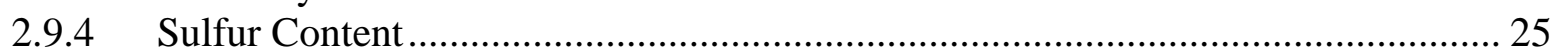

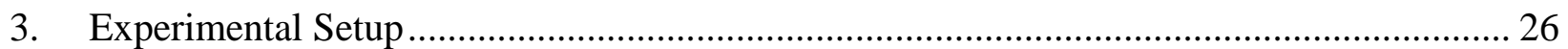

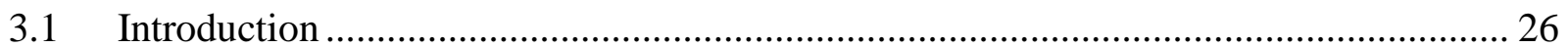

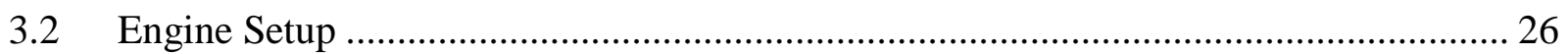

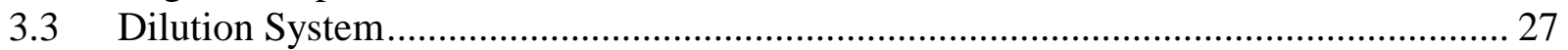

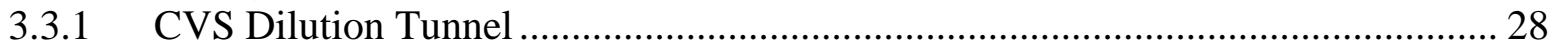

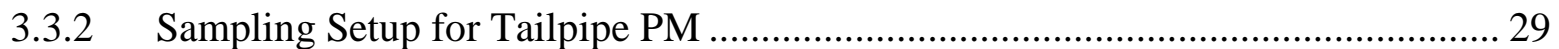

3.4 Temperature and Humidity Control of Intake and Dilution Air ..................................... 33

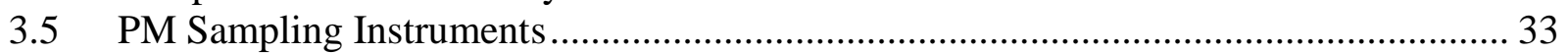

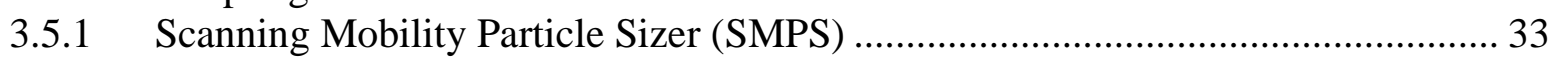

3.5.2 Engine Exhaust Particle Sizer (EEPS) .................................................................... 37

3.5.3 AVL Micro Soot Sensor …………………..................................................... 39

3.6 Total Hydrocarbon Measurement..................................................................................... 41

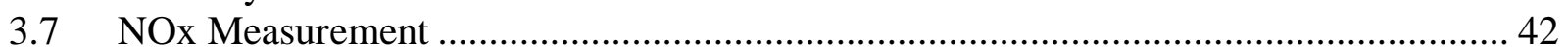




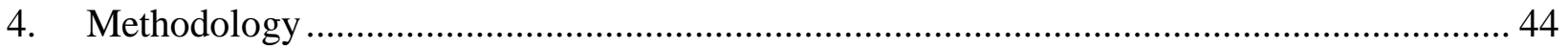

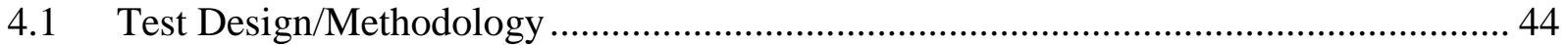

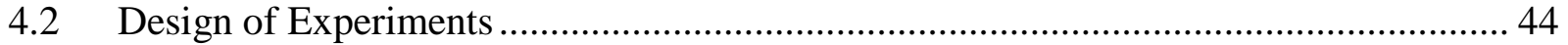

4.3 Determination of Parameters along with the Number of Levels................................. 45

4.4 Strategy Implementation for High Cetane/Low Cetane Fuel........................................ 45

4.5 Level Assignment for High Cetane/Low Cetane Fuel ................................................. 46

4.5.1 SOI level Assignment for High Cetane Fuel ..................................................... 47

4.5.2 SOI Level Assignment for Low Cetane Fuel................................................... 47

4.6 Analysis of Variance .......................................................................................... 48

4.7 Selection of Optimum Combination of Parameters ................................................. 51

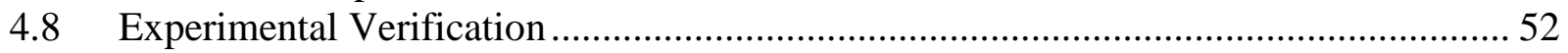

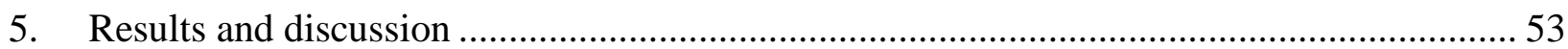

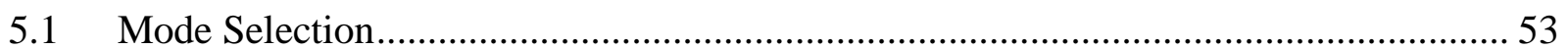

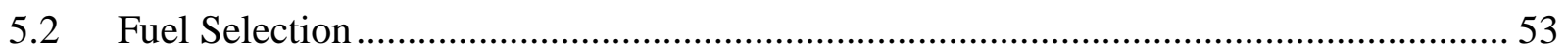

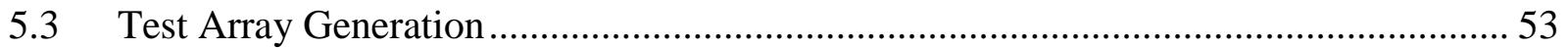

5.4 Results for High Cetane Fuel ............................................................................ 54

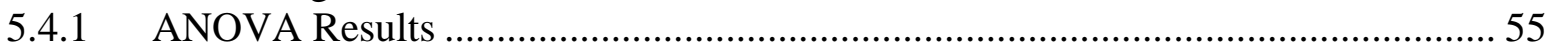

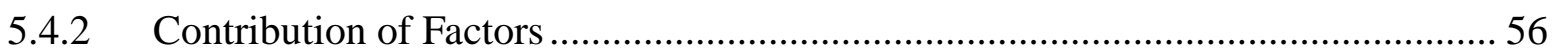

5.4.3 Effect of Control Factors on In-Cylinder Bulk Temperature............................... 57

5.4.4 Effect of Control Factors on NOx Emissions ................................................... 58

5.4.5 Effect of Control Factors on Particle CMD ...................................................... 58

5.4.6 Strongest Parameters influencing In-Cylinder Bulk Temperature......................... 59

5.4.7 Strongest Parameters influencing NOx Emissions and Particle CMD ................... 60

5.4.8 Optimal Configuration for High Cetane Fuel .................................................... 64

5.4.9 Comparison of NOx and Soot Emissions Between Optimum Strategy and

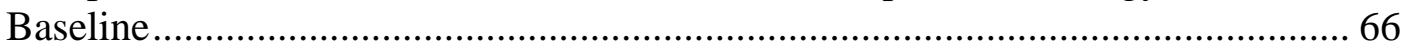

5.4.9 Comparison of NOx and Soot Emissions Between Optimum Strategy and

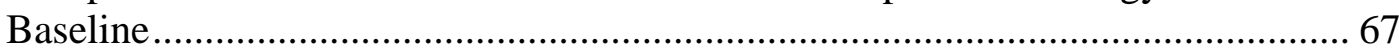

5.4.10 Comparison of PM Size Distribution Between Optimum Strategy and Low NOx

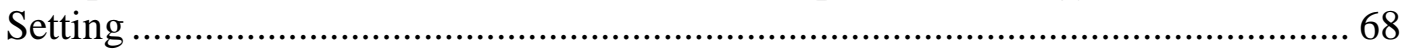

5.4.11 Comparison of PM Size Distribution Between Optimum Strategy and Low Soot

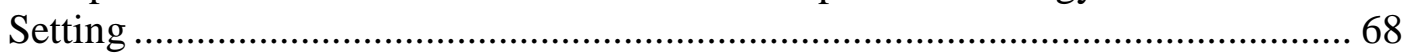

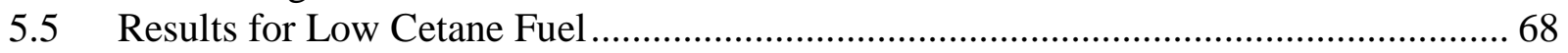

5.5.1 Test Matrix for Low Cetane Fuel with Responses............................................ 69

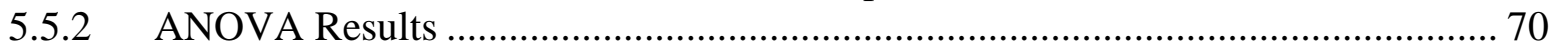

5.5.3 Contribution of Fators............................................................................ 70

5.5.4 Effect of Control Factors on In-Cylinder Bulk Temperature.................................. 71

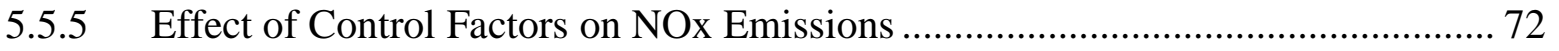

5.5.6 Effect of Control Factors on Particle CMD ....................................................... 73

5.5.7 Strongest Parameters Influencing In-Cylinder Bulk Temperature ........................ 73

5.5.8 Strongest Parameters Influencing NOx Emissions ............................................. 74

5.5.9 Strongest Parameters Influencing Particle CMD .............................................. 76 
5.5.10 Optimal Strategy for Low Cetane Fuel ........................................................ 78

5.5.11 Comparison of Emissions Between Optimum Strategy and Baseline ................... 80

5.5.12 Comparison of PM Size Distribution Between Optimum Strategy and Baseline .. 81

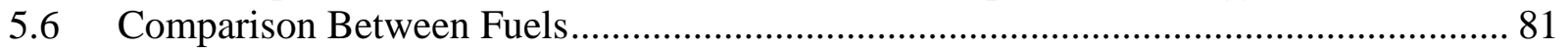

5.6.1 Comparison of Emissions Between Optimum Strategy of the Fuels..................... 81

5.6.2 Comparison of PM Size Distribution Between Optimum Strategy of the Fuels .... 83

5.6.3 Comparison of Particle CMD Between Fuels during Optimum Strategy Based on

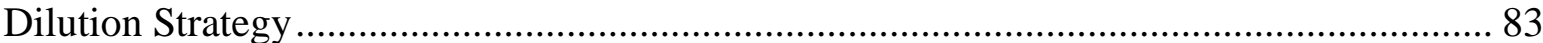

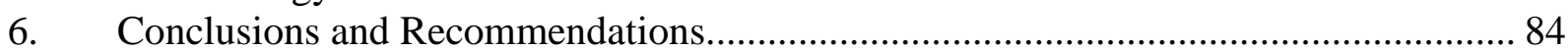

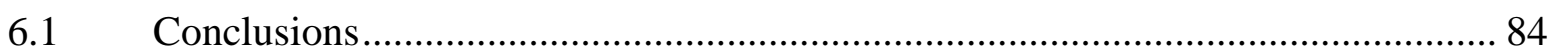

6.2 Recommendations ............................................................................... 85

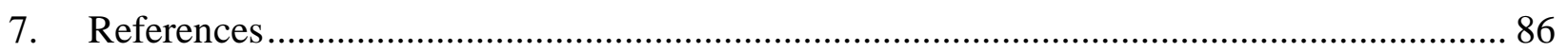

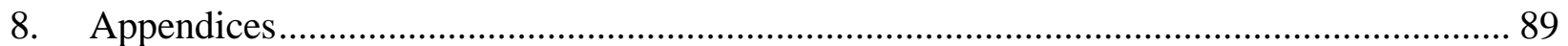




\section{List of Figures}

Figure 1: Illustration of Normal Combustion Left and HCCI Right [4] ....................................

Figure 2: Conceptual Model for Conventional Combustion with LTC [3] .................................

Figure 3: Cut-Away View of a Turbocharger [8] .................................................................. 6

Figure 4: VGT Vane Position at Low Speeds [7] .............................................................

Figure 5: VGT Vane Position at High Speeds [7] …………...............................................

Figure 6: Effects of $\mathrm{O}_{2}$ Variability in Intake Charge on In-Cylinder Pressures [9]...................9

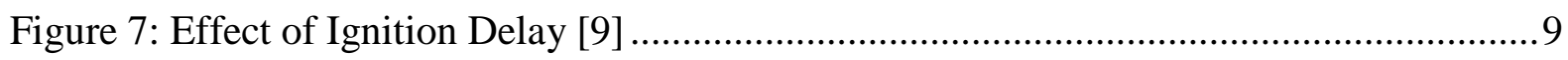

Figure 8: Effects of Cooled/Uncooled EGR on PM and BSFC [10] ......................................10

Figure 9: Effect of EGR on Hydrocarbons [11]................................................................1

Figure 10: Cylinder Pressure and Heat Release Rates with Retarded SOI [12] ......................12

Figure 11: UNIBUS and Comparison Injection Strategies [13] ..............................................13

Figure 12: NOx Emission as a Function of SOI for Different Injection Pressures [15] ..........14

Figure 13: PM Emission as a Function of SOI for Different Injection Pressures [15] .............14

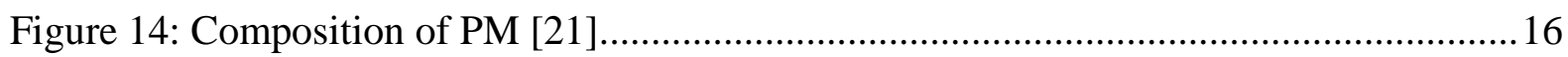

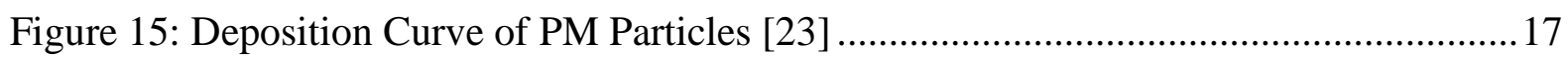

Figure 16: Effects of Dilution Temperature on PM [17] ....................................................19

Figure 17: Effects of Residence Time on Particle Growth [21] ...............................................20

Figure 18: Comparison of Particle Size Distribution Between Different Thermal Denuder

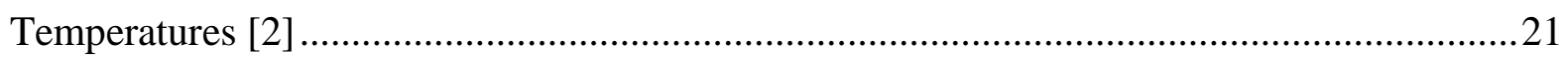

Figure 19: PM Composition for Conventional Vs. PCCI [24] ................................................22

Figure 20: PM Size Distribution Between Conventional Combustion and PCCI [24]............22

Figure 21: PM Size Distribution Between Conventional Combustion and PCCI [24]............23

Figure 22: PM Size Distribution Comparison Between PCCI and HCCI [24].........................23

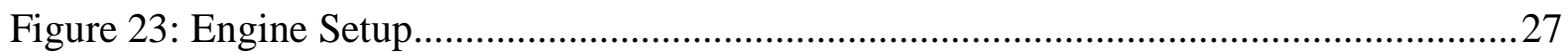

Figure 24: CVS System at EERL, West Virginia University ..................................................28

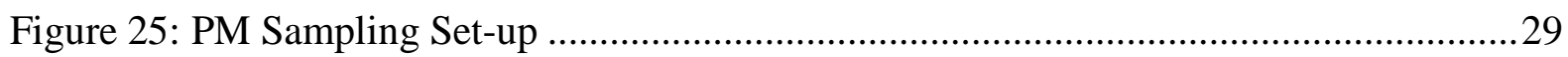

Figure 26: Working Principle of an Ejector Diluter [31]...........................................................32

Figure 27: Ejector Diluter Model TD-110H [32] ...............................................................

Figure 28: SMPS with Nano DMA and CPC Model 3786 [34] ..............................................34

Figure 29: Cross Sectional View of Inertial Impactor [34] ....................................................35 
Figure 30: Flow Schematic of Electrostatic Classifier with Long DNA [34]........................36

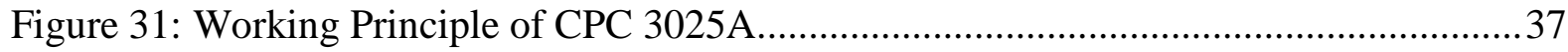

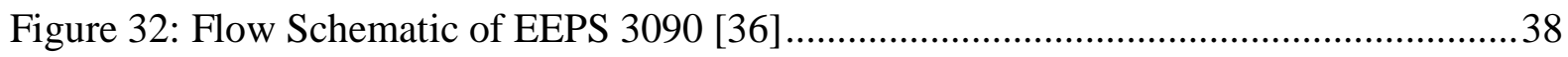

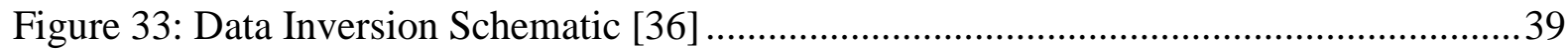

Figure 34: A Comparison of SMPS and EEPS Particle Size Data for a Heavy-Duty Diesel

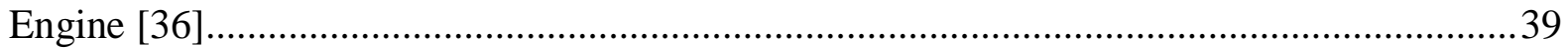

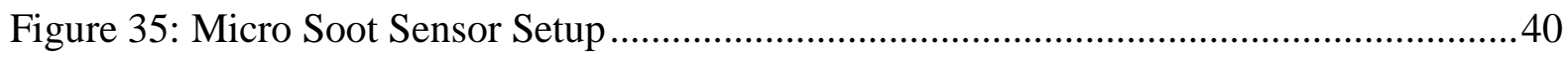

Figure 36: Working of a Micro-Soot Sensor [37] .............................................................. 40

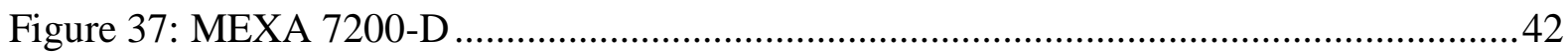

Figure 38: Effect of Control Factors on In-Cylinder Bulk Temperature ..............................57

Figure 39: Effect of Control Factors on NOx Emissions..................................................58

Figure 40: Effect of Control Factors on PM Count Median Diameter .................................59

Figure 41: Effects of Rail Pressure on In-Cylinder Bulk Temperature ...............................59

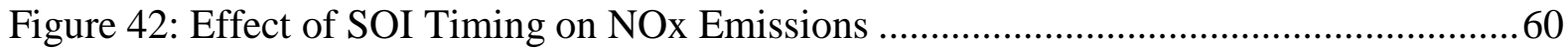

Figure 43: Effect of EGR on NOx Emissions................................................................61

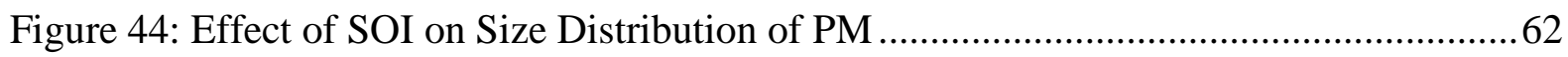

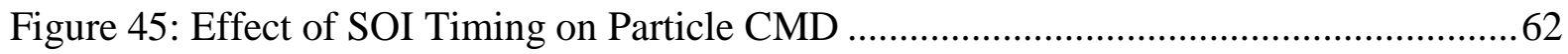

Figure 46: Effect of EGR on Particle Size Distribution ....................................................63

Figure 47: Total Number Concentration of PM Particles ..................................................64

Figure 48: Response Curve for High Cetane Fuel ...........................................................65

Figure 49: Comparison Between Baseline and Optimum Point for NOx and Soot................66

Figure 50: Comparison of Gaseous and Soot Emissions Between Baseline and Optimum

Strategy

Figure 51: Comparison of Particle Size Distribution Between Identified Optimal Strategy and

Low NOx Strategy.

Figure 52: Comparison of PM Size Distribution Between Low Soot Strategy and Optimum

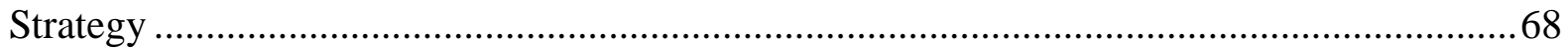

Figure 53: Effect of Control Factors on In-Cylinder Bulk Temperature .............................. 72

Figure 54: Figure 54: Effect of Control Factors on NOx Emissions ...................................72

Figure 55: Figure 54: Effect of Control Factors on Particle CMD .....................................73

Figure 56: Effects of Rail Pressure on In-Cylinder Bulk Temperature ...............................74 
Figure 57: Effect of EGR Rate on NOx Emissions ........................................................75

Figure 58: Effects of VGT on NOx Emissions.............................................................75

Figure 59: Effect of VGT Vane Position on Particle CMD at Same EGR Rate....................76

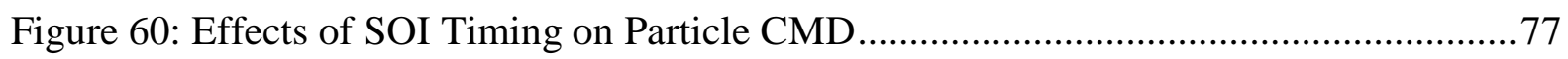

Figure 61: Total Number Concentration of PM Particles ...................................................77

Figure 62: Response Curve for Low Cetane Fuel.........................................................78

Figure 63: Comparison Between NOx and Soot Emissions during Baseline Operation and

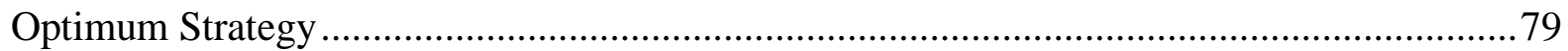

Figure 64: Comparison of Emissions Between Baseline and Optimum Strategy for Low Cetane

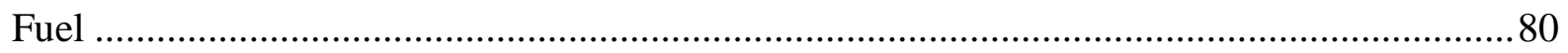

Figure 65: Comparison of PM Size Distribution Between Baseline and Optimum Strategy for

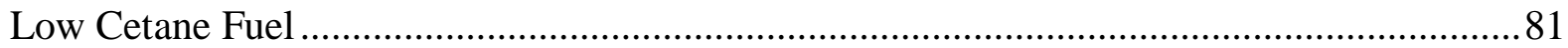

Figure 66: Comparison of Gaseous Emissions Between Fuels ........................................82

Figure 67: Comparison of Soot Emissions Between Fuels...............................................82

Figure 68: Comparison of PM Size Distribution Between Fuels .......................................83 


\section{List of Tables}

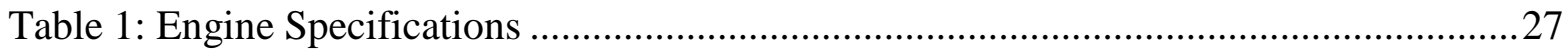

Table 2: Dilution Settings for Accumulation Mode Particles..................................................30

Table 3: Dilution Settings for Nuclei Mode Particles................................................................. 31

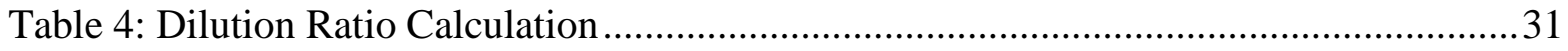

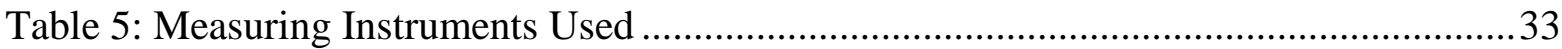

Table 6: Specifications of AVL Miro Soot Sensor [37] ......................................................... 41

Table 7: Test Matrix L18 ....................................................................................................45

Table 8: Strategy Implementation for the Tests...................................................................46

Table 9: Level Assignment for High Cetane Fuel ......................................................................4

Table 10: Level Assignment for Low Cetane Fuel ..................................................................48

Table 11: FACE Properties....................................................................................................53

Table 12: Test Matrix for High Cetane Fuel Along with Responses........................................54

Table 13: ANOVA Table for High Cetane Fuel .....................................................................56

Table 14: Contribution of Control Factors on Responses...........................................................56

Table 15: Strongest Parameters on Response for High Cetane Fuel .......................................57

Table 16: Optimal Parameter Settings for High Cetane Fuel ...................................................65

Table 17: Test Matrix with Responses for Low Cetane Fuel ....................................................69

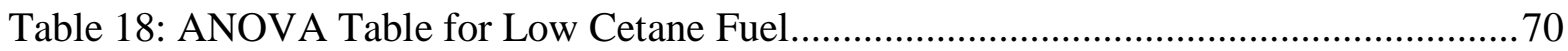

Table 19: Effects of Control Factors on Emissions Responses ................................................ 71

Table 20: Strongest Parameters on Response for Low Cetane Fuel.........................................71

Table 21: Optimum Strategy for Low Cetane Fuel .................................................................79

Table 22: CMD Comparison Between Fuels for Different Dilution Strategies........................83

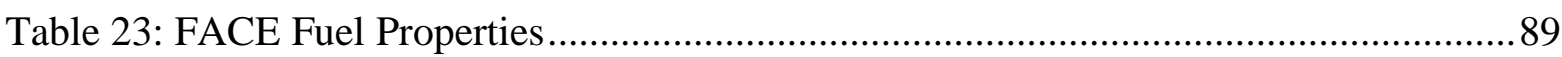




\section{Nomenclature}

After Top Dead Center

ATDC

Air Fuel Ratio

$\mathrm{A} / \mathrm{F}$

Analysis of Variance

ANOVA

Analyzer Rack

ANR

Aspect Ratio

$\mathrm{A} / \mathrm{R}$ ratio

Before Top Dead Center

BTDC

Break Mean Effective Pressure

BMEP

Break Specific Fuel Consumption

BSFC

Break Specific Particulate Matter

BSPM

California Air Resources Board

CARB

Carbon Dioxide

$\mathrm{CO}_{2}$

Carbon Monoxide

$\mathrm{CO}$

Cetane Number

$\mathrm{CN}$

Code of Federal Regulations

CFR

Combustion Temperature

CT

Compression Ignition

CI

Condensation Particle Counter

CPC

Constant Volume Sampler

CVS

Controlled Auto Ignition

CAI

Coordinating Research Council

CRC

Count Median Diameter

CMD

Data Acquisition

DAQ

Degrees of Freedom

DOF

Design of Experiments

DOE

Diesel Particulate Filter

DPF

Diesel Particulate Matter

DPM

Differential Mobility Analyzer

DMA

Electronic Control Unit

ECU

Electrostatic Classifier

EC

Engine Exhaust Particle Sizer

EEPS 


$\begin{array}{ll}\text { Engines Emissions Research Laboratory } & \text { EERL } \\ \text { Exhaust Gas Recirculation } & \text { EGR } \\ \text { Fuels for Advanced Combustion Engines } & \text { FACE } \\ \text { High Efficient Clean Combustion } & \text { HECC } \\ \text { Homogeneous Charge Compression Ignition } & \text { HCCI } \\ \text { Homogeneous Charge Diesel Charge Combustion } & \text { HCDC } \\ \text { Insoluble Organic Fraction } & \text { ISOF } \\ \text { Interface Unit } & \text { IFU } \\ \text { Low Temperature Combustion } & \text { LTC } \\ \text { Main Control Unit } & \text { MCU } \\ \text { Manifold Air Pressure } & \mathrm{MAP} \\ \text { Mean Square } & \mathrm{MS} \\ \text { Nitric Oxide } & \mathrm{NO} \\ \text { Nitrogen Dioxide } & \mathrm{NO} 2 \\ \text { Original Equipment Manufacturer } & \mathrm{OEM} \\ \text { Oxides of Nitrogen } & \mathrm{NOx} \\ \text { Oxygen } & \mathrm{O} 2 \\ \text { Parts per Million } & \mathrm{PPM} \\ \text { Polycyclic Aromatic Hydrocarbon } & \mathrm{PAH} \\ \text { Power Supply Unit } & \mathrm{PSU} \\ \text { Premix Charge Compression Ignition } & \mathrm{PCCI} \\ \text { Rail Pressures } & \mathrm{RP} \\ \text { Sample Handling System } & \mathrm{SHS} \\ \text { Scanning Mobility Particle Sizer } & \mathrm{SMPS} \\ \text { Solenoid Valve System } & \mathrm{SVS} \\ \text { Solid Organic Fraction } & \mathrm{SOF} \\ \text { Start of Injection } & \mathrm{SOI} \\ \text { Subsonic Venturi } & \mathrm{SSV} \\ \text { Sulfur Trioxide } & \mathrm{SO} 3 \\ \text { Sum of Squares } & \mathrm{SS} \\ \text { Total Hydrocarbons } & \end{array}$


Uniform Bulky Combustion System

United States Environment Protection Agency

Variable Geometry Turbocharger

Water
UNIBUS

USEPA

VGT

$\mathrm{H}_{2} \mathrm{O}$ 


\section{Introduction}

Diesel engines have been very popular for both on-road and off- road heavy duty applications owing to their robustness and ability to produce high torque. However, with stricter emission regulations diesel engine manufactures have found it very difficult to attain a balance between cleaner emissions, better fuel economy and higher thermal efficiencies. One of the biggest challenges that engine manufacturers have been facing is the trade-off between the oxides of nitrogen (NOx) and particulate matter (PM) formation. As a result advanced low temperature combustion strategies have been identified as one of the ways by which NOx and PM can be simultaneously reduced without increasing fuel consumption. Advanced combustion in a diesel engine can be achieved by varying engine parameters such as exhaust gas recirculation (EGR), fuel injection timing and rail pressures. Practical implementation of advanced combustion strategies such as homogeneous charge compression ignition (HCCI), premix charge compression ignition (PCCI), and low temperature combustion (LTC) have been restricted by lean flammability limits at low loads and high in-cylinder pressures at high loads [1]. However, recent advancements in sensor technologies, injector design and controls have aided in the implementation of advanced combustion strategies in real world applications [1].

Conventional combustion studies show increased PM with higher EGR rates and start of injection (SOI) near top dead centre (TDC). The working hypothesis is that during LTC increased EGR and advancing pilot SOI will result in lower elemental carbon (EC). However, very early injections before TDC may expose the cylinder wall and result in higher total hydrocarbons (THC) emissions accompanied by an increase in nano-particles. Furthermore, it is also hypothesized that with no concomitant change in combustion chamber and cylinder geometry, and fuel injection equipment (FIE) use of higher rail pressures may result in wallwetting and subsequently, increase in nanoparticles may be observed.

\subsection{Objective}

Various studies pertaining to advanced combustion have been conducted in the past. The global objective of this study was to investigate the impact of LTC on the number concentration and size distribution of PM emissions. The specific objectives were (1) to optimize engine control 
parameters namely variable geometry turbocharger (VGT) vane position, EGR rate, SOI timing and fuel injection rail pressure (RP) to attain LTC and compare the PM size distribution between LTC and conventional combustion (using a OEM ECU) and (2) to study the effects of cetane number (CN) of fuels on PM concentration and size distribution. Results of this study will provide insights into effects of $\mathrm{CN}$ of fuels on an advanced combustion enabled engine; thereby leading to lower PM and NOx emissions. 


\section{Literature Review}

\subsection{Introduction}

HCCI is synonymous with other advance combustion methods such as controlled auto ignition (CAI), PCCI, homogeneous charge diesel charge combustion (HCDC), LTC etc [1]. HCCI is an efficient clean combustion technique wherein a premix charge of air and fuel which is homogeneous enters the cylinder. HCCI/PCCI which combines the benefits of a gasoline and diesel engine, has created a breakthrough in technology towards attaining stringent USEPA emission regulations with minimal exhaust after-treatment devices. Differences exists between HCCI and PCCI although the purposes of these techniques are the same [2]. HCCI involves injection of a homogenous charge of air and fuel into the cylinder, whereas in PCCI, the fuel injection is advanced into the cylinder to give it more time to mix thoroughly with air and form a homogenous mixture [2]. In both of these techniques the combustion temperature (CT) is lowered to reduce the NOx emissions relative to the conventional combustion [2]. The use of HCCI is not consistent in the literature since a completely homogeneous mixture has to address challenges such as limited load range, engine controllability and knocking, and thus various concepts have evolved to initiate a stratified charge. Thus a generic term, LTC, is used since the main purpose of all the advanced combustion techniques revolves around the concept of lowering the temperature of combustion, hence resulting in lower emissions [3].

\subsection{Advanced Combustion Versus Conventional Combustion}

The primary factor affecting the NOx formation is the in-cylinder temperature. Conventional combustion characterized by elevated temperatures of approximately $1800 \mathrm{~K}-2200 \mathrm{~K}$ results in increased thermal NOx formation [5]. An alternative to conventional combustion is LTC which could result in lower NOx formation. Figure 1 shows the difference between conventional and advanced combustion. 

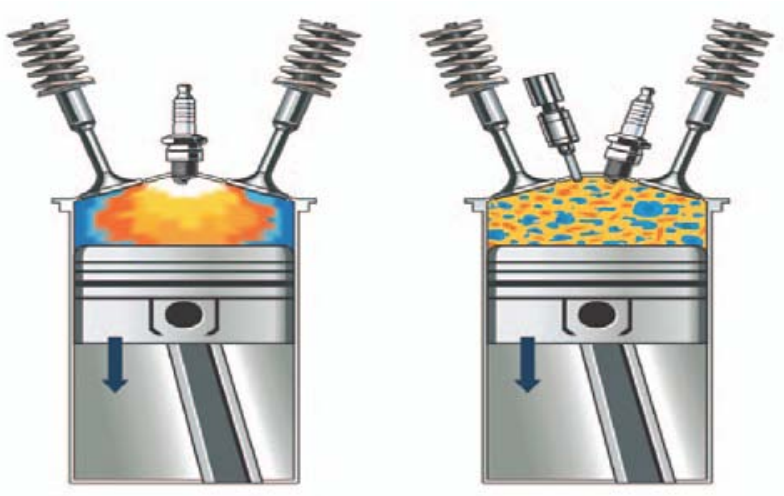

Figure 1: Illustration of Normal Combustion Left and HCCI Right [4]

LTC is characterized by significantly low combustion temperatures in the range of $1000 \mathrm{~K}$ 1400K. However, this may result in an increased brake specific THC, carbon monoxide (CO) and PM emissions due to incomplete combustion [5]. LTC can be achieved in an electronically controlled diesel engine through changes in VGT vane position, injection timings, EGR rate and rail pressures. The EGR reduces the NOx by lowering the combustion temperature by substituting carbon dioxide $\left(\mathrm{CO}_{2}\right)$ and water $\left(\mathrm{H}_{2} \mathrm{O}\right)$ for $\mathrm{O}_{2}$. The substituted carbon dioxide has a higher specific heat capacity and acts as a heat sink; thus absorbing the heat and reducing the combustion temperature. The lower combustion temperature in turn inhibits the formation of thermal NOx. Increased EGR rates are characterized by higher PM emissions due to the decrease in combustion efficiencies. Hence, LTC techniques employ a combination of advanced injection timing and high injection pressures to counter the PM formation by increasing fuel burn fraction. Figure 2 shows the soot formation from a conventional diesel and LTC spray cone [3]. 


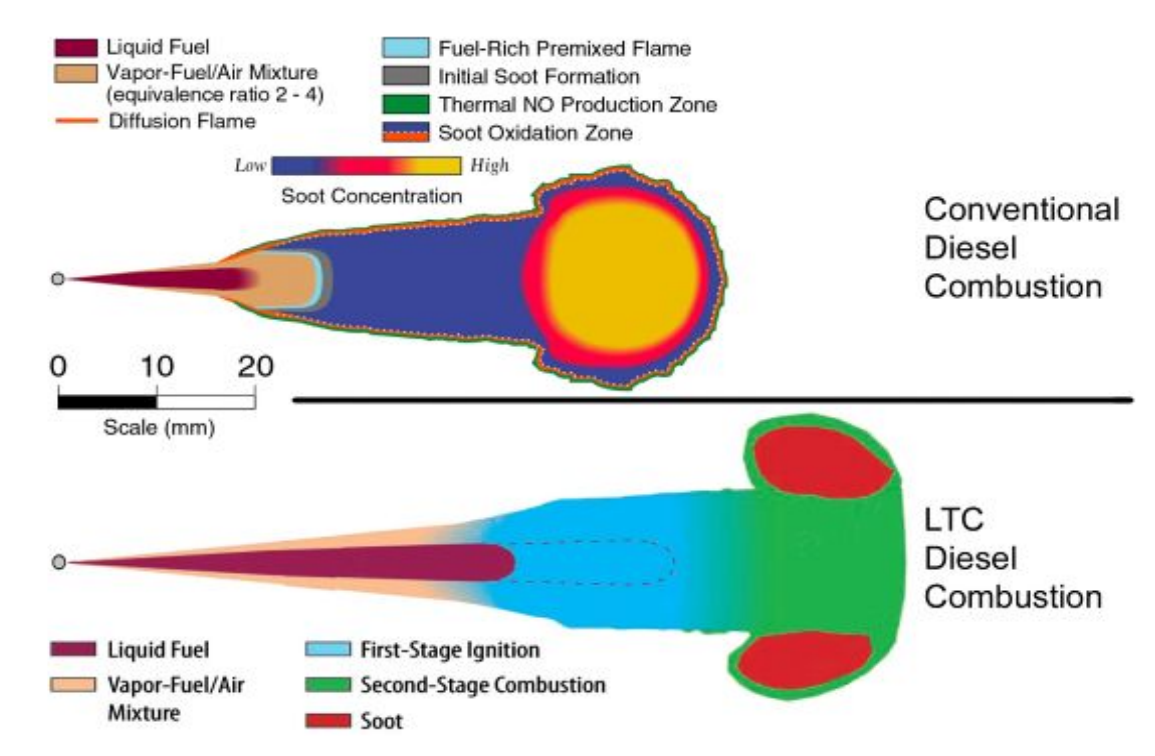

Figure 2: Conceptual Model for Conventional Combustion with LTC [3]

During LTC, early injections along with lower combustion temperatures leads to a long diesel jet penetration before the liquid and vapour separate out. This results in wall wetting and hence incomplete oxidation of hydrocarbons [3].

\subsection{Advantages of Advanced Combustion}

In conventional diesel engines the combustion chamber would consist of rich and lean pockets. The bulk of soot is usually formed in the fuel rich zone at the head of spray jet. In the case of a LTC fuel jet, such a zone does not exist as early injections ensure a better mixture of fuel and air as shown in Figure 2. Furthermore, advanced combustion can be initiated in a conventional diesel engine without any change in engine geometry and hardware. Advanced combustion also reduces the dependence on after treatment systems namely DPF, SCR and their associated complexities. Though having these advantages LTC has not been commercially implemented because of the plethora of challenges (see section 2.4) that need to be addressed.

\subsection{Disadvantages of Advanced Combustion}

LTC has not been practically implemented because of the difficulties in effectively controlling combustion under varying load conditions of the engine. LTC has proved to result in stable combustion during engine operation at low and medium load conditions. However, at higher loads a steep increase in the combustion temperature and pressure has contributed to elevated 
levels of NOx and possible engine material failure. Another disadvantage associated with advanced combustion is cold start operation where low combustion temperature leads to heat dissipation across cold cylinder walls contributing to high $\mathrm{HC}$ and $\mathrm{CO}$ as a result of misfiring [6]. Thus PM emissions have high soluble organic fraction (SOF) content [1]. To address this issue, a dual mode operation has been suggested. During cold start and at higher loads conventional combustion could be an option while LTC can be employed at low and medium loads. Another disadvantage of LTC is the trade-off between HC and NOx levels. With lower temperature combustion the $\mathrm{HC}$ and $\mathrm{CO}$ levels are very high compared to conventional combustion. This is because of incomplete oxidation of fuel. Lower exhaust temperatures also increase complexities in exhaust after-treatment system design to counter THC and CO emissions.

\subsection{Combustion Parameters}

In-cylinder combustion in a compression ignition (CI) engine can be controlled by a number of parameters, namely VGT vane position, EGR fraction, rail pressure and start of injection.

\subsubsection{Turbocharger}

A turbocharger is employed to improve the volumetric efficiency of an engine. It can pressurize the intake manifold with up to 2.5 times more air than the engines natural displacement [7].

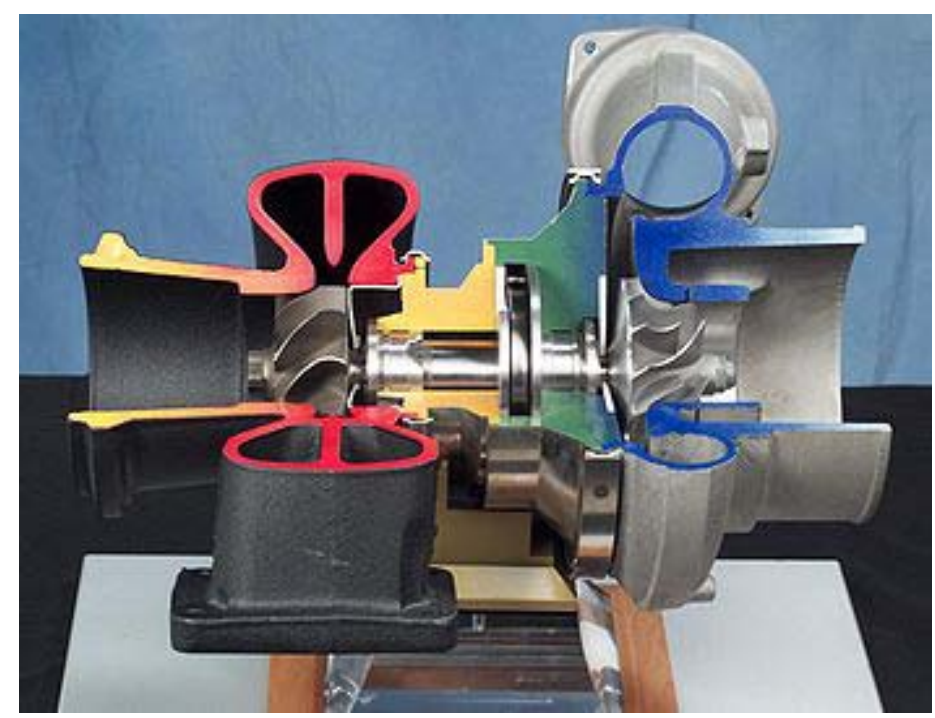

Figure 3: Cut-away View of a Turbocharger [8] 
Types of turbocharger include

- Fixed geometry turbocharger

- Variable geometry turbocharger (VGT)

A fixed geometry turbocharger suffers from the inability to provide sufficient boost at lower speeds/loads and fails to provide quick response to throttle input. At higher speeds, presence of wastegate carefully bypasses the exhaust to avoid spinning the turbine shaft at speeds beyond its safe operation and excess boost the inlet manifold. Thus the fixed aspect ratio(A/R ratio) has to be chosen in such a way to provide higher power at lower engine speeds reducing turbo lag or at higher engine speeds to produce greater total power output [8].

\subsubsection{Variable Geometry Turbocharger}

Boost must be controlled during the load/speed variations of an engine operation resulting in production of more net power. Moreover, advanced diesel engines technologies are equipped with a EGR loop, which along with the VGT is an integral part of a control strategy to limit the NOx emissions. Thus, apart from producing boost during the load/speed changes in an engine operation, VGT is also responsible for creating a gradient across the exhaust and intake manifolds that would drive the EGR into the intake manifold.

A VGT shown in Figure 4, is designed in a way that the geometry and thus the A/R ratio changes with change in the vane position. The most common design of a VGT is a set of movable vanes in the turbine housing controlling the amount of boost by controlling the turbine inlet pressure. During lower engine speeds when the exhaust flow rate is low the vanes remain partially closed to increase the exhaust pressure pushing the turbine blades faster thus producing more boost shown in Figure 4. At higher engine speeds the vanes remains fully open to decrease the exhaust pressure thus controlling the boost as seen in Figure 5. These vanes are adjusted by actuators controlled by ECU based on various parameters, such as manifold air pressure (MAP), throttle, EGR rate. 

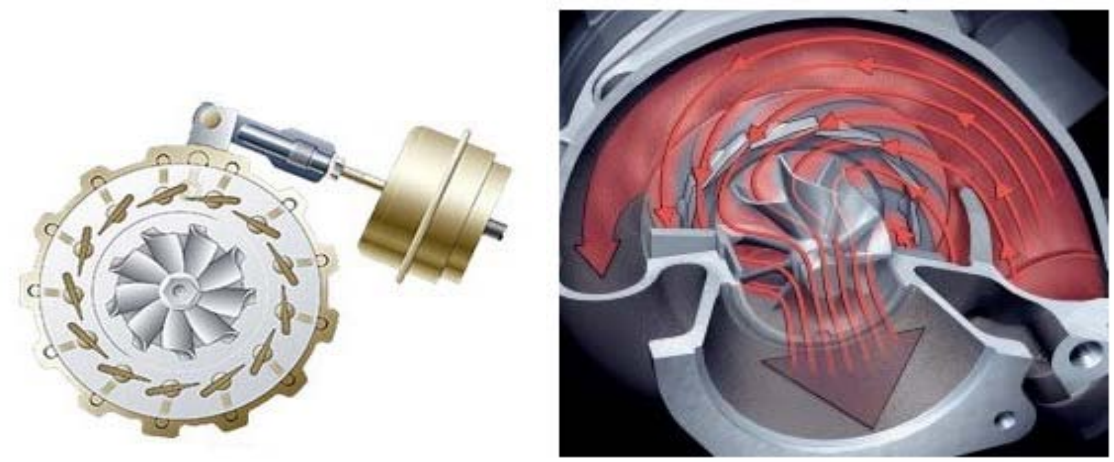

Figure 4: VGT Vane Position at Low Speeds [7]
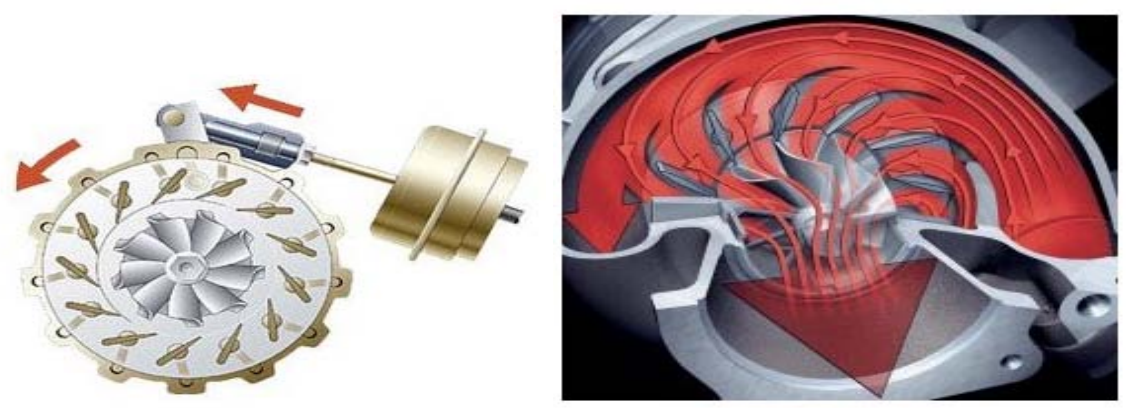

Figure 5: VGT Vane Position at High Speeds [7]

\subsubsection{Exhaust Gas Recirculation}

Exhaust gas recirculation is an in-cylinder NOx control technique, which employs re-circulation of exhaust gases back into the intake system resulting in reduction of cylinder pressures and pressure rise rates.

EGR operates by substituting $\mathrm{CO}_{2}$ and $\mathrm{H}_{2} \mathrm{O}$ for $\mathrm{O}_{2}$ and diluting the charge. Decreasing $\mathrm{O}_{2}$ concentration aids in delayed combustion phasing seen in Figure 6 and reduced cylinder pressures observed in Figure 7. This behaviour is a result of variability in $\mathrm{O}_{2}$ concentration which affects the mixing rates of fuel and oxygen. Thus, reduced $\mathrm{O}_{2}$ decreases the oxidation reactions and diffusion rates resulting in reduced cylinder pressures. 


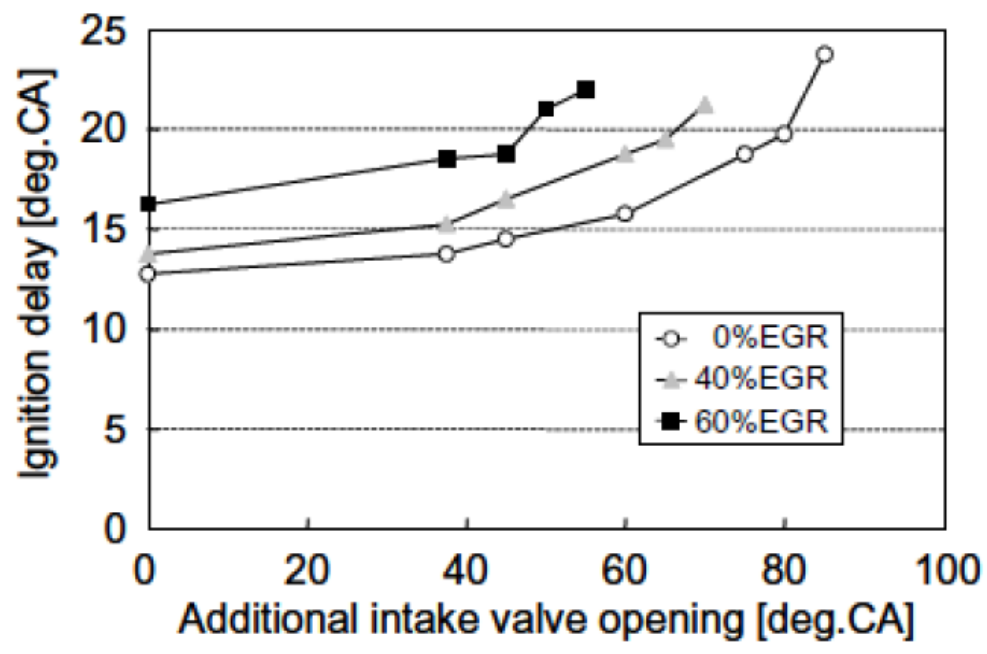

Figure 6: Effect of Ignition Delay as a Function of CA [9]

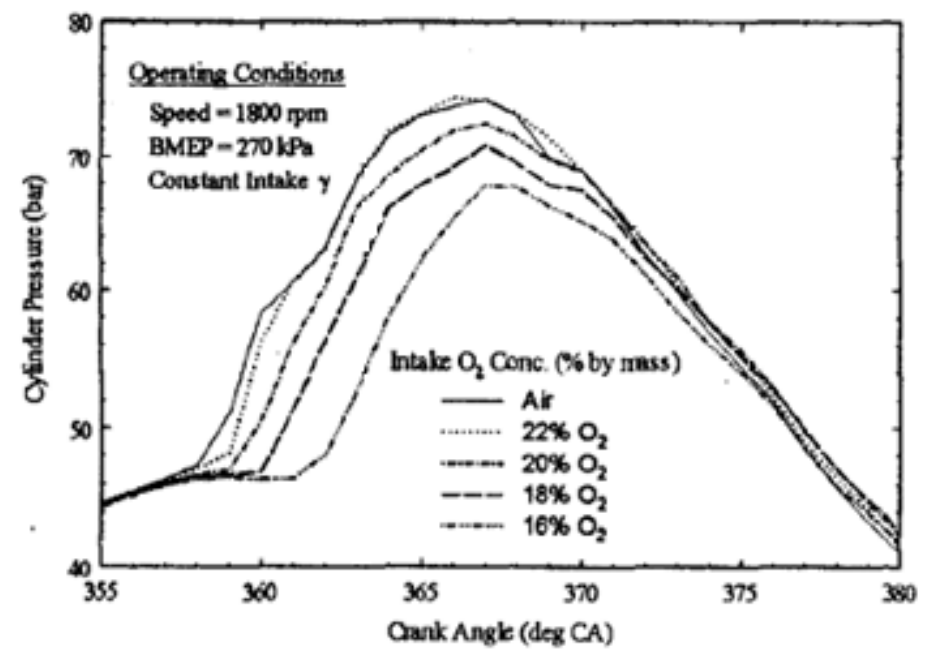

Figure 7: Effects of $\mathrm{O}_{2}$ Variability in Intake Charge on In-Cylinder Pressures [10]

EGR can be implemented as hot/cooled, high pressure/low pressure. Each EGR strategy has its advantages/disadvantages. Although EGR helps in reducing the NOx it has an incremental effect on soot formation. Effects of cooled/hot EGR on PM emissions and brake-specific fuel consumption can be seen in Figure 8.

Figure 8 shows increased brake specific particulate matter (BSPM) and brake specific fuel consumption (BSFC) for higher EGR rates. It further shows that uncooled EGR yields lower BSPM numbers than cooled EGR with higher fuel consumption. Cooled EGR results in better 
NOx reduction in comparison to hot EGR [10]. This is because when adding the same amount of heat the resulting combustion temperatures are lower due to the lower inlet temperatures. In addition, a lower inlet temperature allows cramming more air and EGR into the cylinder absorbing more heat.

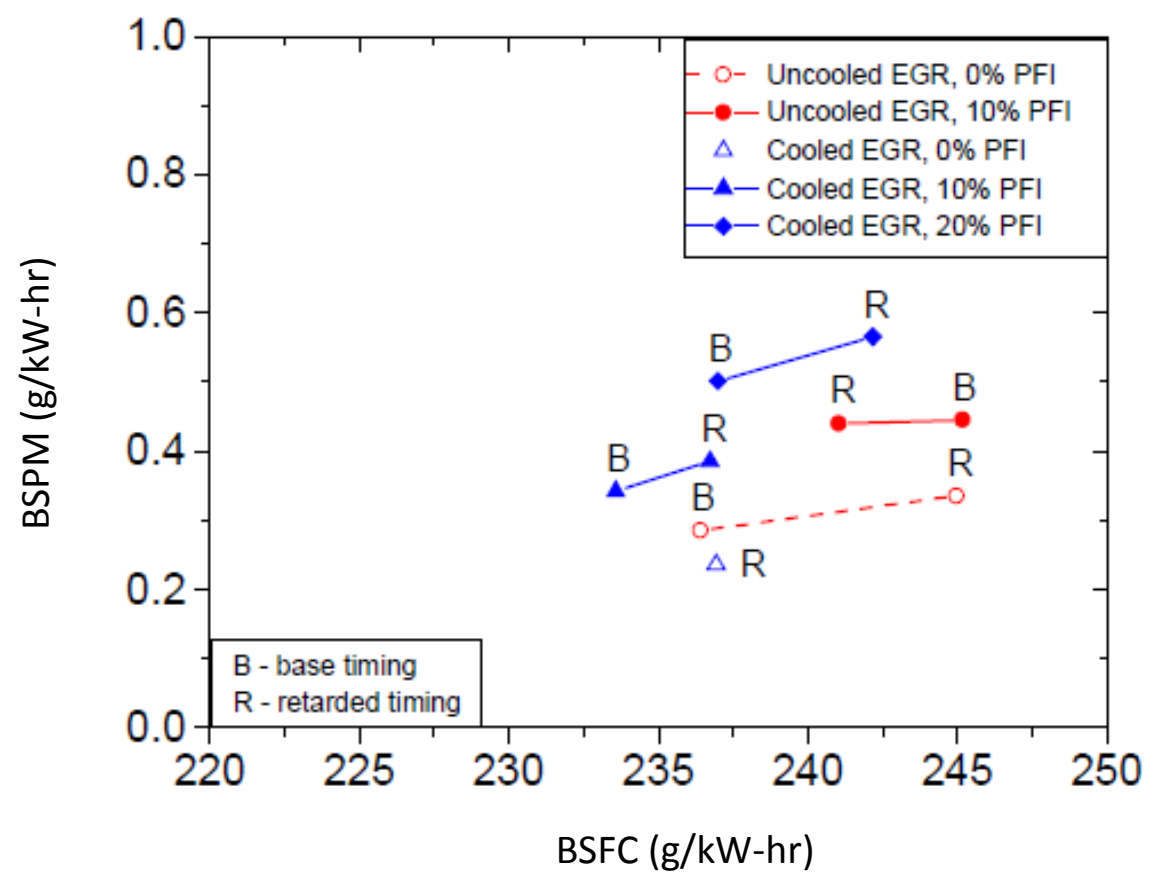

Figure 8: Effects of Cooled/Uncooled EGR on PM and BSFC [10]

Figure 9 shows the concentration of total hydrocarbon emissions with an increase in percentage of EGR. The increase in hydrocarbon concentration is primarily due to the reduction in combustion temperature caused by higher EGR rates which primarily results in lower fuel burn fraction. 


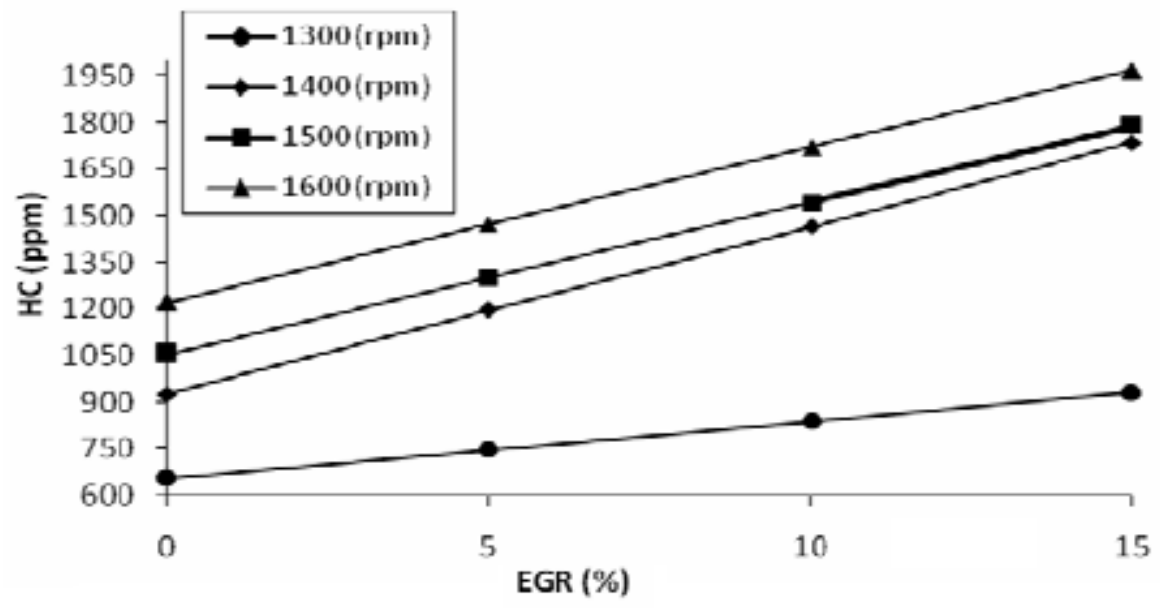

Figure 9: Effect of EGR on Hydrocarbons [11]

EGR will remain the most crucial factor in achieving advanced combustion since an optimized EGR ratio along with advanced start of injection will help achieve lower NOx and PM emissions.

\subsubsection{Start of Injection}

Start of injection is one of the prime parameters that is controlled to achieve advanced combustion. Literature shows that retarded SOI timing helps in reduced cylinder pressures resulting in lower heat release rates (see Figure 10) and delayed combustion phasing [12]. 

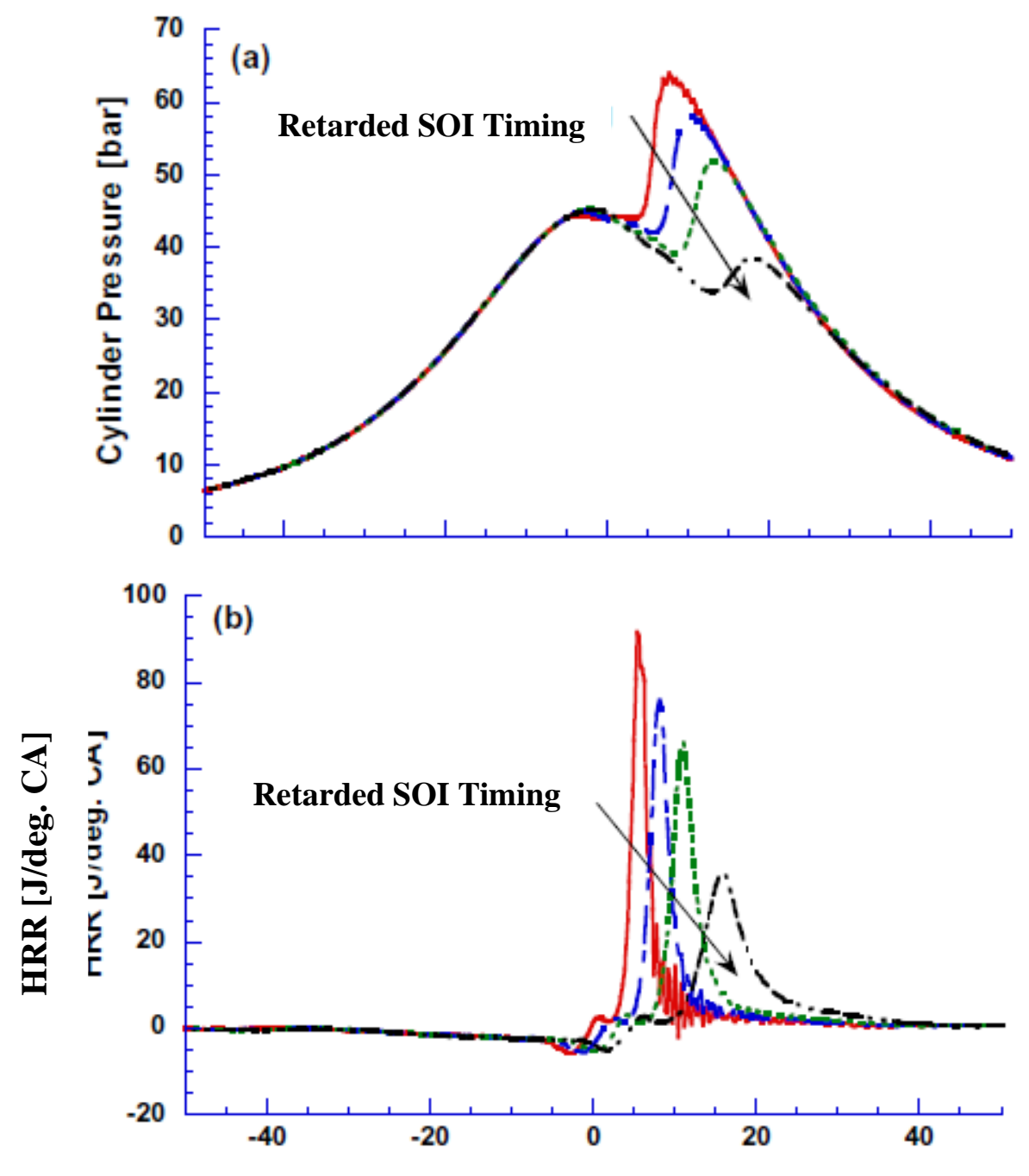

Crank Angle [deg. ATDC]

Figure 10: Cylinder Pressure and Heat Release Rates with Retarded SOI [12]

To achieve advanced combustion with homogeneous charge, advancing SOI timing is the most common path. Along with advanced injection, higher rail pressures are also implemented in modern compression ignition engines for better atomization and better spray mixing. However this control strategy is limited by higher in-cylinder pressures, thus requiring a diluent such as EGR or split injection to control high pressure rise rates.

\subsubsection{Split Fuel Injection}

Electronically controlled fuel injection has led to the implementation of split fuel injection strategies. Split fuel injection helps in lowering peak cylinder pressures, thus helps in producing 
lower engine-out NOx. Optimal split injection strategies could ensure lower EGR rates, hence lower PM emissions and better brake-specific fuel consumption. Hasegawa et al. explored multiple injection strategies (see Figure 11) on an HCCI concept termed uniform bulky combustion system (UNIBUS) [13].

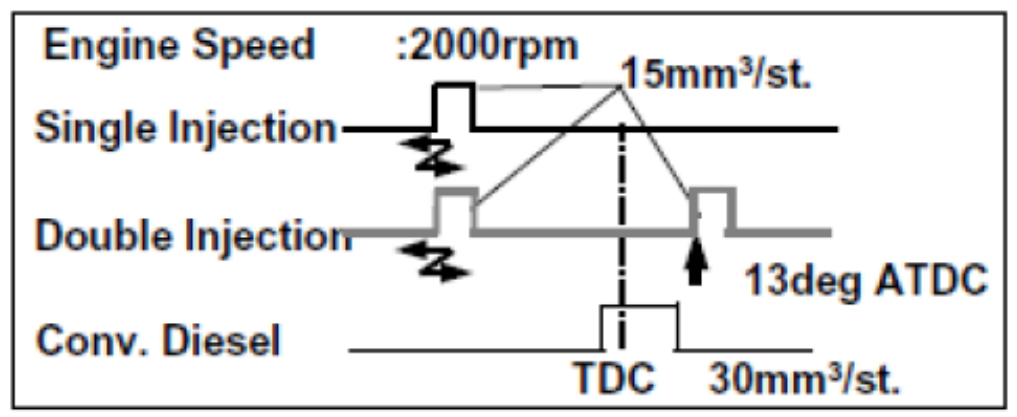

Figure 11: UNIBUS and Comparison Injection strategies [13]

Results of this study by Toyota Motor Company showed that by using split injection techniques the NOx and smoke can be reduced without sacrificing brake mean effective pressure (BMEP). This meant that for the same amount of fuel injected compared to conventional combustion the amount of work done by the engine was similar with lower NOx and smoke levels [13].

\subsubsection{Injection Pressure}

Electronic control over fuel injection time and quantity, along with higher injection pressures achieved by the modern injection technologies is another factor contributing to advanced combustion [14]. Higher injection pressure of the fuel essentially means better atomization of fuel and thus better mixing of the fuel with the intake air ensuring lower PM emissions. Increased fuel injection pressure also affects the combustion phasing subsequently affecting emission formation as observed in Figure 12. 


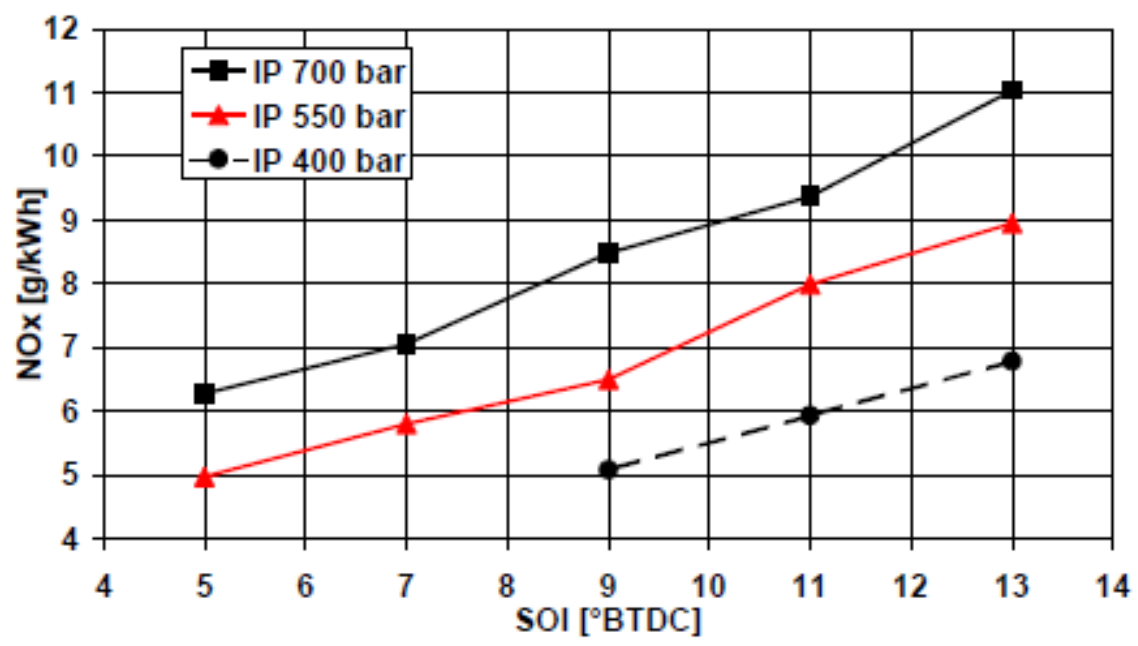

Figure 12: NOx Emission as a Function of SOI for Different Injection Pressures [15]

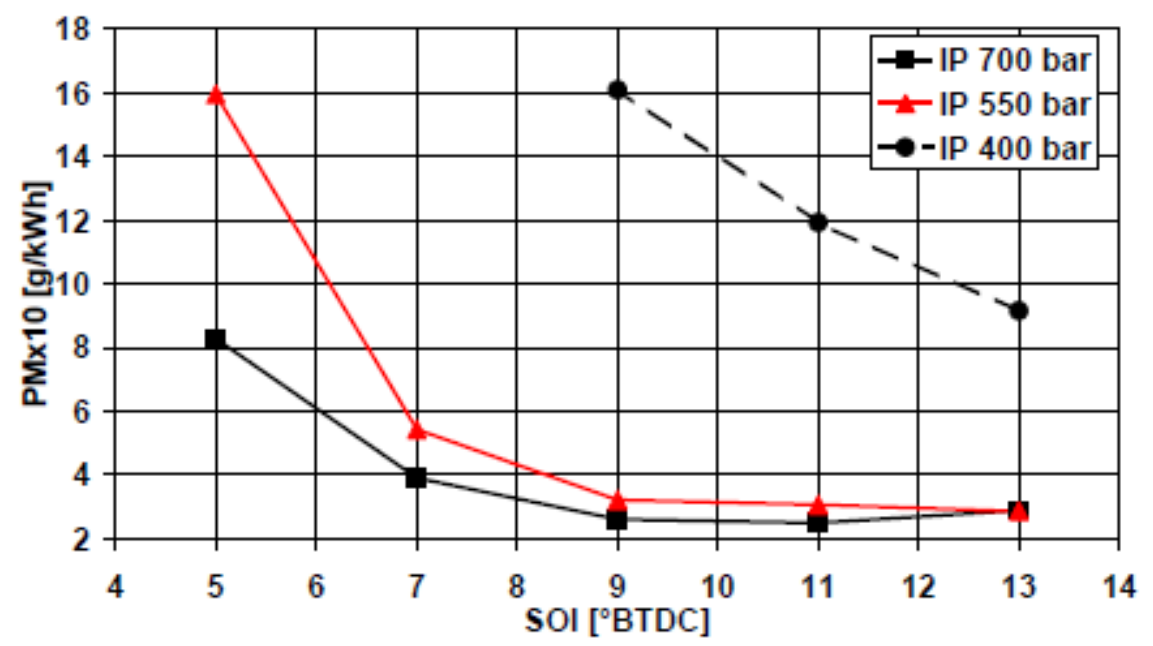

Figure 13: PM Emission as a Function of SOI for Different Injection Pressures [15]

Figure 13 shows the reduction in PM emissions with higher rail pressures. Results from this study conducted by Mallamo et al. further shows that advancing injection with higher rail pressures produced lower PM with a penalty in NOx emissions. Better mixing capabilities are initiated at higher rail pressures thus ensuring an early start of combustion and therefore more NOx and more complete combustion to reduce the PM.

\subsection{Particulate Matter}

Diesel particulate matter (DPM) is composed of two phases namely gas and particle phase. Gas phase consists of air pollutants such as acetaldehyde, acrolein, benzene, 1, 3-butadiene, 
formaldehyde and polycyclic aromatic hydrocarbons [16]. Particle phase may consist of fine and ultrafine particles [16]. They may also consist of organic compounds, sulfates, nitrates other metals adsorbed onto elemental carbon [16].

DPM can be broadly classified into elemental carbon (EC) and volatile or organic carbon (OC) formed during dilution and cooling of exhaust. Organic carbon predominantly consists of condensed hydrocarbons compounds [17]. European Union has developed PM regulation to regulate the particle number count above a cut point aerodynamic diameter of 23nm. However, the current European particle measurement protocol only considers contribution of elemental carbon towards particle number count due to variability's associated with the production of nucleation mode particles. The European particle measurement protocol has been developed to quantify the elemental carbon fraction of PM only, due to the better measurement accuracy and to monitor the efficiency of diesel particulate filter (DPF). Studies show that although the PM mass emissions downstream of a DPF are close to detection limits, PM number concentrations have found to be an order of magnitude higher than baseline concentration [18]. Moreover nanoparticles found downstream of DPF are completely volatile in characteristic and their formation is highly dependent on exhaust temperature and dilution conditions. In the US, PM mass emissions have been heavily regulated owing to their potential health and environmental hazards. Diesel PM has been attributed for reduced visibility and other health hazards. Studies suggest that particles with diameter smaller than $50 \mathrm{~nm}$ have adverse health effects in humans and animals [19]. The small liquid droplets and solid particles of nanometre size have the capacity to get deep into human lungs and cause asthma and lung diseases [19]. There have been cases of decreased lung function, chronic bronchitis and irregular heartbeats in humans with the deposition of these small particles [19]. Oberdorster [20] revealed that these nanoparticles can penetrate through to the blood stream and reach the brain. Somers et al. [20] made a study on PM to reveal that the nanoparticles are capable of causing hereditary mutation. These health effects have prompted the EPA to regulate PM from 1988 at $0.6 \mathrm{~g} / \mathrm{bhp}$-hr to the present $0.01 \mathrm{~g} / \mathrm{bhp}$-hr which is a reduction of about an order of magnitude over the past two decades. 


\subsubsection{Composition of Particulate Matter:}

Particulate matter is composed of three fractions namely solid fraction, soluble organic fraction and sulfate fraction (see Figure 14). Solid fraction is generally the elemental carbon formed due to the in-cylinder combustion process and ash that is formed due to engine wear and lube oil contribution. This portion is the major contribution to the total mass of the particulate matter. The soluble organic fraction and sulfate fraction are a result of volatile hydrocarbons and sulfates that form particles during dilution and effect of humidity to form sulfuric acid particles [22]. This fraction contributes to the number count of the particles and adds very little to the mass emissions. The soluble organic fraction and the sulphate fraction together are called the volatile organic matter.

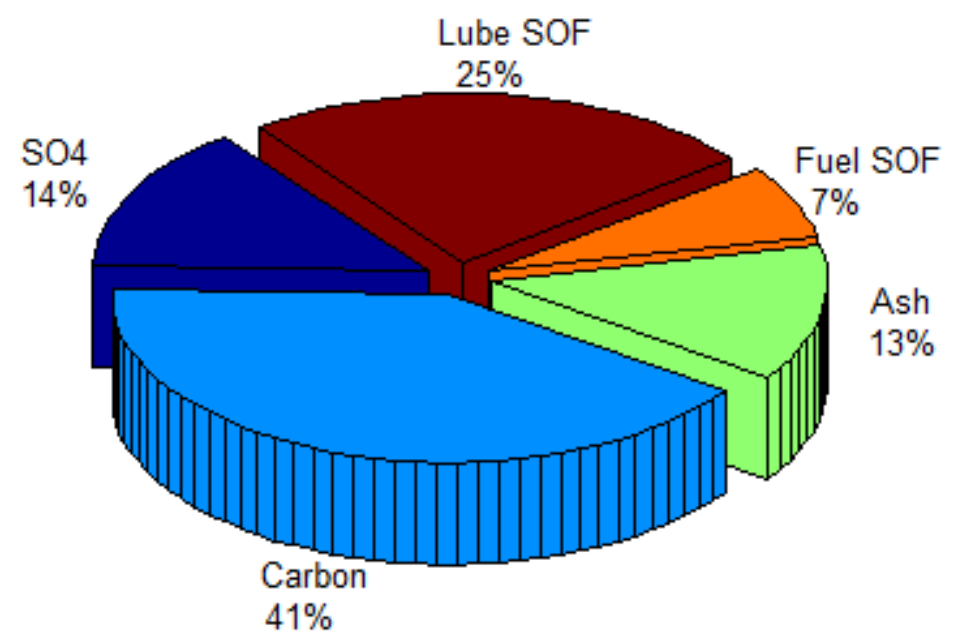

Figure 14: Composition of PM by Mass [21]

\subsubsection{Formation of Particulate Matter:}

It is essential to understand the fundamental science behind particulate matter formation in order to determine its effects and thus reduce it further. The formation of particulate matter is highly non linear. The effect of PM on health greatly depends on the type and distance of exposure from its source. This is due to the changing characteristics of PM with constant dilution and ageing ambient conditions. 


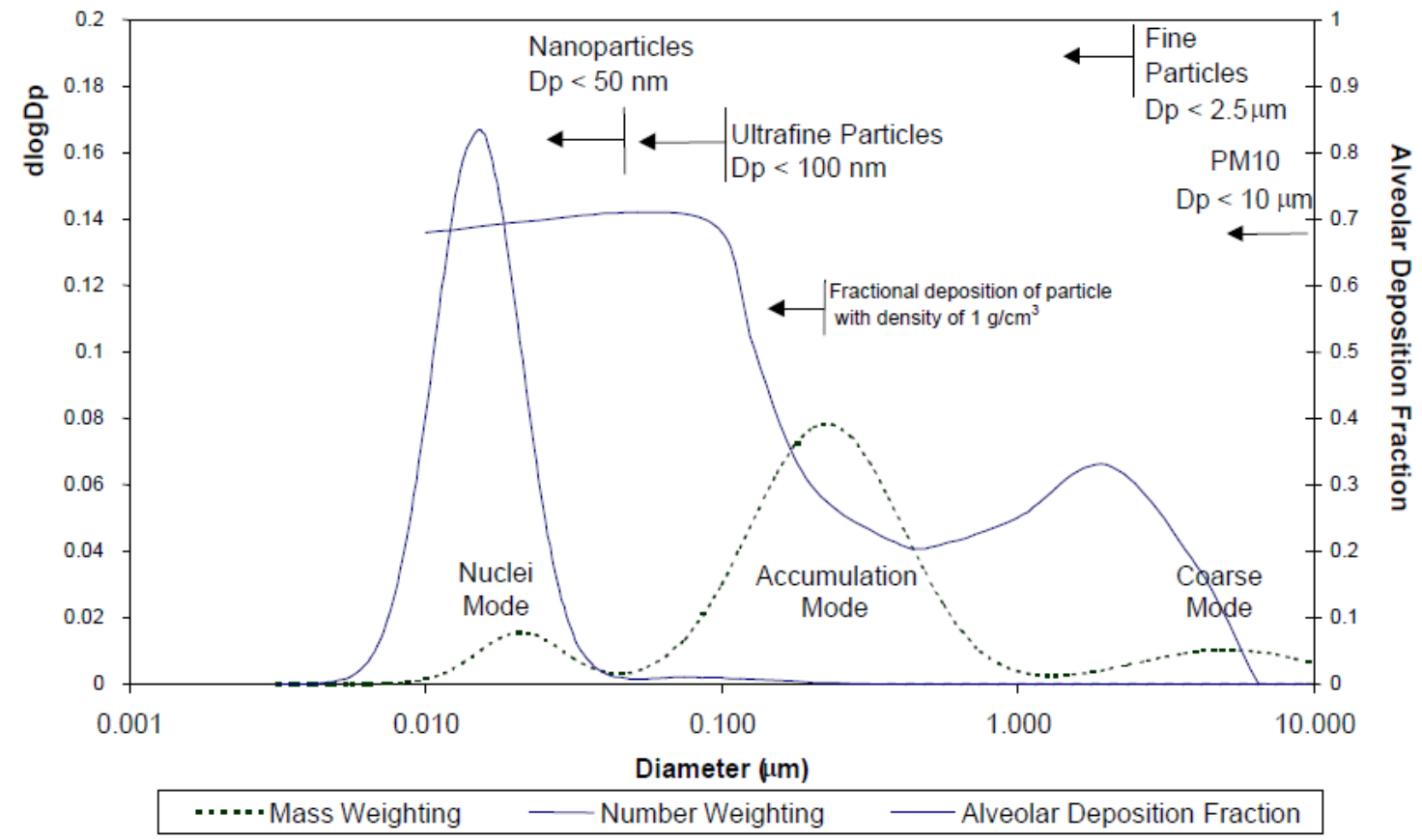

Figure 15: Deposition Curve of PM Particles [23]

Figure 15 shows the classification of particles based upon their size namely nuclei mode, accumulation mode and course mode. The figure also shows the size of PM10, PM2.5 and PM1. Typically, nuclei mode particles vary in diameter from 5-50nm and contribute to about $20 \%$ of the total mass concentration while contributing to more than $90 \%$ towards the particle number concentration [23]. The accumulation mode particles range between 50nm to $1000 \mathrm{~nm}$ and it mainly contributes to $70 \%$ of the total particulate mass [23]. The course mode particles greater than 1 micrometer diameter typically contributes to about $10 \%$ of the total mass concentration. However, they are no longer produced by modern engines and are thus considered as an artefact and removed [23].

\subsubsection{Mechanisms of PM Formation}

The three major types of PM formation mechanisms are discussed briefly in this section.

- Homogenous Particle Formation

- Heterogeneous Particle Formation

- Secondary Particulate Matter 


\subsection{Homogeneous Particle formation}

When the exhaust is diluted and cooled with ambient air, condensation occurs. As a result of it, super saturation if reached, the gaseous phase of PM may condense on itself and nucleate to produce large number of ultrafine nanoparticles. This process is known as homogeneous nucleation (gas to particle conversion).

\subsection{Heterogeneous Particle formation}

Heterogeneous nucleation may arise when the volatile compounds condense onto the carbon species and coagulate. The elemental carbon particle absorbs the volatile components thus not allowing the saturation ratio to reach super saturation and hence preventing homogeneous nucleation [23].

\subsection{Secondary Particulate matter}

Gaseous emissions like sulfur dioxide, sulfur trioxide and oxides of nitrogen when emitted from the engine react with humidity in the atmosphere and may form sulphuric acid particles, sulphate particles and nitrate particles which contributes to the secondary particulate matter.

\subsection{Factors affecting Nanoparticle Formation}

Complexity in understanding ultrafine nanoparticle formation arises from the fact that it is very difficult to reproduce the actual ambient conditions in the laboratory. Various factors affect the nanoparticle formation. They have been discussed briefly below

\subsubsection{Dilution Temperature}

The dilution temperature is a critical factor that determines the particle concentration as it directly affects the nucleation mode. The particle formation is highly dependent upon the saturation ratio which in turn depends on the dilution temperature, ratio and hydrocarbon concentration. A cooler ambient air will drive the saturation ratio higher, thereby approaching super saturation; hence, contributing to nucleation while a warmer dilution air is going to result in lower saturation ratio and thus a lower PM concentration. Figure 16 shows the effect of dilution temperature on PM size distribution and concentration. Lower dilution temperature lead to a higher particle count compared to a higher dilution temperature. 


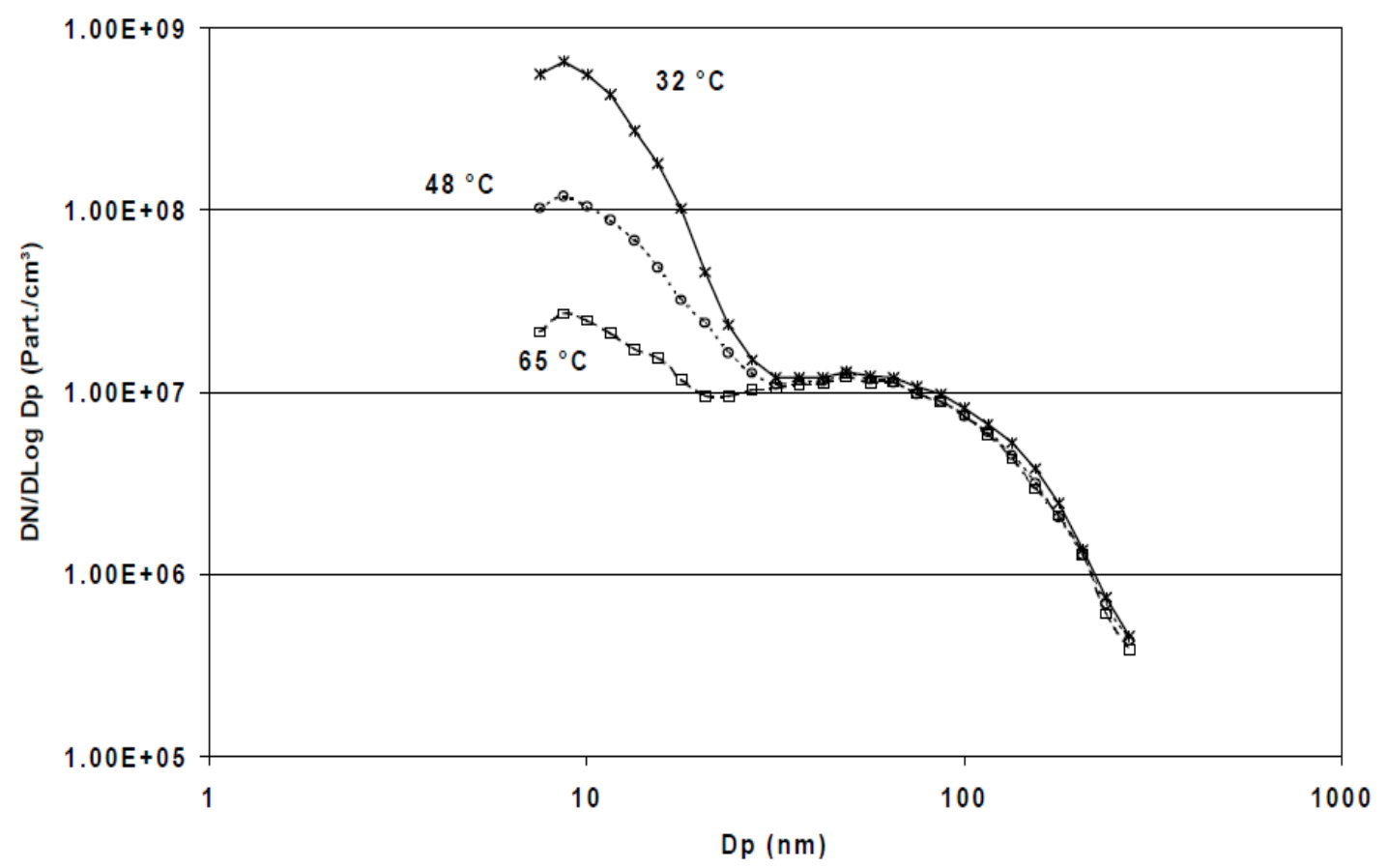

Figure 16: Effects of Dilution Temperature on PM [17]

\subsubsection{Dilution Ratio}

Several studies have been conducted to simulate the atmospheric dilution ratio rates in a laboratory. The exhaust when emitted is diluted by atmospheric air in a quick succession to a ratio of about 1000:1. Kittelson et al. conducted a study to conclude that the strongest driving forces for nucleation, condensation and adsorption is at a dilution ratio of 5-50:1 [23]. Studies reveal that at intermediate rates of dilution the tendency for nucleation is maximum. Nuclei mode particles less than 50nm were solitarily affected by dilution rates, humidity, residence time and dilution temperature. Research conducted by Kittelson using a 1992 International 7.3 L diesel engine in 2003 supports the fact that the nucleation mode in the particle size distribution is strongly affected by dilution ratio. Kittelson et al. [23] also concluded in their report that very high dilution rates meant that the particle remains in an intermediate dilution ratio only for a small time where the nucleation is maximum and thus minimizing the nucleation.

\subsubsection{Residence Time and Humidity}

Other factors that significantly contribute to particle formation are residence time and humidity. Residence time is defined as the time the particles remains in the dilution environment. Longer 
residence time contributes to better exhaust mixing with dilution air and longer time for complete particle formation. As a result higher residence time would result in a shift towards nucleation mode distribution. Figure 17 shows the effects of residence time on particles less than $40 \mathrm{~nm}$ in diameter.

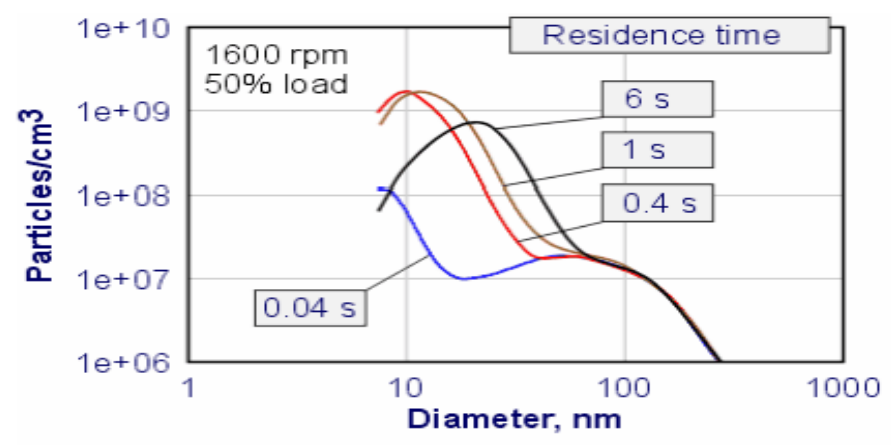

Figure 17: Effects of Residence Time on Particle Growth [21]

Studies on effects of humidity explain the secondary particle matter formation. Sulfur in lubricating oil or fuel is oxidized to form sulfur dioxide. Sulfur dioxide in the presence of oxidation catalysts might form sulfur trioxide which would react with humidity to form sulfuric acid droplets or sulfate particle thus aiding nucleation.

Representing the atmospheric dilution conditions in a laboratory is the biggest challenge. Presence of nanoparticles when exhaust is diluted by atmospheric air has already been observed; thus their presence under laboratory conditions is not an artefact. Future regulations are mandatory by United States Environmental Protection Agency (USEPA), keeping in mind the health and environment hazards of the nuclei mode particles, but their implementation still remains a challenge because replicating the PM size distributions and number concentration is difficult as various laboratories have different sampling and dilution strategies.

\subsection{PM in Advanced Diesel Combustion}

Studies reveal that the PM in advanced combustion is significantly different than conventional diesel operation. The PM in advanced combustion has larger organic fraction and smaller particle sizes [2]. A test conducted on a DDC/VM Motori 2.5 L, four cylinder, turbocharged, common rail, direct-injection light-duty diesel engine by Wagner et al. [2] showed that the brake specific 
PM mass emissions decreased by $80 \%$ while brake-specific fuel consumption increased by 3\%. It was observed that the volatile organic fraction dominated the total PM emissions from the engine. This explains the fact that most of the volatile portion of the PM could be a result of the increase in $\mathrm{HC}$ emissions by $72 \%$ compared to conventional combustion [2]. The study also observed that the PM mass emission of the LTC was more than the high efficient clean combustion (HECC) mode. The author attributed this trend to the higher EGR used. The authors further defined HECC as a mode, which was characterized by a dominant premix combustion phase and thus lower PM at the same EGR used [4]. The author also states that in HECC techniques the premix combustion phase increases which results in a lean charge and reduced combustion temperature to simultaneously reduce PM and NOx [2].

The above study investigated the PM size distribution using Scanning Mobility Particle Sizer (SMPS) under HECC mode operation. The EGR was kept constant and the particle concentration was studied for various configurations with the thermal denuder at $30^{\circ} \mathrm{C}$ and $300^{\circ} \mathrm{C}$.

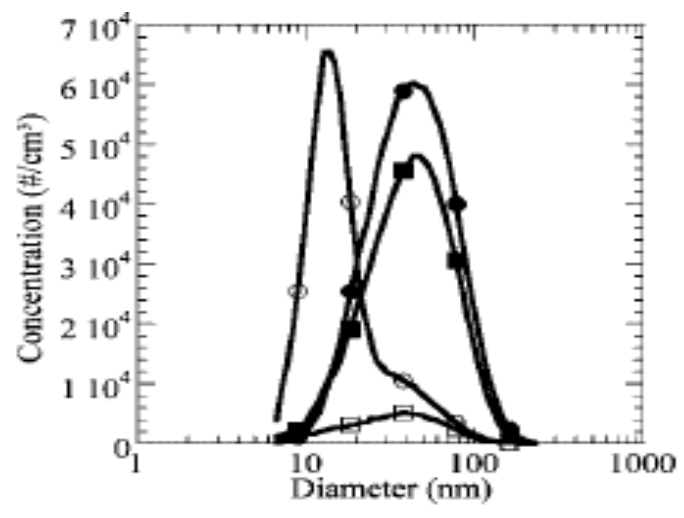

Particle size distribution from SMPS under HECC mode operation at $1800 \mathrm{rpm}, 4.2$ bmep, and $\sim 50 \%$ EGR with rail pressure at 490 bar with different thermal denuder (TD) temperatures and start of injection timing (SOI): (O) TD at $30^{\circ} \mathrm{C}$ and SOI at $-2^{\circ}$ ATDC, (ㅁ) TD at $300{ }^{\circ} \mathrm{C}$ and SOI at $-2^{\circ}$ ATDC, (@) TD at $30^{\circ} \mathrm{C}$ and SOI at $-4^{\circ}$ ATDC, and (ש) TD at $300^{\circ} \mathrm{C}$ and SOI at $-4^{\circ}$ ATDC.

Figure 18: Comparison of Particle Size Distribution Between Different Thermal Denuder Temperatures [2]

Figure 18 compares the effect of thermal denuder at a particular SOI. It is understood that at a different SOI of -2ATDC and -4ATDC, the thermal denuder at $300^{\circ} \mathrm{C}$ produces lower PM number count than at $30^{\circ} \mathrm{F}$. The reason could be the removal of the volatile fraction from the $\mathrm{PM}$. At $30^{\circ} \mathrm{C}$ when the thermal denuder is ineffective for both SOI timings, there was a higher number count. 
Another test conducted at the Oak Ridge National Laboratory (ORNL) supports the fact that the SOF portion of the PM increases and forms most of the PM during advanced combustion [24].

Figure 19 shows that PCCI has larger soluble fraction of PM than conventional combustion engine.

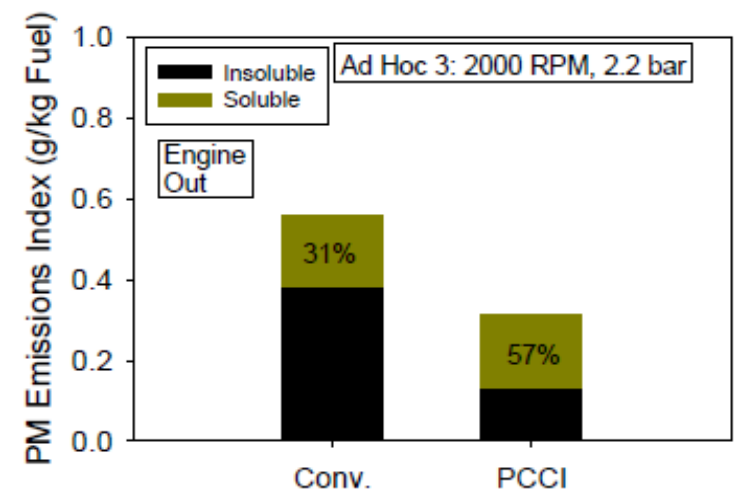

Figure 19: PM Composition for Conventional Vs. PCCI [24]

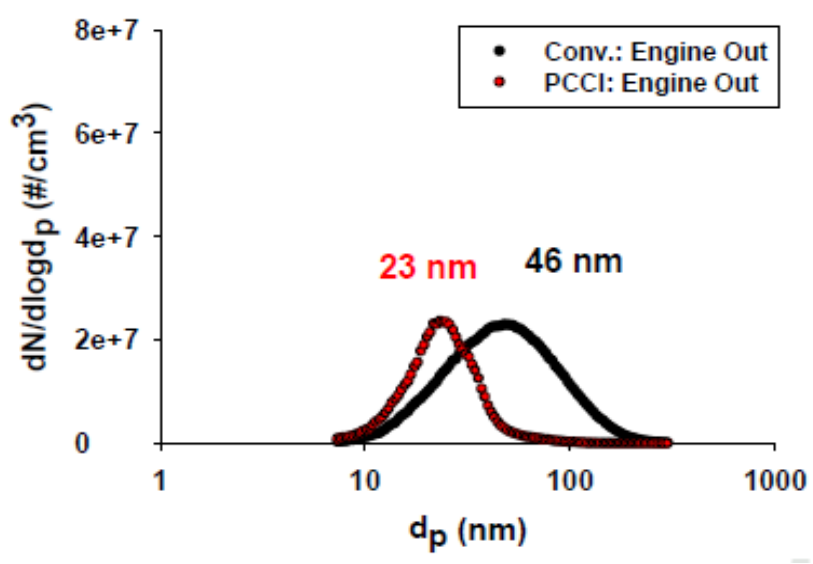

Figure 20: PM Size Distribution Between Conventional Combustion and PCCI [24]

Figures 20 shows that the PCCI count mode diameter (CMD) reduces to half compared to a particle size distribution observed in a conventional mode operation. Size distribution of PM was assessed for low speeds between conventional and PCCI only to reveal that the number concentrations were higher for PCCI than conventional (see Figure 21). This may be due to lower combustion temperature; hence, higher engine out HC that increases the SOF portion of PM and thereby the number count. 


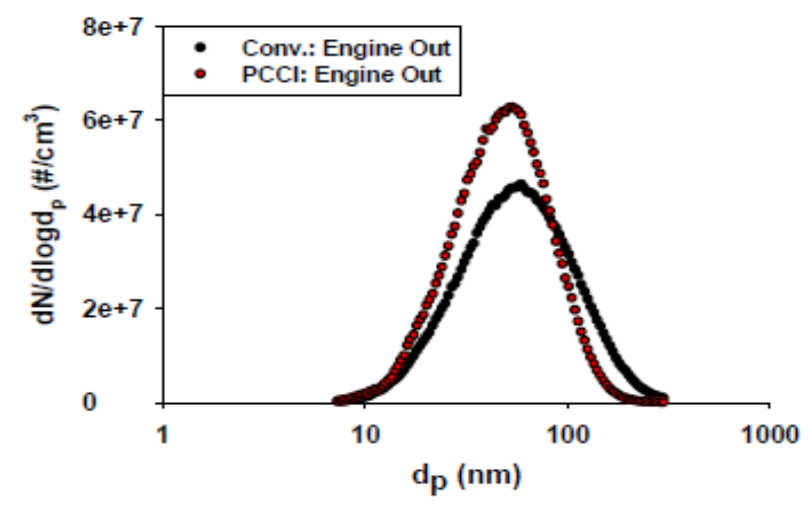

Figure 21: PM Size Distribution Between Conventional Combustion and PCCI [24]

The HCCI was seen to produce smaller particles than PCCI probably due to complete homogeneous charge combustion when compared to PCCI, thus producing lower soot surface area in the exhaust favouring nucleation (see Figure 22).

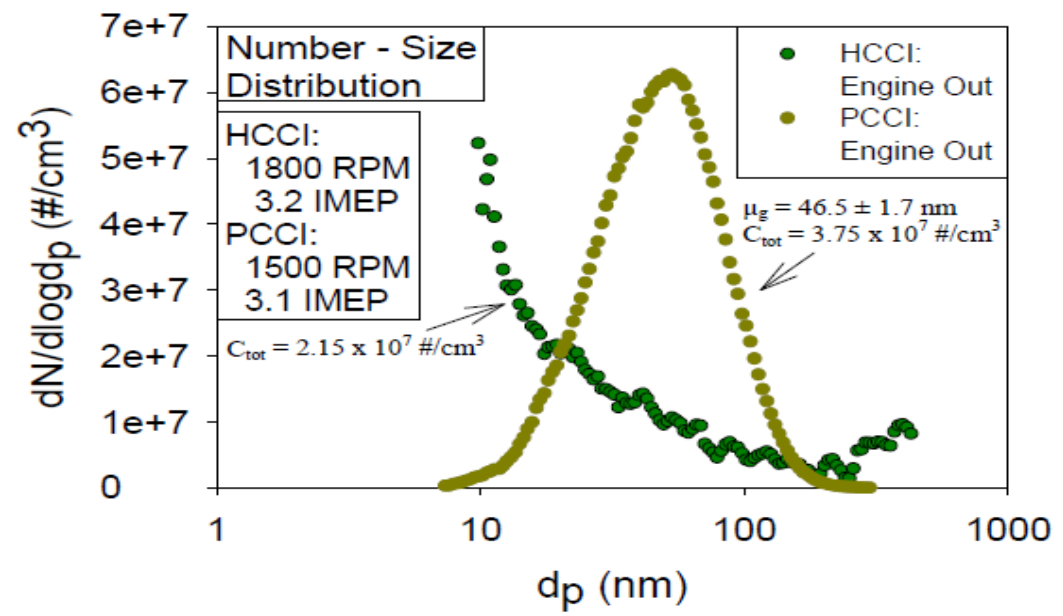

Figure 22: Size Distribution Comparison Between PCCI and HCCI [24]

Natti [25] reported that the accumulation mode particles during LTC could be reduced by increasing rail pressures. Thus with an advanced injection timing, a homogeneous/near homogeneous charge is obtained with a resulting reduction of PM mass and NOx. LTC/PCCI has lower peak temperatures and thus reduces NOx. The rail pressures are high enough to atomize the fuel ending up in the reduction of PM. Thus the optimization of these techniques may lead to low brake-specific emissions compared to conventional combustion. 


\subsection{Fuel Study}

\section{Fuel properties}

United States Environment Protection Agency (USEPA) and California Air Resources Board (CARB) regulate the diesel fuel properties because of its potential impacts on emissions such as the PM, NOx and after-treatment durability. Apart from the various combustion parameters, efforts to optimize the fuel characteristics are necessary to achieve future emission standards before adapting to after-treatment devices. This section shows some of the fuel properties that most affect the performance, emissions and fuel economy in diesel engines.

\subsubsection{Cetane number}

Cetane number is an important property of a diesel fuel as it indicates the readiness with which the diesel fuel auto ignites. A higher cetane number diesel fuel compared to a commercially available diesel fuel, essentially means reduced ignition delay, decreasing NOx due to lower cylinder temperatures. However, the disadvantage is that the charge is going to have fuel rich zones due to improper mixing and hence high PM. A study conducted by the Toyota Motor Company on a DI 1.91 turbocharged, cooled EGR and common rail injection diesel engine observed that the cetane number affected the insoluble organic fraction portion (ISOF) of PM. Lower CN number generated lower ISOF compared to higher CN. Oakridge National Laboratory tested a 1.9l Opel engine equipped with EGR, turbocharger and common rail injection and concluded that lower CN fuel was preferable for PCCI type operation as it produced nearly zero PM and acceptable levels of NOx [12]. Various methods are available to accurately determine the cetane number of fuels. ASTM D613 is one such method to determine the cetane number of diesel fuels [26].

\subsubsection{Aromatic content}

The most reliable test method to obtain the aromatic content and polycyclic aromatic hydrocarbon (PAH) content in diesel fuels is the ASTM D-5186. This test method takes into account materials in the boiling range of the diesel fuel whereas the ASTM D1319 mandated by the USEPA excludes the boiling points greater than $315^{\circ} \mathrm{C}$ [27]. Aromatic content of the fuel is related to the ignition quality of the fuel. Studies conducted in ORNL show that the NOx emissions may rise due to higher aromatic content as the fuel ignites completely and higher 
combustion temperatures are obtained [12]. However, this observation was limited to lower cetane fuels. Studies also reveal lower HC and CO numbers for higher aromatic content fuels due to higher combustion temperatures.

\subsubsection{Volatility}

Volatility of diesel fuel is an important factor affecting emissions in low temperature combustion techniques [28]. This is because in LTC, fuel is injected early in order to mix properly and subsequently vaporize to ignite to form a lean mixture minimizing the combustion temperatures and hence NOx. Fuels with high distillation temperature may result in cylinder wall impingement and might result in higher $\mathrm{HC}$ and $\mathrm{CO}$ emissions. For advanced combustion techniques fuels with lower volatility are preferred in order to vaporize at a lower temperature and ignite.

\subsubsection{Sulfur Content}

The sulfur level in fuel has a direct effect on factors affecting PM mass and number concentrations. The 2007 regulation which demand sulfur content in the fuel to be less than 15ppm has enabled the use of catalysed exhaust after treatment devices which are very sensitive to the sulfur content in the fuel [29]. Sulfur in the fuel produces sulfur dioxide which is oxidized within the diesel oxidation catalysts and catalysed DPF's to form sulfur trioxide $\left(\mathrm{SO}_{3}\right) . \mathrm{SO}_{3}$ reacts with water vapor to result in secondary particulate matter. ASTM D129 was a suitable method to determine the sulfur content in 90's and early 2000's. However, with 2007 regulation, which demanded less than 15ppm sulfur content in diesel fuel a revised method in the form of ASTM D2622 and X-ray spectroscopy method for accurate measurements of sulfur in diesel fuel was required [29]. 


\section{Experimental Setup}

\subsection{Introduction}

The objective of the study was to compare the PM size distribution and number concentrations from an advanced combustion enabled engine for a set of two fuels, namely high cetane and low cetane. All tests for the proposed study were conducted in the Engines Emissions Research Laboratory (EERL). The EERL is equipped with a total exhaust 1065 compliant CVS-SSV dilution system for mixing of dilution air with exhaust gas. Due to an expected increase in hydrocarbon emissions, the PM sampling setup was designed to remove the volatile components by means of a two stage dilution system, with a first stage hot dilution and the second stage cold dilution. All tests were conducted at an operational point of 2100 rpm to achieve a BMEP of 3.5 bar.

\subsection{Engine Setup}

The engine used for this study was a model year 2005 Opel diesel engine with a displacement of 1.9L (see Figure 23). The engine specifications are listed in Table 1. The engine intake was modified and fitted with a heating element to heat the intake air to aid combustion of low cetane number fuels and cold starts. Oxygen concentrations were measured in the intake and raw exhaust by two MEXA 720 analyzers to determine the EGR fraction. Thermocouples were installed in the intake and exhaust manifold to record temperatures while a pressure transducer was fitted in one of the cylinders to record the in-cylinder pressure. OEM ECU was replaced with an independent ECU designed by Drivven Automotive Control and Data Acquisition Systems for complete open control of ECU parameters [9]. 


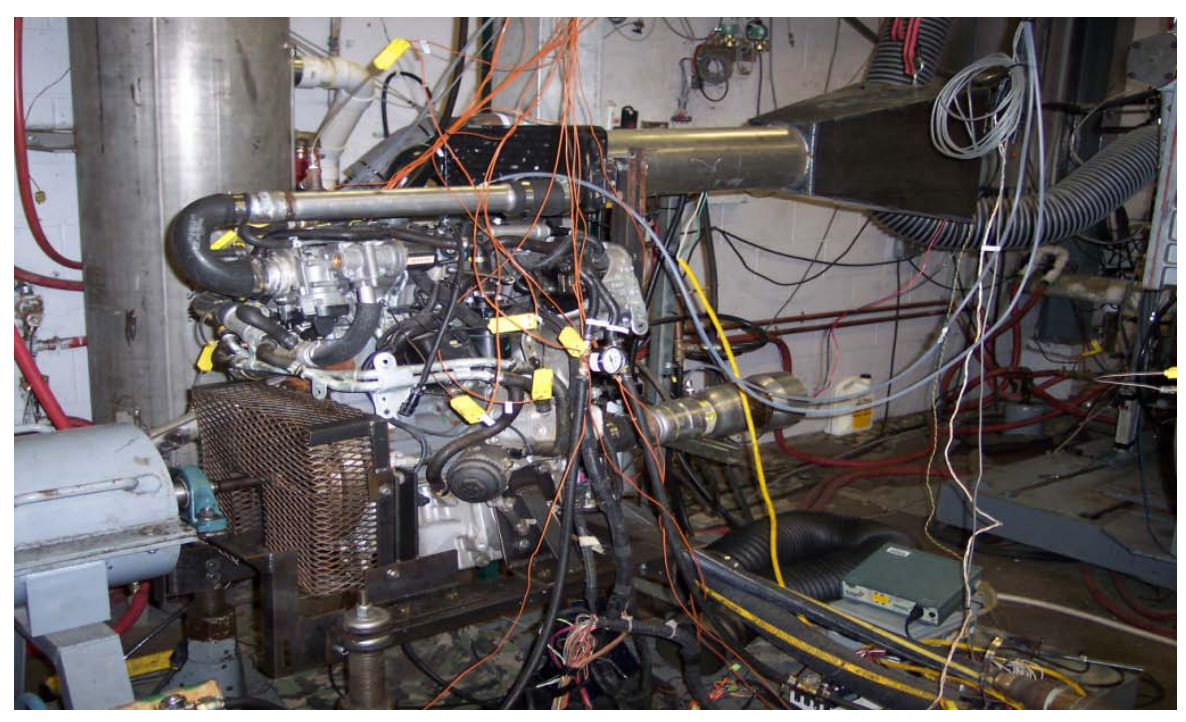

Figure 23: Engine Set-up

Table 1: Engine Specifications

\begin{tabular}{|c|c|}
\hline Type & CDTi Diesel Engine \\
\hline Manufacturer & General Motors \\
\hline Model & Z19DTH \\
\hline Valve Configuration & 4 valves per cylinder \\
\hline Year & 2005 \\
\hline Configuration & In-line 4 Cylinder \\
\hline Displacement & 1.9 L \\
\hline Bore & 82 mm \\
\hline Stroke & 90.4 mm \\
\hline Compression Ratio & $17.5: 1$ \\
\hline Turbocharger & Garret VGT \\
\hline Injection System & Common Rail \\
\hline EGR & Cooled, External \\
\hline Rated Power & $110 \mathrm{~kW} @ 4000$ RPM \\
\hline
\end{tabular}

\subsection{Dilution System}

Studies reveal that thermodynamic condition of dilution air effects the particle growth and hence has to be maintained stable to achieve repeatability [33]. The effects of temperature and humidity on particle growth have been discussed in Sections 2.5.1 and 2.5.3. Thus, a dilution system is one 
of the most important component of the experimental set-up determining an accurate and repeatable size distribution of the PM particles.

\subsubsection{CVS Dilution Tunnel}

The WVU engine test facility is equipped with a CFR 401065 compliant constant volume sampler (CVS) primary dilution tunnel. Flow control is achieved through a sub sonic venturi (SSV) and variable speed blower. The dilution tunnel is capable of diluting the total exhaust with high efficiency particulate air (HEPA) filtered dilution air. The engine exhaust is introduced into the CVS system via a transfer pipe. The exhaust gas is mixed with dilution air upstream of a mixing orifice at the inlet of the primary tunnel. Downstream of the mixing orifice the two streams are mixed further to a dilution ratio of at least two in compliance with Part 1065 [30]. Downstream of the mixing region that extends for ten times the tunnel diameter are the sampling probes which transfer the exhaust gases to the MEXA 7200D through heated tubes for gaseous exhaust emissions quantification.

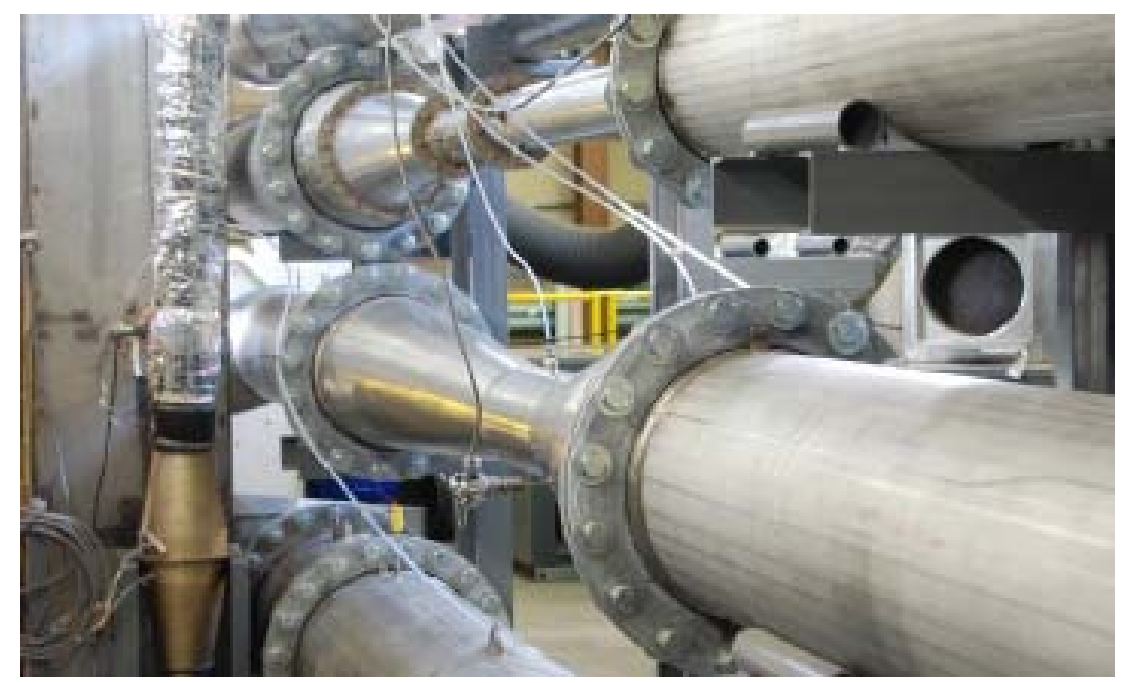

Figure 24: CVS System at EERL, West Virginia University

The PM sample is drawn from the sampling system and transferred to a secondary dilution system further diluting the sample with conditioned HEPA filtered air passed. The exhaust sample passes through a broad cut cyclone prior to the filter holder. PM filters are gravimetrically analysed. The presence of cyclone is employed to remove the mechanically generated coarse particles, thus avoiding sampling artefacts. 


\subsubsection{CVS System Verification}

In compliance with the CFR 1065.341 regular checks on the CVS tunnel were performed using a propane injection kit. The pressure and temperature were recorded at the point of injection to calculate the mass of the propane injected. The mass of propane recovered was calculated with the flow rate measured by the SSV and the duration for which the propane was injected.

The deviation in the measured mass of propane by the SSV to the amount of propane injected should be less than $\pm 2 \%$ thus ensuring accurate exhaust flow rates.

\subsubsection{Dilution Ratio of the CVS Tunnel}

Dilution ratio of the CVS tunnel is calculated as follows

$$
\text { Dilution Ratio }=\frac{\text { Total Flow Rate }(\text { Vmix })}{\text { Engine Intake Air Flow Rate }+ \text { Fuel Flow Rate }}
$$

\subsubsection{Sampling Setup for Tailpipe PM}

Sampling of the PM has been carefully set up since factors like dilution temperature, dilution ratio and residence time effects the formation of nanoparticles. Two different dilution strategies were used to quantify the accumulation and nuclei mode particles. The setup can be seen in Figure 25.

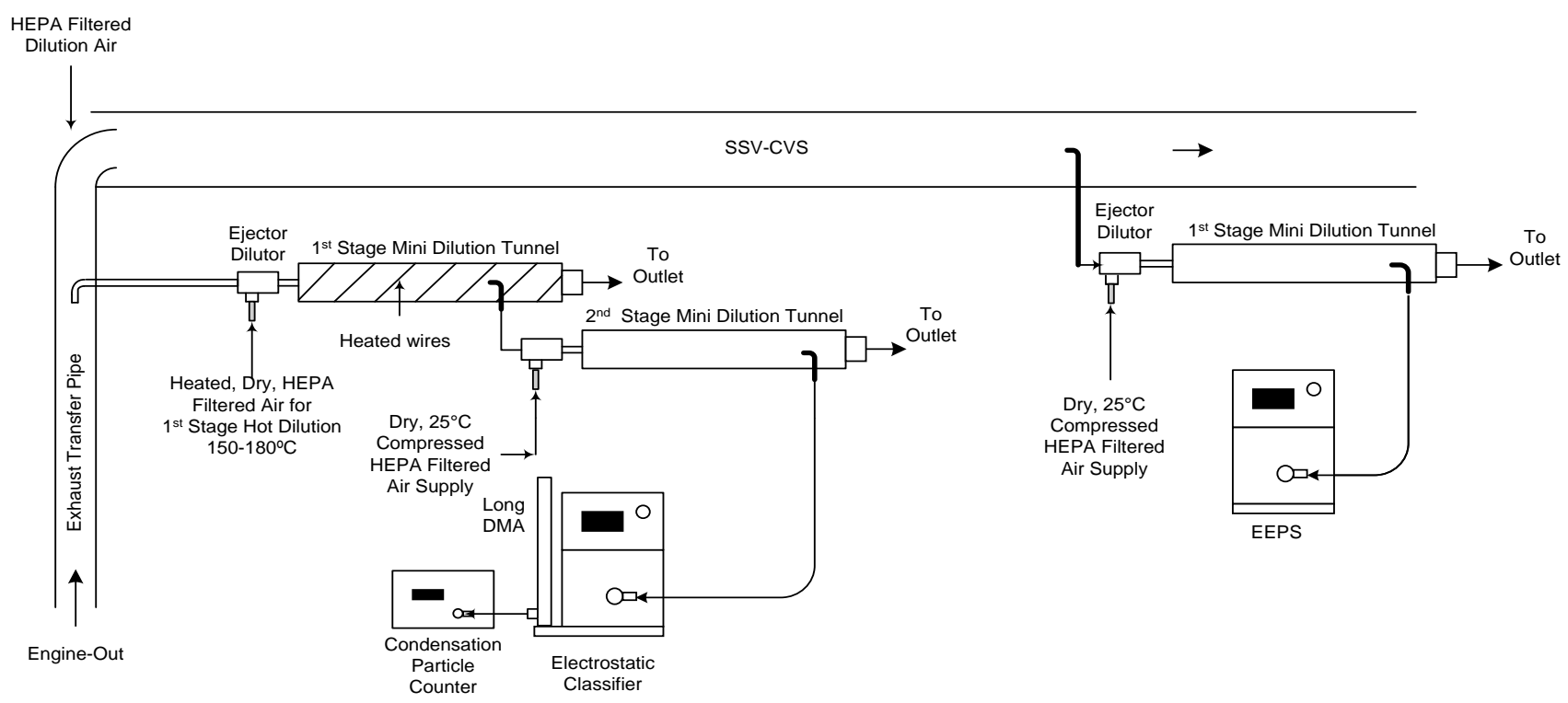

Figure 25: PM Sampling Setup 


\subsubsection{Accumulation Mode Particle Sampling Setup}

Due to an expected increase in hydrocarbon emissions, the PM sampling setup was designed to prevent the volatile components from condensing by means of a two stage dilution system, with a first stage hot and second stage cold dilution. An immediate cold dilution after the hot dilution was used to prevent the hot diluted exhaust from entering the SMPS. Settings for the $1^{\text {st }}$ stage and $2^{\text {nd }}$ stage dilution can be seen from Table 2. Dilution ratios were established with the help of a vacuum pump made by Air-Vac whose principle of operation is explained in section number 3.3.2.4.

Table 2: Dilution Settings for Accumulation Mode Particles

\begin{tabular}{|c|c|}
\hline $\mathbf{1}^{\text {st }}$ stage dilution & $\mathbf{2}^{\text {nd }}$ stage dilution \\
\hline $\begin{array}{c}\text { Dilution Air Temperature } \\
150^{\circ} \mathrm{C}\end{array}$ & $\begin{array}{c}\text { Dilution Air } \\
\text { Temperature } 25^{\circ} \mathrm{C}\end{array}$ \\
\hline Residence Time & Residence Time \\
\hline$\sim 0.6 \mathrm{~s}$ & $\sim 0.6 \mathrm{~s}$ \\
\hline Dilution Ratio & Dilution Ratio \\
\hline 6 & 24 \\
\hline Total Dilution Ratio & 144 \\
\hline
\end{tabular}

\subsubsection{Nuclei Mode Particle Sampling Setup}

Although the study of nuclei mode particles were not of paramount importance for this research, a cold dilution was set up after the CVS dilution to study the trend in nuclei-mode particle and to make a comparison with the size distribution obtained from the hot dilution.

Nucleation particle formation depends on the type of dilution environment. Factors affecting the nucleation mode particles are discussed in section 2.7 in detail. A mini dilution system developed by WVU was used for this purpose. The set-up can be seen from Figure 25. A vacuum pump was used to achieve a constant dilution ratio and its working is discussed in section 3.3.2.4. 
Table 3: Dilution Settings for Nuclei Mode Particles

\begin{tabular}{|c|c|}
\hline CVS dilution & $\mathbf{2}^{\text {nd }}$ stage dilution \\
\hline $\begin{array}{c}\text { Dilution Air } \\
\text { Temperature } 24^{\circ} \mathrm{C}\end{array}$ & $\begin{array}{c}\text { Dilution Air Temperature } \\
25^{\circ} \mathrm{C}\end{array}$ \\
\hline Residence Time & Residence Time \\
\hline$\sim 6.7 \mathrm{~s}$ & $\sim 1.9 \mathrm{~s}$ \\
\hline Dilution Ratio & Dilution Ratio \\
\hline$\sim 10$ & 11 \\
\hline Total Dilution Ratio & 110 \\
\hline
\end{tabular}

\subsubsection{Dilution Ratio for Mini Dilution Tunnel}

The dilution ratio calculation of the mini dilution tunnel corresponding to a $5 \mathrm{l} / \mathrm{m}$ orifice is shown in Table 4 [31].

Table 4: Dilution Ratio Calculation

\begin{tabular}{|c|c|c|}
\hline \multicolumn{2}{|c|}{ Mini dilution tunnel } & Units \\
\hline Compressed air flow rate & 4 & scfm \\
\hline Exhaust flow rate & 5 & $\mathrm{l} / \mathrm{m}$ \\
\hline Compressed air flow rate & 113.24 & $\mathrm{l} / \mathrm{m}$ \\
\hline Total flow rate & 118.24 & $\mathrm{l} / \mathrm{m}$ \\
\hline Dilution ratio & 24 & \\
\hline
\end{tabular}

The Dilution ratio was calculated using the following equation

$$
D R=\frac{\text { Raw Exhaust Flow Rate }+ \text { Dilution Air Flow Rate }}{\text { Raw Exhaust Flow Rate }}
$$

The dilution air flow rate was calculated based on the model number of the vacuum pump and the compressed air flow rate corresponding to the pressure as given in the reference [32].

\subsubsection{Vacuum Pump Model TD110H}

The mini dilution tunnel used here consists of a vacuum pump (Model TD-110H) with a critical orifice at its inlet [24]. Compressed air flows through an annular opening to generate high 
velocity. This air expands into an unobstructed vacuum passage allowing solid material to flow through the pump with no decrease in vacuum flow. This design is capable of vacuum flows up to $7.6 \mathrm{scfm}$ [32]. The working principle is illustrated in Figure 26.

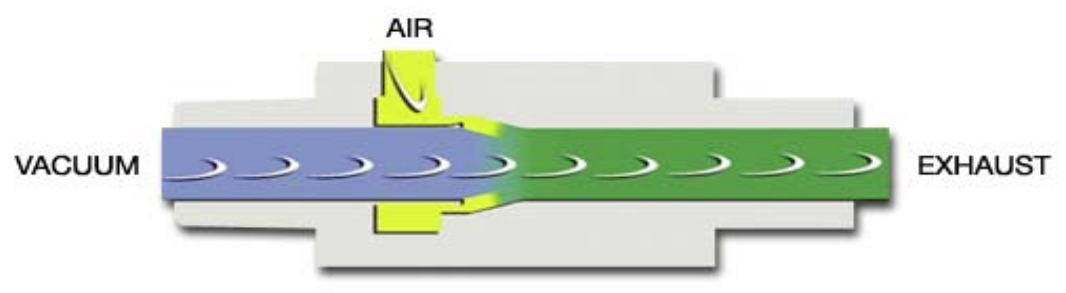

Figure 26: Working Principle of an Ejector Diluter [31]

The ejector diluter model TD-110H is shown in Figure 27. Compressed air flows through the air supply port $(\mathrm{P}+)$ and expands rapidly creating a vacuum at Vacuum (P-). The created vacuum draws the exhaust from the sampling plane of the CVS dilution tunnel for dilution [33]. The compressed air for dilution was maintained at a constant pressure of $60 \mathrm{psi}$ to achieve a particular dilution ratio.

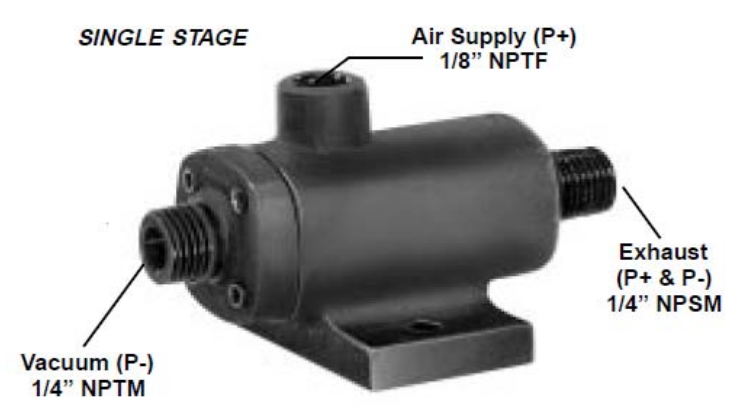

Figure 27: Ejector Diluter Model TD-110H [32]

The dilution air for the secondary dilution was HEPA filtered. This was carried out to remove artefacts in the sampling system by removing any intrusion of coarse particles. The moisture in the dilution air was further removed using balston compressed air flow filters. These filters are capable of removing moisture and other contaminants in the air at a high efficiency upto $99.99 \%$ of 0.01 micron particles and droplets. 


\subsection{Temperature and Humidity Control of Intake and Dilution Air}

The humidity and the temperature of the intake and dilution air is closely monitored and controlled by General Eastern Chilled Mirror hygrometers model Dew 10-2A1 [9]. Two hygrometer units are installed downstream of the steam injectors. The air conditioning system and steam injectors plays an integral part in maintaining the temperature and humidity. Depending on the time of the year testing takes place, a secondary air conditioning unit is used to keep the temperature and humidity under regulations defined by Title 40 PART 1065 Subpart B ( $25^{\circ} \mathrm{C} \pm 5^{\circ} \mathrm{C}, 50 \%$ relative humidity). During the case of excessive humidity, the air was first dehumidified and then humidified using steam injectors to have better repeatability.

\subsection{PM Sampling Instruments}

This section deals with the PM sampling instruments used and their theory of operation. Table 5 shows the various instruments used.

Table 5: Measuring Instruments Used

\begin{tabular}{|c|c|}
\hline Measuring Instrument & Measured Value \\
\hline Scanning Mobility Particle Sizer 3936 & $\begin{array}{l}\text { PM size distribution and number } \\
\text { concentration }\end{array}$ \\
\hline Engine Exhaust Particle Sizer 3090 & $\begin{array}{l}\text { PM size distribution and number } \\
\text { concentration }\end{array}$ \\
\hline AVL Micro Soot Sensor 483 & $\begin{array}{c}\text { Instantaneous } \\
\text { Concentration of soot }\left(\mathrm{mg} / \mathrm{m}^{3}, \mu \mathrm{g} / \mathrm{m}^{3}\right) \\
\text { raw exhaust stream. }\end{array}$ \\
\hline
\end{tabular}

\subsubsection{SMPS}

The SMPS 3936 has been used for this study. An Electrostatic Classifier (EC), a long DMA 3081 along with a CPC model 3025A makes up the SMPS. SMPS has been specifically designed for basic aerosol research. The EC classifies the particle whereas the concentration is recorded by the condensation particle counter (CPC) [34] 


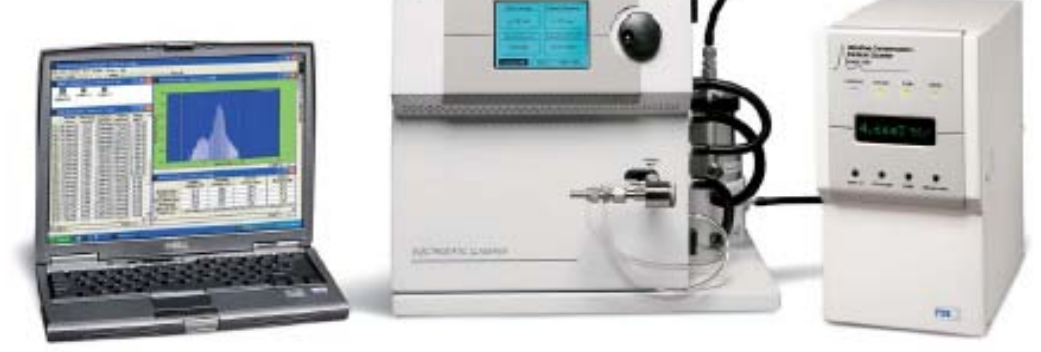

SMPS Spectrometer Shown with a Model 3085 Nano DMA and Model 3786 UWCPC

Figure 28: SMPS with Nano DMA and CPC Model 3786 [34]

\subsubsection{Basic Components of SMPS 3936}

Basic components of an SMPS are listed below.

- Electrostatic Classifier (EC)

- Long Differential Mobility Analyzer (DMA)

- Condensation Particle Counter (CPC)

The aerosol enters the Electrostatic Classifier through an impactor which is characterized by a nozzle diameter. The purpose of the impactor is to remove particles with diameter above a cutpoint diameter. These large particles may be an artefact of the sampling system. Thus a cut-point diameter may be defined as an aerodynamic particle size at which the particle is separated. This cut-point diameter is a function of nozzle diameter and impactor flow rate.

The impactor removes the particle based on inertial impaction. The aerosol is directed to a flat place through the nozzle of the impactor where it is required to make a 90 degree bend. Particles above the cut point diameter will have sufficient inertia and impact on the plate whereas lighter particles will follow the streamline and exit the impactor without contacting the plate. This can be seen in Figure 29. 


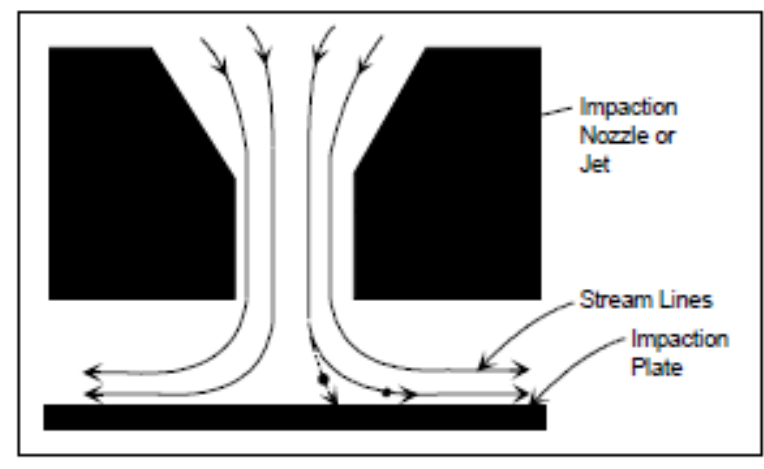

Figure 29: Cross Sectional View of Inertial Impactor [34]

\subsection{Electrostatic Classifier}

The purpose of the classifier is to classify the aerosol based on size from the incoming polydisperse aerosol and generates a monodisperse flow which later enters the CPC. The aerosol first enters the neutralizer where it is charged by a $\mathrm{Kr}-85$ bipolar charger. Here the aerosol is subject to bipolar ions. The charged aerosol particle then enters the differential mobility analyzer where the aerosol is classified. The DMA contains two concentric metal cylinders. The inner cylinder is maintained at negative voltage while the outer cylinder is grounded. Thus an electric field between the two cylinders is created. The positively charged aerosol is attracted to the inner core and is precipitated along the length of the inner core depending on the electrical mobility. The particles with higher electrical mobility are precipitated along the top of the rod and ones with lower electrical mobility is precipitated on the lower portion of the rod. A slit present in the bottom of the rod exits the particles with narrow range of electrical mobility along with monodisperse flow of air to the Condensation Particle Counter. 


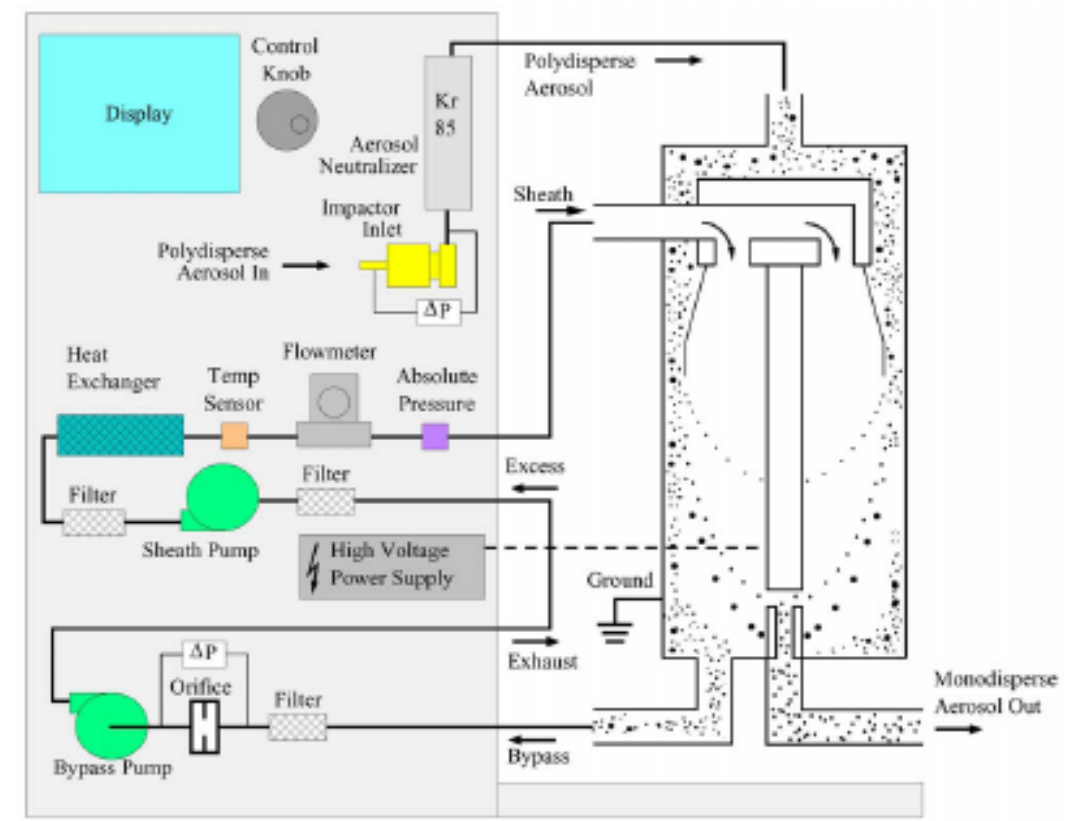

Figure 30: Flow Schematic of Electrostatic Classifier with Long DNA [34]

\subsection{Condensation Particle Counter (CPC)}

CPC model number 3025A uses butanol as the condensing fluid. CPC works on the principle (see Figure 31) of heterogeneous condensation. The aerosol on exiting the Electrostatic Classifier enters the CPC where it is subjected to a heated saturator. The aerosol gets saturated with the alcohol. The particle grows to make them optically detectable by flowing through a cooled condenser where the alcohol condenses over the aerosol. Once the particles have grown enough to be optically detectable they pass through a light beam scattering light onto a photo detector. This is translated into a number concentration. 


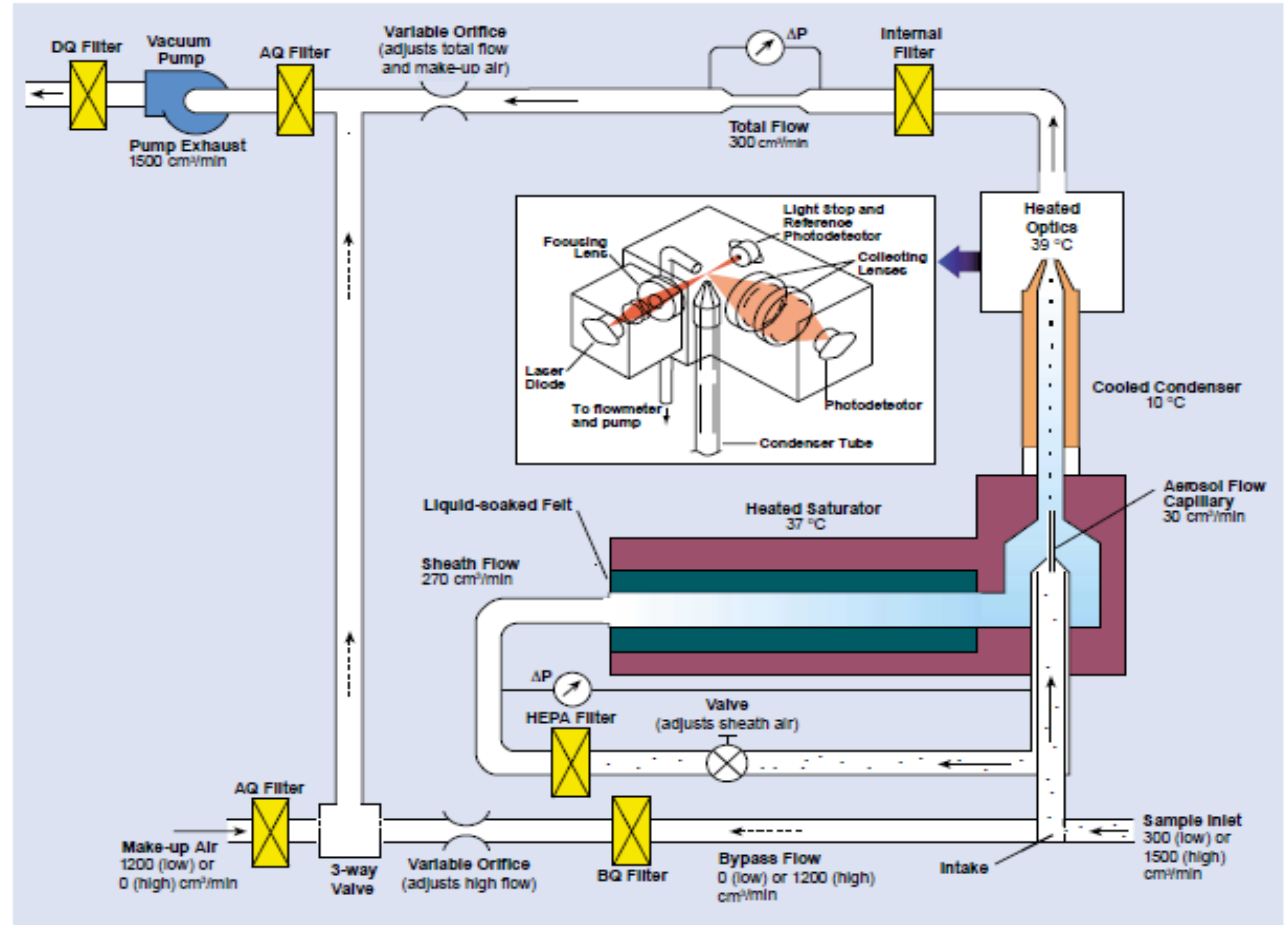

Figure 31: Working Principle of CPC 3025A [37]

During the experiment the ratio of the sheath air flow to the aerosol flow was always maintained at 10:1 upon manufacturer's recommendation. Flow calibration was performed on a monthly basis to have accurate flows and thus accurate size distribution.

\subsubsection{Engine Exhaust Particle Sizer (EEPS)}

The EEPS reports real-time PM size distribution with a wide range of particle handling capability. It is a fast response instrument unlike the SMPS and can report $10 \mathrm{~Hz}$ data thus making it suitable for transient testing. It can report particulate size in the range from $5.6 \mathrm{~nm}$ to 560nm [35].

The EEPS consists of a charger and a measuring column. The aerosol enters the inlet of the EEPS through a cyclone and is subjected to a known positive charge by two unipolar diffusion chargers. Charged particles are then introduced to the measuring column which consists of an in inner cylinder composed of multiple electrical sections of different voltages and column diameter. A recirculation particle free sheath flow of air joins the aerosol just before it enters the measuring column. A positive voltage is applied to the inner high voltage electrode as shown in 
Figure 32 thus creating an electric field. The positively charged particles repels from the central voltage towards the 22 electrometers along its length. These charged particles lose their charge on striking the electrometers producing current. The flow schematic of EEPS is shown below.

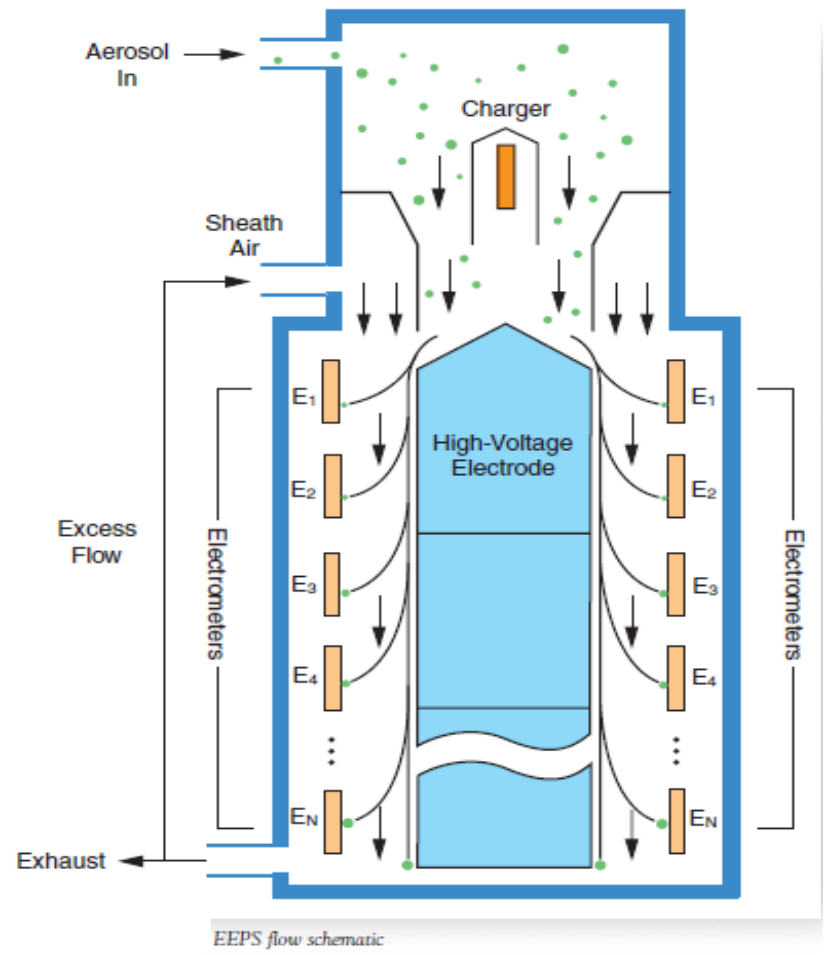

Figure 32: Flow Schematic of EEPS 3090 [36]

This current is translated by a digital signal processor (DSP) to a size distribution and number concentration. The DSP from Figure 33 accounts for time delay between electrometers, image charges, multiple voltages on the centre rod and the multiple charges to generate a number concentration and size distribution. 


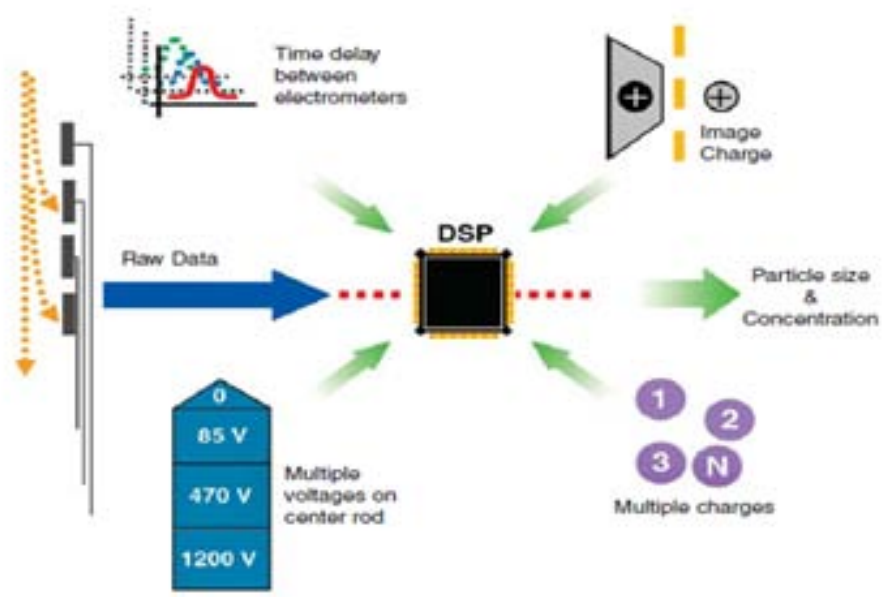

Figure 33: Data Inversion Schematic [36]

Since the SMPS works with a DMA it has been defined as a NIST standard for basic aerosol research. The SMPS takes a minimum of 120 seconds to generate a complete scan of the PM size distribution, thus making it suitable for only steady state testing. However, the EEPS is designed to measure transient PM size distribution at $10 \mathrm{~Hz}$. The Figure 34 shows the comparison of a size distribution obtained from SMPS and EEPS for a steady state test only to show correspondence between the data from both.

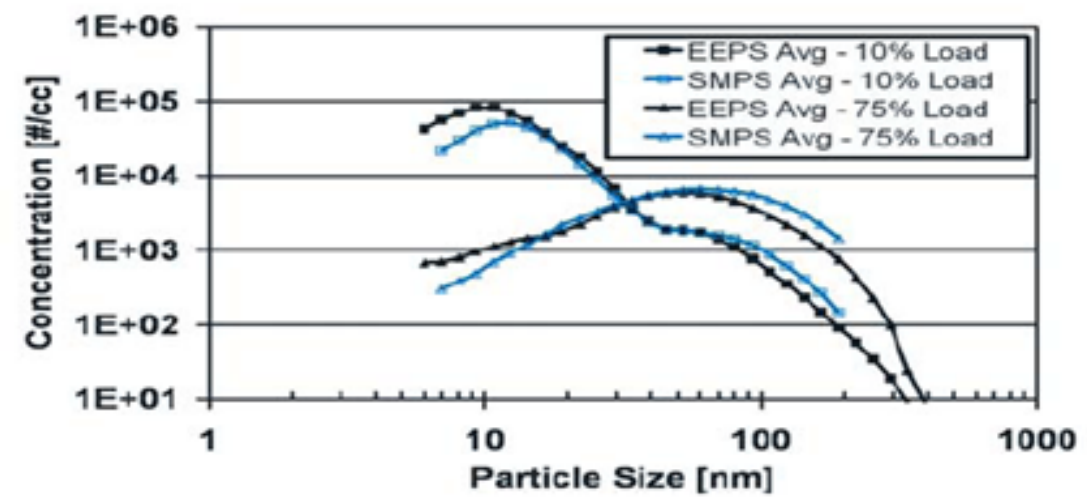

Figure 34: A Comparison of SMPS and EEPS Particle Size Data for a Heavy-Duty Diesel Engine [36]

\subsubsection{AVL MICRO-SOOT SENSOR 483}

The Soot Sensor 483 measures the mass concentration of the raw soot from the exhaust. It comprises of the measuring and the conditioning unit. It has a single stage dilution system 
allowing the user to select up to a dilution ratio of 18:1 based on the type and configuration of the engine. It works on the photo-acoustic principle [37].

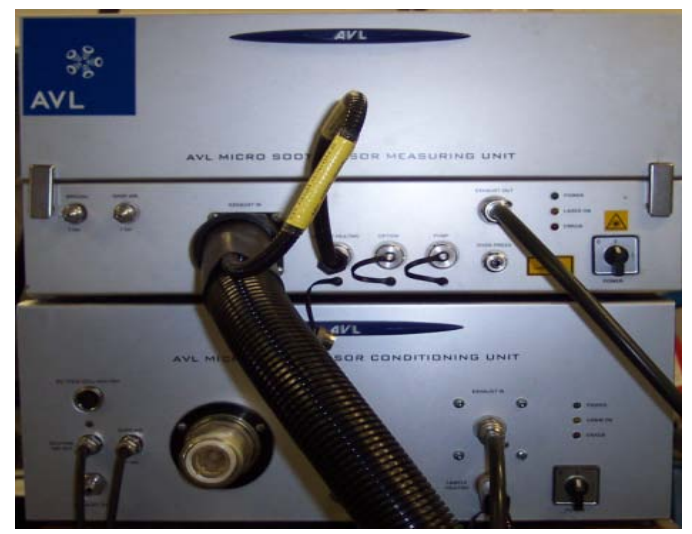

Figure 35: Micro Soot Sensor Setup [37]

The exhaust gas comprising the carbon particles enters the soot sensor where it is exposed to modulated IR light with a wavelength very specific to black carbon or elemental carbon. The periodic warming and cooling result in the expansion and contraction of the carrier gas and can be viewed as a sound wave and detected by a microphone. Clean filtered air does not produce a signal. The sound wave changes proportionately with the change in the soot thus giving an instantaneous soot concentration. This process is demonstrated in Figure 36.

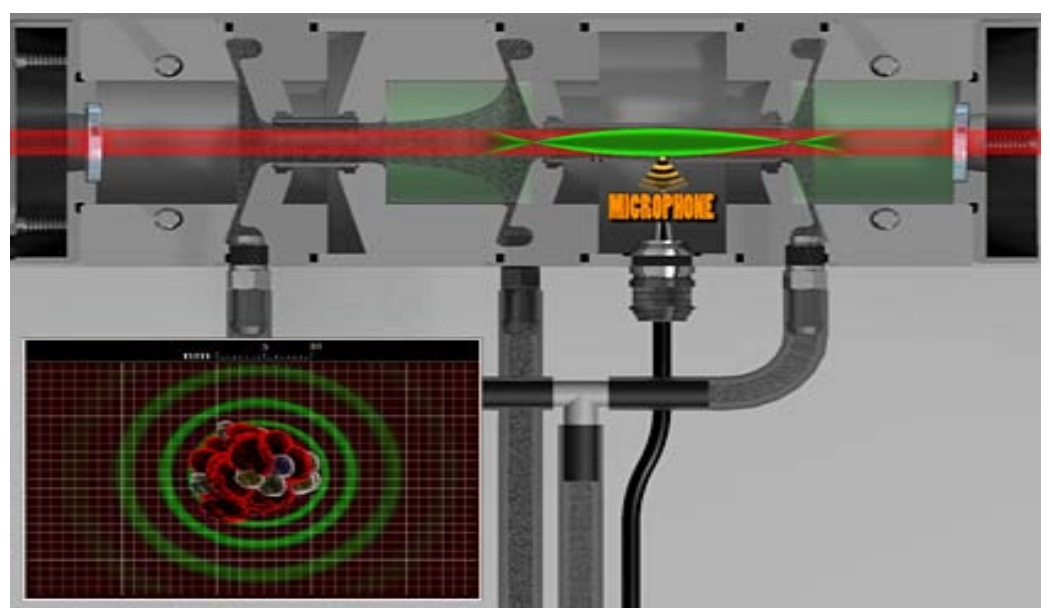

Figure 36: Working of a Micro-Soot Sensor [37]

Apart from the measuring unit, a conditioning unit is present to condition the exhaust gas entering the measuring chamber. In order to avoid condensate, sufficient dilution has to be provided. Also, during engine acceleration the soot level may exceed the detection limit of the soot sensor. These problems are addressed by the conditioning unit [37]. 
Specifications of a Micro Soot Sensor can be seen below.

Table 6: Specifications of AVL Micro Soot Sensor [37]

\begin{tabular}{|c|c|}
\hline Measured value: & $\begin{array}{c}\text { Concentration of soot }\left(\mathrm{mg} / \mathrm{m}^{3}, \mu \mathrm{g} / \mathrm{m}^{3}\right) \text { in the } \\
\text { diluted exhaust gas }\end{array}$ \\
\hline Measuring range: & $0-50 \mathrm{mg} / \mathrm{m}^{3}$ \\
\hline Display resolution: & $0,001 \mathrm{mg} / \mathrm{m}^{3}$ \\
\hline Detection limit: & $\sim 5 \mu \mathrm{g} / \mathrm{m}^{3}$ \\
\hline Turndown ratio: & $01: 05.0$ \\
\hline Rise time: & $\leq 1 \mathrm{sec}$ \\
\hline Operation temperature: & $5^{\circ} \mathrm{C}$ to $43^{\circ} \mathrm{C}$ \\
\hline Probe/Bypass flow: & $\sim 2+2 \mathrm{lmin}$ \\
\hline CONDITIONING UNIT & Adjustable from $2-10$ and from $10-20$ \\
\hline Dilution ratio (DR): & $90 \ldots 230 \mathrm{~V}, 50 / 60 \mathrm{~Hz}$ \\
\hline Power supply: & Input pressure $1 \pm 0.2 \mathrm{bar}$ over pressure \\
\hline Pressurized air: & Up to $1000^{\circ} \mathrm{C}$ \\
\hline Exhaust gas temperature: & Up to $2000 \mathrm{mbar}$ \\
\hline Exhaust gas back pressure &
\end{tabular}

\subsection{Total Hydrocarbon Measurement}

MEXA 7200D, as seen in Figure 37 is capable of measuring regulated emissions such as THC, $\mathrm{NOx}, \mathrm{CO}$ and $\mathrm{CO}_{2}$. It has eight units namely the gas divider, main control unit (MCU), interface unit (IFU), the analyzer rack (ANR), power supply unit (PSU), solenoid valve system (SVS), sample handling system (SHS) and OVN-700 module [30].

OVN-700 consists of FIA-725A THC analyzer capable of measuring only THC and the FIA721A which is capable of measuring THC or methane concentration. THC is transferred to the OVN by the SHS through heated probes and heated lines. Moreover, the OVN is maintained at a heated temperature such that the analyzers are always at a temperature higher than the dew point of the measured gases to prevent any condensation.

In a flame ionization detector the gas burns and produces ions corresponding to the carbon atoms in it. In the presence of electrodes on either side and when applied a voltage, a current is produced which is a measure of the carbon atoms in the gas [9]. SVS is equipped with a solenoid valve to flow zero, span and sample gas when necessary to check for any drift in the analyzer. 


\subsection{NOx Measurement}

MEXA 7200D uses two analyzers namely hot NOx/NO analyzer (CLA-720MA) and cold NOx/NO analyzer (CLA-720) to measure the concentration of NOx emissions. The hot NOx/NO analyzer which measures $\mathrm{NOx}$ is located in the OVN while the cold $\mathrm{NOx} / \mathrm{NO}$ analyzer which measures NO is located in the ANR [30].

NOx emissions are measured using the chemiluminescence detection technique. Ozone $\left(\mathrm{O}_{3}\right)$ produced by the ozone generator reacts with nitric oxide (NO) to produce nitrogen dioxide $\left(\mathrm{NO}_{2}\right)$. This $\mathrm{NO}_{2}$ is in excited state and produces energy in the form of light. Thus, the light produced is proportional to the NO present in the mixture. The other analyzer consists of a NOx convertor which converts all the $\mathrm{NO}_{2}$ to $\mathrm{NO}$. Thus the mixture contains only $\mathrm{NO}$ and the total NOx is measured using the CLD technique [9].

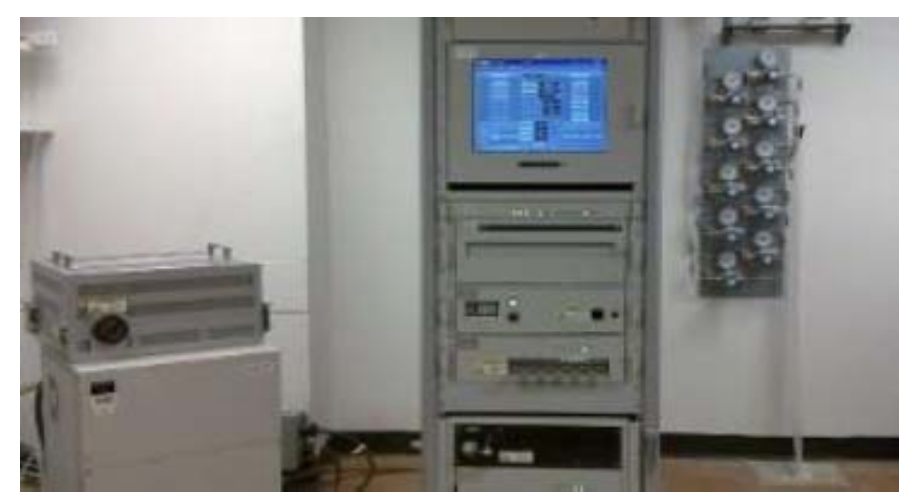

Figure 37: MEXA 7200-D

\subsection{In-Cylinder Bulk Temperature}

In-cylinder bulk temperature was one of the many parameters that were calculated from the recorded in-cylinder pressures from a fitted pressure transducer in the cylinder. For measuring the in-cylinder pressure a set up, designed by Dr. John Nuszkowzki was used [38]. A charge in Coulombs corresponding to the in-cylinder pressure was produced by the pressure transducer which was later amplified by charge amplifiers and related to a voltage sent to the National Instruments data acquisition (DAQ). Other inputs to the DAQ were intake and exhaust manifold temperatures along with the engine speed measured from the crankshaft by a shaft encoder. Ideal 
gas law and first law of thermodynamics have been assumed to calculate the mass fraction burned, heat release rate and bulk combustion temperature among other various parameters.

\subsubsection{In- Cylinder Bulk Temperature Calculation}

In-cylinder bulk temperature was calculated from following equations assuming ideal gas law [38]

$$
\begin{gathered}
T_{\theta}=P_{\theta} * V_{\theta} *\left(\frac{1}{n * R}\right) \\
\frac{T_{I V C}}{P_{I V C} * V_{I V C}}=\left(\frac{1}{n * R}\right) \\
T_{\theta}=P_{\theta} * V_{\theta} *\left(\frac{T_{I V C}}{P_{I V C} * V_{I V C}}\right)
\end{gathered}
$$

Where $\mathrm{T}_{\boldsymbol{\theta}}=$ Temperature at any crank angle

$\mathrm{P}_{\Theta}=$ Pressure at any crank angle, $\mathrm{V}_{\Theta}=$ Volume at any crank angle

$\mathrm{T}_{\mathrm{IVC}}, \mathrm{P}_{\mathrm{IVC}}, \mathrm{V}_{\mathrm{IVC}}=$ temperature, pressure and volume at intake valve closure.

The $\mathrm{T}_{\text {IVC }}$ is the reference temperature at the intake manifold while $\mathrm{V}_{\Theta}$ is calculated using the slider crank mechanism. 


\section{Methodology}

\subsection{Test Design/Methodology}

The methodology used to find the significant parameter affecting the characteristic functions, namely in-cylinder bulk temperature, brake specific NOx emissions and particle count median diameter (CMD) along with their optimum levels is discussed below [39].

- Decide the objective

- Determine the parameters along with the number of levels

- Create a test matrix

- Conduct the actual tests

- Data analysis using analysis of variance (ANOVA)

- Select optimum combination of parameters

- Verification tests

\subsection{Design of Experiments}

Traditional single parameter approach is no longer possible due to the advancements in engine technology, which were essential to meet the stringent emission standards. Not only does the number of tests increase but also it is difficult to isolate the effects of each parameter from interactions among various parameters [40]. Thus design of experiments (DOE) was used to plan the set of experiments in which all input parameters were varied over a working range. A DOE was conducted using the commercially available software package JMP ${ }^{\circledR}$ where an array of tests was created to test all the possible combinations of these control parameters over a limited number of tests and study their impacts on characteristic functions namely in-cylinder bulk temperature, NOx emissions and particle CMD. The orthogonal array 'L18' consisting of 4 control parameters and two interactions corresponding to a case where NOx emissions, particle CMD and bulk in-cylinder temperature are to be minimized is shown below in Table 7. 
Table 7: Test Matrix L18

\begin{tabular}{|c|c|c|c|c|}
\hline Experiment & VGT & EGR & SOI & RP \\
\hline $\mathbf{1}$ & L1 & L3 & L3 & L3 \\
\hline $\mathbf{2}$ & L3 & L3 & L1 & L3 \\
\hline $\mathbf{3}$ & L2 & L3 & L3 & L2 \\
\hline $\mathbf{4}$ & L2 & L1 & L1 & L2 \\
\hline $\mathbf{5}$ & L3 & L3 & L3 & L3 \\
\hline $\mathbf{6}$ & L3 & L1 & L1 & L1 \\
\hline $\mathbf{7}$ & L3 & L2 & L3 & L1 \\
\hline $\mathbf{8}$ & L1 & L2 & L3 & L1 \\
\hline $\mathbf{9}$ & L3 & L2 & L2 & L1 \\
\hline $\mathbf{1 0}$ & L2 & L1 & L2 & L1 \\
\hline $\mathbf{1 1}$ & L2 & L2 & L2 & L2 \\
\hline $\mathbf{1 2}$ & L1 & L3 & L2 & L3 \\
\hline $\mathbf{1 3}$ & L2 & L3 & L1 & L2 \\
\hline $\mathbf{1 4}$ & L1 & L1 & L2 & L2 \\
\hline $\mathbf{1 5}$ & L2 & L2 & L1 & L1 \\
\hline $\mathbf{1 6}$ & L1 & L1 & L3 & L2 \\
\hline $\mathbf{1 7}$ & L1 & L2 & L1 & L3 \\
\hline $\mathbf{1 8}$ & L3 & L1 & L2 & L3 \\
\hline
\end{tabular}

\subsection{Determination of Parameters Along with the Number of Levels}

The parameters namely variable geometry turbocharger (VGT) vane position, EGR rate, rail pressures and start of injection timing and their levels (see Table 9 and Table 10) were selected to arrive at a combination of parameters that produced the lowest temperature of combustion possible without compromising engine out particle CMD and NOx emissions.

\subsection{Strategy Implementation for High Cetane/Low Cetane Fuel}

A common strategy was implemented for both fuels. Three levels for each control factor were fixed to study their effects on responses, namely in-cylinder bulk temperature, brake specific NOx emissions and particle CMD. Table 8 illustrates the implementation of the strategy that permits LTC by advancing the combustion before TDC and by using high rail pressures (1200 bar - 1600 bar) along with variations in the values of EGR and VGT vane position. 
Table 8: Strategy Implementation for the Tests

\begin{tabular}{|c|c|c|c|}
\hline Engine Parameters & Level 1 & Level 2 & Level 3 \\
\hline VGT Vane Position & - & Baseline & + \\
\hline EGR & - & Baseline & + \\
\hline Pilot SOI Injection & Baseline & + & ++ \\
\hline Rail Pressure & Baseline & + & ++ \\
\hline
\end{tabular}

In order to test the hypothesis, highly advanced SOI timing before TDC and high rail pressure strategy was implemented by strategically assigning the baseline values to these parameters. Baseline values for SOI and rail pressure have been assigned to 'level 1' from prior testing [41] whereas 'level 2' and 'level 3' have been assigned to achieve test points with higher rail pressures and more advanced SOI timing during the L18 test strategy (see Table 8). The strategy does not provide any indication regarding the direction of VGT vane position and EGR ratio, thus baseline value has been assigned to 'level 2' such that 'level 1' and 'level 3' have values higher and lower than the baseline value respectively. Section 4.5 discusses in detail the level assignment for VGT vane position and EGR ratio.

\subsection{Level Assignment for High Cetane/Low Cetane Fuel}

The levels were selected based on the following guidelines:

- The engine physical limitations such as exhaust temperature, coolant and oil temperature, emission limits and cylinder pressure.

- Prior work conducted to achieve LTC [41].

Levels for VGT were fixed at $45 \%, 70 \%$ and $100 \%$ based on the boost that was obtained. Minimum boost for both fuels was obtained at 45\% VGT vane position, and a maximum boost was obtained at a $100 \%$ setting. Misfire in the engine was used as a metric to obtain the maximum allowable EGR at each VGT vane position while the minimum EGR was fixed such that its corresponding NOx did not exceed the baseline engine-out values. In order to test the hypothesis, pilot injection and rail pressure were incremented by 2 levels from the baseline configuration (as seen in Table 8) to enhance mixing of the fuel and air to achieve a homogeneous like charge prior to start of combustion. However, this could result in advancing the combustion event before TDC producing high cylinder pressures and pressure rise rates; thus 
needing compensation by a diluent such as EGR, and a VGT to create pressure gradient for EGR flow. Finally, an identical sampling set-up as described in Section 3.3.2 was employed for both the fuels to study the particle size distribution during LTC.

Data points which included 40\%-45\% EGR flow rate for 45\% VGT vane position could not be achieved due to a possible interaction between EGR and VGT. At 45\% VGT, a maximum of 25\%-30\% EGR was used because the pressure gradient between the exhaust and intake manifold was not enough to allow for a flow rate of 40-45\% EGR.

\subsubsection{SOI Level Assignment for High Cetane Fuel}

The cetane property of the fuel had a major impact on the main SOI timing. Being a high cetane number fuel its ability to burn immediately produced best results at retarded injection timings. Initial work was performed prior to main SOI level assignment in order to have satisfactory brake specific NOx and soot emissions at $5^{\circ}$ ATDC.

Table 9: Level Assignment for High Cetane Fuel

\begin{tabular}{|c|c|c|c|}
\hline \multicolumn{5}{|c|}{ High Cetane Fuel } \\
\hline High Cetane & $\begin{array}{c}\text { Level } \\
1\end{array}$ & $\begin{array}{c}\text { Level } \\
2\end{array}$ & $\begin{array}{c}\text { Level } \\
3\end{array}$ \\
\hline VGT (\%) & 45 & 70 & 100 \\
\hline EGR (\%) & $20-25$ & $30-35$ & $40-45$ \\
\hline Pilot Injection (Deg) & 30 & 40 & 50 \\
\hline Rail pressure (Bar) & 1200 & 1400 & 1600 \\
\hline Main SOI (Deg) & \multicolumn{4}{|c}{ 5TDC } \\
\hline
\end{tabular}

\subsubsection{SOI Level Assignment for Low Cetane Fuel}

Operating the engine over the same SOI levels as for the high cetane fuel (see Table 9) could not be accomplished due to physical limitations such as misfiring. The engine did not favor very high advanced pilot injection coupled with high EGR levels for this fuel. The reason was possible wall wetting at very advanced injection before TDC leading to incomplete oxidation of hydrocarbons. Thus an intake air heater was used to blow hot air across the intercooler to obtain high intake manifold temperatures thus allowing the use of high EGR without misfiring. Table 10 shows similar level assignment for VGT, EGR and rail pressures with different pilot and main SOI timing as compared to the high cetane fuel. 
Table 10: Level Assignment for Low Cetane Fuel

\begin{tabular}{|c|c|c|c|}
\hline \multicolumn{5}{|c|}{ Low Cetane Fuel } \\
\hline High Cetane & $\begin{array}{c}\text { Level } \\
1\end{array}$ & $\begin{array}{c}\text { Level } \\
2\end{array}$ & $\begin{array}{c}\text { Level } \\
3\end{array}$ \\
\hline VGT (\%) & 45 & 70 & 100 \\
\hline EGR (\%) & $20-25$ & $30-35$ & $40-45$ \\
\hline Pilot Injection (Deg) & 35 & 40 & 45 \\
\hline Rail pressure (Bar) & 1200 & 1400 & 1600 \\
\hline Main SOI (Deg) & \multicolumn{4}{|c}{ BTDC } \\
\hline
\end{tabular}

\subsection{Analysis Of Variance (ANOVA)}

ANOVA is a statistical tool which accounts for the contribution of variance from each control factor, interactions and experimental error [40]. The significance of each factor is found by comparing the variance between the factor effects and the variance associated with experimental data, which can comprise of random error or interactions among control factors [40].

Results from tests conducted as per the test matrix (see Table 7) were processed with ANOVA only to find out the strongest control factor along with its optimum level on the maximum temperature of combustion, particle CMD and NOx emissions. Once that was determined the optimum setting for each fuel considering the strongest influences was identified and the results were compared with the baseline strategy.

\subsubsection{Model Calculation in ANOVA}

This section presents the calculation, methodology to construct the ANOVA table in order to determine the significant parameters on a particular response.

\subsubsection{Sum of Squares}

The sum of squares (SS) is a measure of the deviation of the experimental data from the mean value of the data. Calculation of SS corresponding to an individual factor, for example pilot injection assuming no interaction, is given by

$$
S S_{p i}=\left(n_{p i 1}\right) *\left(\overline{N O x}_{p i 1}-\overline{N O x}\right)^{2}+. .+\left(n_{p i 3}\right) *\left(\overline{N O x}_{p i 3}-\overline{N O x}\right)^{2}
$$


Where,

$n_{p i 1}$ is the number of tests conducted at first level of pilot injection

$\overline{N O x}_{p i 1}$ is the average of the brake specific NOx emissions at first level of pilot injection

$\overline{N O x}$ is the average value of NOx emissions from all the data points.

The sum of squares corresponding to individual parameters for e.g NOx emissions is given by

$$
S S_{N O x}=\sum_{1}^{18}\left(N O x_{i}-\overline{N O x}\right)^{2}
$$

The total SS is given by

$$
\text { Total } S S=S S_{\text {individual parameters }}+S S_{\text {interactions }}+S S_{\text {errors }}
$$

$S S_{\text {interactions }}$ is calculated similarly to the SS for main interactions(see Equation 6). JMP ${ }^{\circledR}$ has been used to simplify the calculation process. It calculates the average of the response value corresponding to a particular level of an interaction and compares that value to the mean of that response to calculate the sum of squares for interactions.

Here errors may be defined as the amount of variation in the response caused by factors other than controllable factors included in the experiment [42].

\subsubsection{Degrees of Freedom}

Degrees of freedom represent the number of terms that are free to vary independently of the other terms in the sum of squares. It determines the number of tests required based on the number of parameters and interactions, along with their corresponding levels [40]. DOF for the experiments is calculated as follows:

$$
D O F_{\text {exp }}=n-1
$$

Where,

DOF $=$ degrees of freedom

$\mathrm{n} \quad=$ number of test points 
Degrees of freedom for the individual parameters depend on their respective levels. If " $l$ " is the number of levels for each identified parameter, then $D O F_{\text {par }}$ is given by

$$
D O F_{\text {par }}=l-1
$$

\subsubsection{Mean Square}

For each source of variation mean square (MS) is the ratio of sum of squares to the degrees of freedom [42].

$$
M S=\frac{S S_{p i}}{d o f_{p i}}
$$

MS may be defined as a measure of variability around the mean or targeted value. Equation 11 shows the mean square ratio for pilot injection on a particular response.

Where

dof $=$ degrees of freedom associated with a particular parameter.

$S S_{p i}=$ Sum of squares due to pilot injection on a response.

\subsubsection{F Test}

ANOVA F-test is done to characterize the means among and within groups. More specifically, it is used to compare the variation among groups to the variation within groups. F-ratio is calculated as shown in Equation 12

$$
F=\frac{M S}{S S_{e}}
$$

\subsubsection{P value}

The $\mathrm{P}$ value is the probability that a random variable having the $\mathrm{F}$ distribution is greater than or equal to the calculated value of F statistic [42]. A P value equal to or less than 0.05 implies that the result is true at least $95 \%$ of the time. A probability of 0.05 is an established level in academic publications, so conclusions cannot be drawn without a high probability of the result occurring.

Therefore,

$$
1-\alpha=0.95
$$


From equation $13, \alpha=0.05$

Thus, if $\mathrm{P}$ value is as small or smaller than $\alpha$, the data is statistically significant at $95 \%$ confidence level [43].

\subsubsection{Percent Significance}

The contribution percentage of each factor and interaction can be calculated as follows

$$
\text { Percent Significance of Pilot Injectionon a Response }=\left(\frac{S S_{\text {factors }}}{S S_{\text {total }}}\right) * 100 \%
$$

\subsection{Selection of Optimum Combination of Parameters}

The optimum levels for each significant parameter were determined by choosing the level which contributes to the lowest response value. Selection of optimum combination of parameters was done using a function called desirability. This function has been incorporated into the software package JMP ${ }^{\circledR}$. Desirability function “D” is a transformation of a response variable to a 0 to 1 scale. Thus a value of 0 essentially represents an undesirable response whereas a value of 1 represents the most desirable response. Desirability is given by:

$$
D=\sqrt[n]{\left(d_{1}+d_{2}+d_{3}+\ldots .+d_{n}\right)}
$$

Where,

$n=$ total number of responses

$d_{n}=$ particular response value

Using the product of the responses (see Equation 15) essentially means that if any one of the single desirability is 0 , the overall desirability becomes 0 . In this way, the simultaneous optimization of various responses has been reduced to optimizing a single response: the overall desirability, D [44]. Finally, a response curve was plotted in the same way as was done for the individual responses to determine the optimum combination of parameters. 


\subsection{Experimental Verification}

Once the optimum combination of parameters producing the lowest in-cylinder bulk temperature, NOx emissions and particle CMD are identified, actual experimental tests were conducted at this data point to record the response values. Finally a comparison between the optimum strategy identified and the baseline strategy was done for both fuels. 


\section{Results and Discussions}

\subsection{Mode Selection}

LTC has been attempted at an operating point of $2100 \mathrm{rpm}$ targeting a BMEP of 3.5 bar equivalent to $39 \mathrm{ft}-\mathrm{lb}$ torque. Achieving low temperature combustion at higher loads may result in elevated NOx emissions along with high in-cylinder pressures, hence possibly leading to engine knocking and failure.

\subsection{Fuel Selection}

$\mathrm{CN}$ has been identified as the most influential fuel property among many affecting the emission properties of an engine [12]. Thus, a high cetane and a low cetane number fuel were chosen for this study. Results show the optimized parameter setting for both fuels. Conclusions were obtained based on the particle count median diameter (CMD), brake specific NOx emissions and in-cylinder bulk temperature to select a better fuel amongst the two used, for operation in the LTC regime. Properties of the FACE (Fuels for Advanced Combustion Engines) are listed below:

Table 11: FACE Properties

\begin{tabular}{|c|c|c|}
\hline Fuel property & Fuel \#1 & Fuel \# 2 \\
\hline Cetane Number & 28 & 54 \\
\hline Aromatic Content (Vol\%) & 49.1 & 22.5 \\
\hline T90 $\left({ }^{\circ} \mathrm{F}\right)$ & 640 & 642 \\
\hline
\end{tabular}

\subsection{Test Array Generation}

The commercially available software package JMP ${ }^{\circledR}$ was used to simplify the procedure for design of experiments, and for post processing the data. In order to design the test matrix, inputs to $\mathrm{JMP}^{\circledR}$ were as follows:

- Number of Control Factors (4)

- Number of Levels for Control Factors (3)

- Number of Responses (3)

- Interactions (2)

The goal of the test matrix was to find the optimal engine parameter settings allowing for simultaneously achieving low particle CMD, low in-cylinder bulk temperature as well as low 
NOx emissions for each of the fuels. The test matrix for each fuel contained 18 data points, and the responses, namely in-cylinder bulk temperature, NOx emissions and particle count median diameter were recorded for each data point.

$\mathrm{JMP}^{\circledR}$ uses a random seed to generate the test matrix, but whatever test matrix is generated by the algorithm, it points to the optimal parameter settings. The advantage of using this approach is to obtain a trend with limited number of experiments involving a large number of parameters. ANOVA table was generated later (explained in section 4.6), which calculates the contribution of various parameters on the responses.

\subsection{Results for High Cetane Fuel}

Table 12 shows the test matrix for high cetane fuel along with the emission responses. A total of 17 test points were generated by JMP ${ }^{\circledR}$ based on the number of input parameters and interactions considered. However, 18 tests were conducted in order to have enough degrees of freedom for the error term and thus enabling the effects of the error on the responses to be determined. Here the error term refers to all other factors apart from the ones considered making an impact on the responses.

All tests were conducted in accordance to procedures outlined in 40 CFR, Part 1065. The engine was fitted with a pressure transducer in order to calculate the bulk cylinder temperature as a function of crank angle degrees. A sampling system setup constituting of a hot and cold dilution tunnel (see section 3.3.2) was employed to study combustion generated nanoparticles.

Table 12: Test Matrix for High Cetane Fuel Along with the Responses

\begin{tabular}{|c|c|c|c|c|c|c|c|}
\hline \multicolumn{8}{|c|}{ Tests for the High Cetane Fuel } \\
\hline Fxneriment & VGT & EGR & SOI & $\mathbf{R P}$ & CT & NOx & $\begin{array}{c}\text { Particle } \\
\text { CMD }\end{array}$ \\
\hline No & $\%$ & $\%$ & Deg & Bar & $\mathbf{K}$ & g/bhp-hr & nm \\
\hline 1 & L1 & L3 & L3 & L3 & 1455 & 0.409 & 37.2 \\
\hline 2 & L3 & L3 & $\mathrm{L} 1$ & L3 & 1442 & 0.338 & 91.4 \\
\hline 3 & L2 & L3 & L3 & L2 & 1452 & 0.092 & 68.5 \\
\hline 4 & L2 & L1 & L1 & $\mathrm{L} 2$ & 1351 & 1.979 & 49.6 \\
\hline 5 & L3 & L3 & L3 & L3 & 1511 & 0.084 & 68.5 \\
\hline
\end{tabular}




\begin{tabular}{|c|c|c|c|c|c|c|c|}
\hline $\mathbf{6}$ & L3 & L1 & L1 & L1 & 1348 & 2.222 & 57.3 \\
\hline $\mathbf{7}$ & L3 & L2 & L3 & L1 & 1413 & 0.252 & 46.1 \\
\hline $\mathbf{8}$ & L1 & L2 & L3 & L1 & 1375 & 0.661 & 33.4 \\
\hline $\mathbf{9}$ & L3 & L2 & L2 & L1 & 1423 & 0.683 & 61.5 \\
\hline $\mathbf{1 0}$ & L2 & L1 & L2 & L1 & 1384 & 0.683 & 42.9 \\
\hline $\mathbf{1 1}$ & L2 & L2 & L2 & L2 & 1461 & 0.38 & 59.4 \\
\hline $\mathbf{1 2}$ & L1 & L3 & L2 & L3 & 1468 & 0.857 & 37.2 \\
\hline $\mathbf{1 3}$ & L2 & L3 & L1 & L2 & 1506 & 0.217 & 121.9 \\
\hline $\mathbf{1 4}$ & L1 & L1 & L2 & L2 & 1406 & 1.526 & 28.9 \\
\hline $\mathbf{1 5}$ & L2 & L2 & L1 & L1 & 1451 & 1.037 & 91.4 \\
\hline $\mathbf{1 6}$ & L1 & L1 & L3 & L2 & 1439 & 0.908 & 7.91 \\
\hline $\mathbf{1 7}$ & L1 & L2 & L1 & L3 & 1424 & 2.304 & 42.9 \\
\hline $\mathbf{1 8}$ & L3 & L1 & L2 & L3 & 1489 & 0.945 & 42.9 \\
\hline
\end{tabular}

The fuel injection strategy employed was a 50\% split injection with varying pilot injection and a fixed main injection at $5^{\circ}$ ATDC. A retarded main injection at $5^{\circ}$ ATDC was favourable for high cetane fuel due to its ability to rapidly combust.

\subsubsection{ANOVA Results}

Results from tests conducted in accordance with the test matrix shown in Table 12 were further processed with ANOVA and calculated as discussed in Section 4.6. The significance of the $P$ value in Table 13 needs to be addressed first before identifying the significance of the factors. "Significance” means 'probably true' (not due to chance) and not 'important.' A P value lower than 0.05 indicates that a particular result is true at least $95 \%$ of the time [45]. Sometimes as in the case of Table 13 where $P$ value is more than 0.05 , which essentially means that, it is uncertain if the obtained result is as true as it was when the probability was at the $95 \%$ level, but it does not essentially mean that the result is false [45]. This research was more focussed towards the values obtained in Table 14 rather than the $\mathrm{P}$ values, as they indicate the trend with limited number of tests. 
Table 13: ANOVA Table for High Cetane Fuel

\begin{tabular}{|c|c|c|c|c|c|c|c|c|c|c|}
\hline \multicolumn{11}{|c|}{ ANOVA Table } \\
\hline \multirow[b]{2}{*}{ Parameters } & \multirow[b]{2}{*}{ DOF } & \multicolumn{3}{|c|}{ SS } & \multicolumn{3}{|c|}{ F value } & \multicolumn{3}{|c|}{$P$ value } \\
\hline & & CT & $\mathrm{NOx}$ & $\begin{array}{c}\text { Particle } \\
\text { CMD }\end{array}$ & CT & NOx & $\begin{array}{l}\text { Particle } \\
\text { CMD }\end{array}$ & CT & NOx & $\begin{array}{l}\text { Particle } \\
\text { CMD }\end{array}$ \\
\hline VGT & 2 & 2308.3 & 0.62 & 1258.5 & 1.72 & 96.378 & 26.46 & 0.47 & 0.07 & 0.14 \\
\hline EGR & 2 & 709.12 & 1.09 & 1365.1 & 0.53 & 170.09 & 28.71 & 0.69 & 0.05 & 0.13 \\
\hline SOI & 2 & 1875.9 & 2.66 & 1808.9 & 1.41 & 419.92 & 38.03 & 0.51 & 0.03 & 0.11 \\
\hline $\mathrm{RP}$ & 2 & 6025.5 & 0.58 & 395.78 & 4.49 & 89.868 & 8.312 & 0.32 & 0.07 & 0.24 \\
\hline VGT*EGR & 4 & 9860.1 & 1.32 & 1009.6 & 3.67 & 102.42 & 10.61 & 0.37 & 0.07 & 0.23 \\
\hline SOI*RP & 4 & 4546.5 & 1.14 & 531.76 & 1.69 & 89.031 & 5.558 & 0.51 & 0.07 & 0.31 \\
\hline Error & 1 & 672.18 & 0.01 & 23.776 & & & & & & \\
\hline Total & & 25997.5 & 7.46 & 6393.6 & & & & & & \\
\hline
\end{tabular}

\subsubsection{Contribution of Factors}

Table 14 was constructed as a result of the ANOVA table, showing the influence of various factors on a response.

Table 14: Contribution of Control Factors on Responses

\begin{tabular}{|c|c|c|c|c|}
\hline \multirow{2}{*}{ No. } & \multirow{2}{*}{$\begin{array}{c}\text { Control } \\
\text { Factor }\end{array}$} & \multicolumn{3}{|c|}{ \% Contribution } \\
\cline { 3 - 5 } & CT & NOx & Particle CMD \\
\hline 1 & VGT & 8.88 & 8.31 & 19.7 \\
\hline 2 & EGR & 2.73 & 14.7 & 21.3 \\
\hline 3 & SOI & 7.22 & 36.2 & 28.3 \\
\hline 4 & RP & 23.2 & 7.75 & 6.2 \\
\hline 5 & VGT*EGR & 37.9 & 17.7 & 15.8 \\
\hline 6 & SOI*RP & 17.5 & 15.3 & 8.32 \\
\hline 7 & Error & 2.57 & 0.043 & 0.372 \\
\hline
\end{tabular}

The above table has been constructed by expressing the individual sum of squares as a percentage of the total sum of squares for each individual response. Only the strong influential factors (parameters having an influence of over $15 \%$ on a response) were considered to find the optimal parameter settings for simultaneous NOx/Particle CMD/In-Cylinder Bulk Temperature reduction. Table 15 lists the strongest parameters on a response. 
Table 15: Strongest Parameters on Response for High Cetane Fuel

\begin{tabular}{|c|c|c|c|}
\hline \multirow{2}{*}{ Response } & $\begin{array}{c}\text { Strongest } \\
\text { Parameters }\end{array}$ & \multicolumn{2}{c|}{ Strongest Interactions } \\
\hline In-Cylinder Bulk Temperature & Rail Pressure & VGT*EGR & SOI*RP \\
\hline Break Specific NOx emissions & EGR, SOI & VGT*EGR & SOI*RP \\
\hline Particle CMD & VGT, EGR, SOI & VGT*EGR & - \\
\hline
\end{tabular}

\subsubsection{Effect of Control Factors on In-Cylinder Bulk Temperature}

Since, the effects of VGT and EGR as main factors on bulk combustion temperature are minimal (see Figure 39) one would assume the interaction between the two parameters to be negligible. However, the interaction between VGT and EGR was found to have the strongest influence on in-cylinder bulk temperature. Thus, a good control strategy between VGT and EGR needs to be implemented, which will not only affect fuel economy but also reduce NOx emissions by creating a pressure gradient between the inlet and exhaust manifolds; hence allowing high EGR flow rate.

Interaction between SOI timing and rail pressure also had a contribution of $17 \%$ on bulk combustion temperature. This could be because of a strong rail pressure influence on bulk combustion temperature. Thus, the majority of the interaction is dominated by the influence of rail pressure on combustion temperature (refer Figure 38).

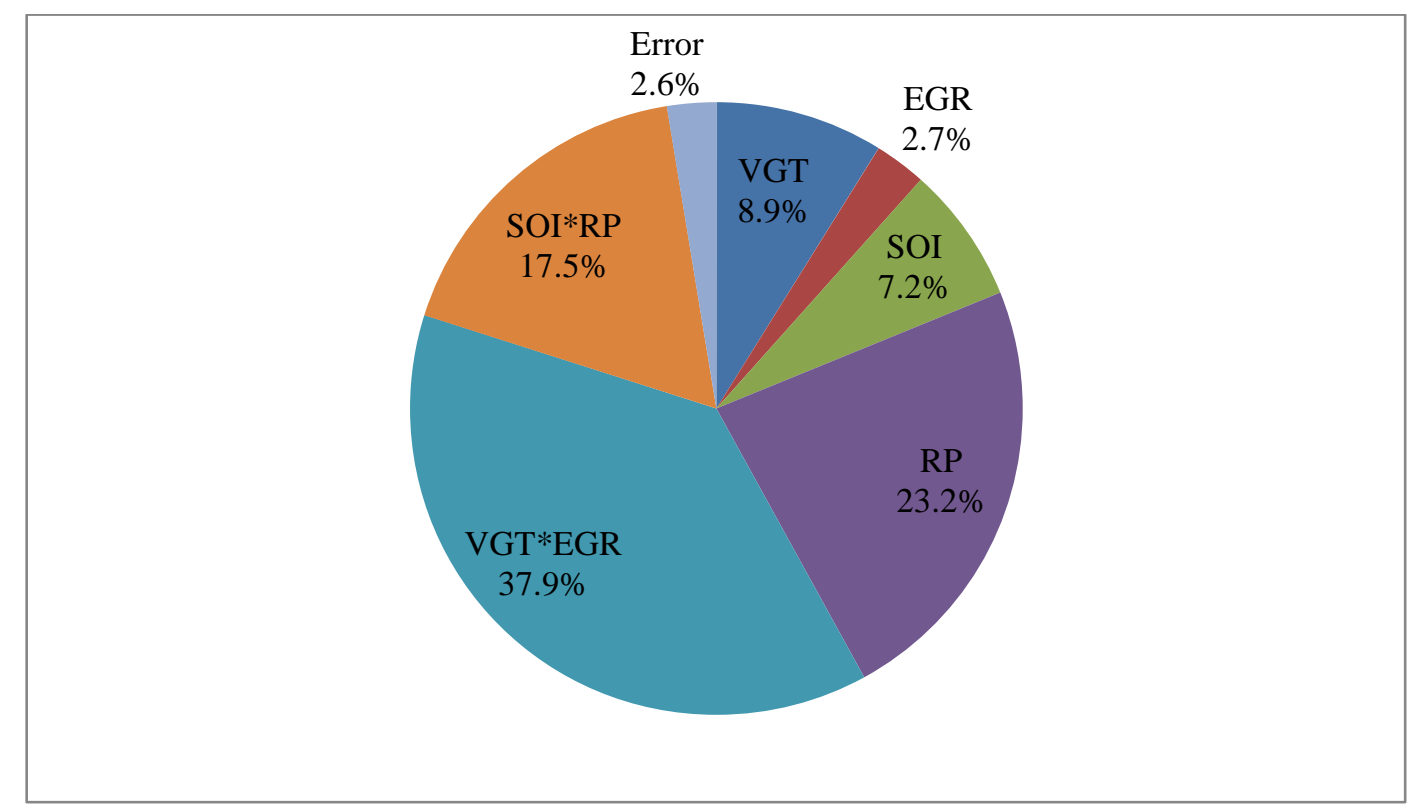

Figure 38: Effect of Control Factors on In-Cylinder Bulk Temperature 


\subsubsection{Effect of Contol Factors on NOx}

Pilot SOI timing followed by the interacton between VGT and EGR were identified as the strongest influencing factors on NOx emissions. The interaction between VGT and EGR was found influential on NOx because of a strong influence of EGR on NOx. Figure 39 depicts the pie graph showing the contribution of various factors on NOx emissions.

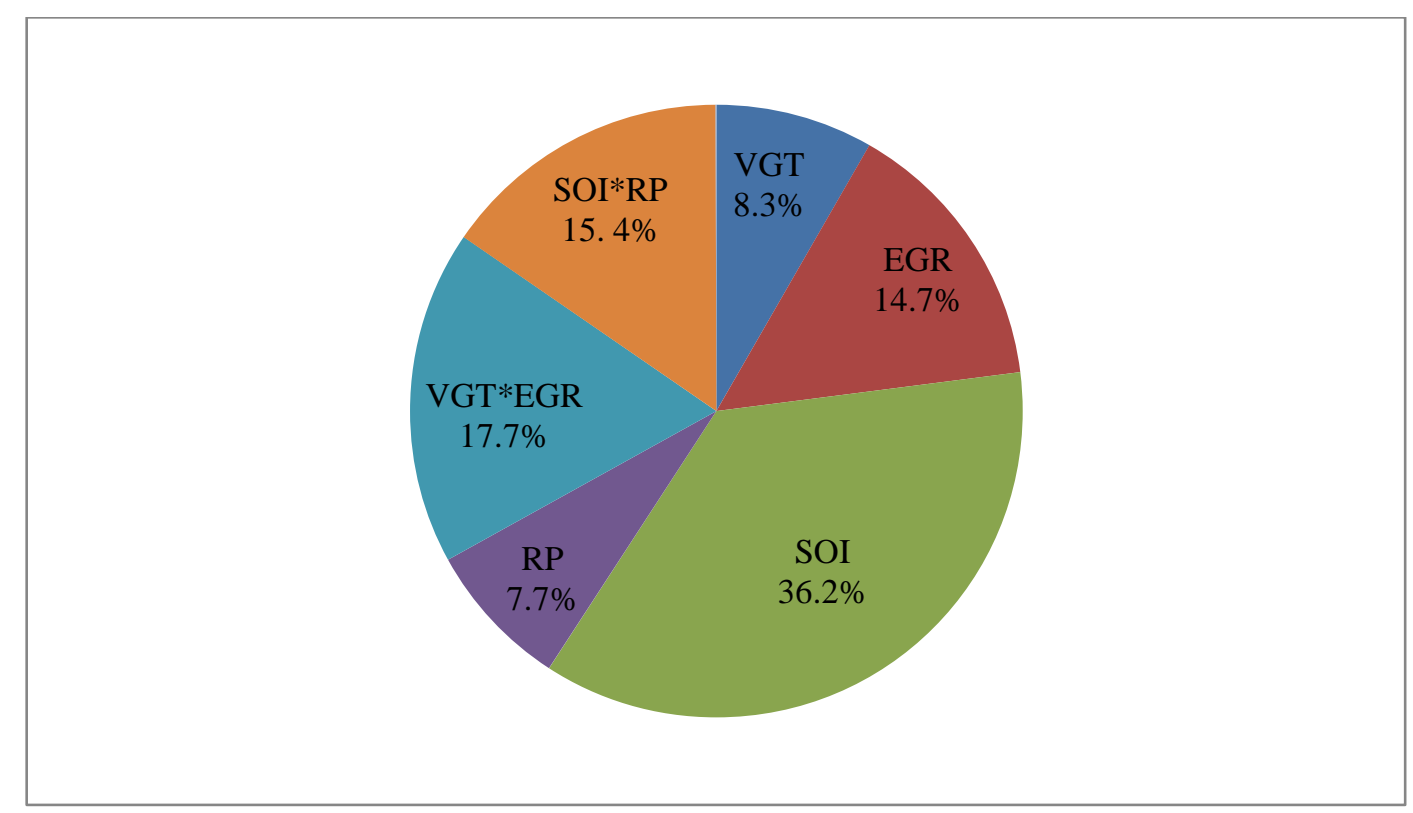

Figure 39: Effect of Control Factors on NOx Emissions

Lastly, interaction between SOI and rail pressure also has a strong influence on NOx emissions. This could be because of a strong influence of SOI timing rather than rail pressure on NOx emissions.

\subsubsection{Effects of Control Factors on Particle CMD}

Pilot SOI has been identified to be the most influential factor on the particle CMD. Thus having an optimum SOI timing along with a good control strategy of VGT and EGR will result in a shift in particle distribution towards smaller nano-particles with lower NOx emissions. High influence of the main factors of EGR and VGT on particle CMD from Figure 40 further illustrates the need to have a good control strategy between VGT and EGR. 


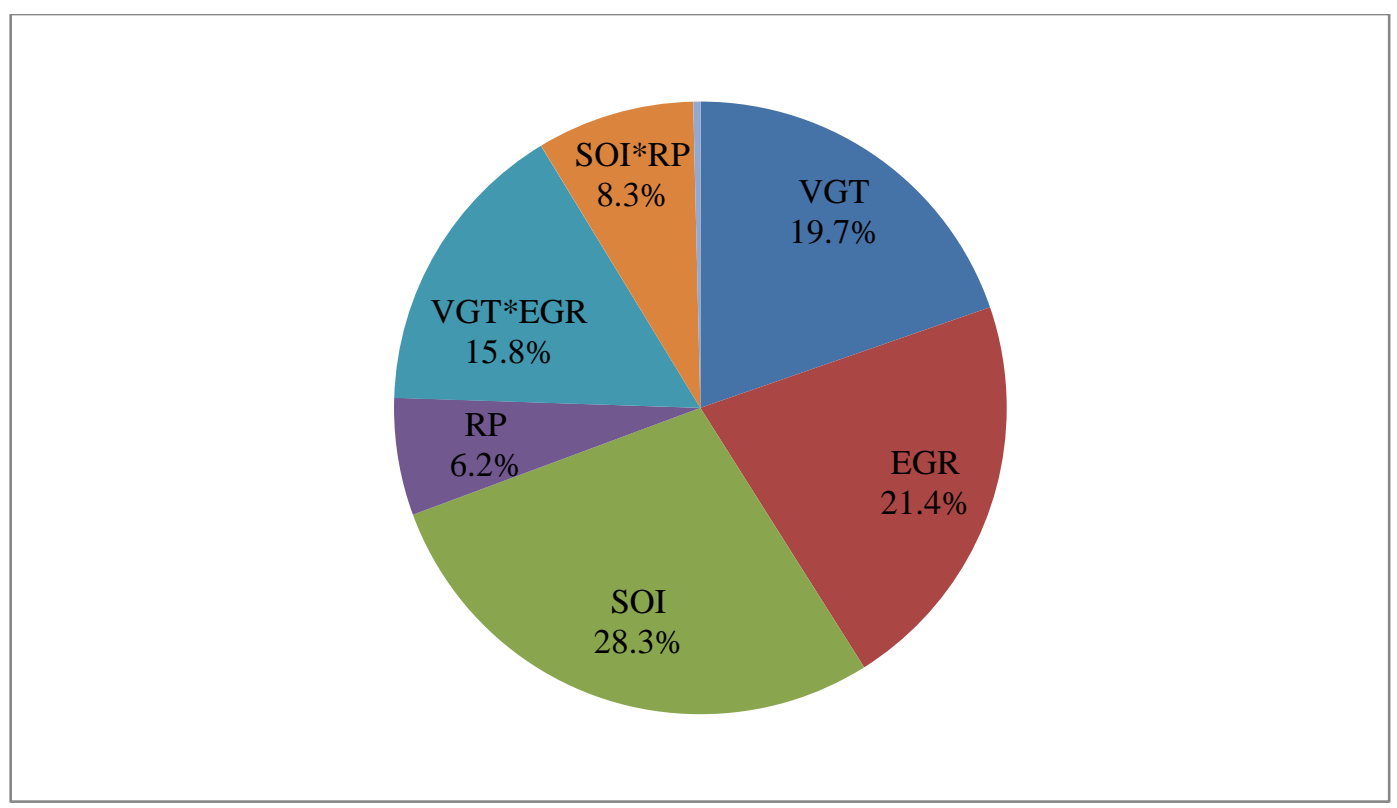

Figure 40: Effect of Control Factors on Particle CMD

\subsubsection{Strongest Parameters Influencing In-Cylinder Bulk Temperature}

Apart from the interaction terms, the most influential parameter on in-cylinder bulk temperature is identified as rail pressure. Figure 41 below shows the effects of rail pressure on bulk combustion temperature for the tests conducted.

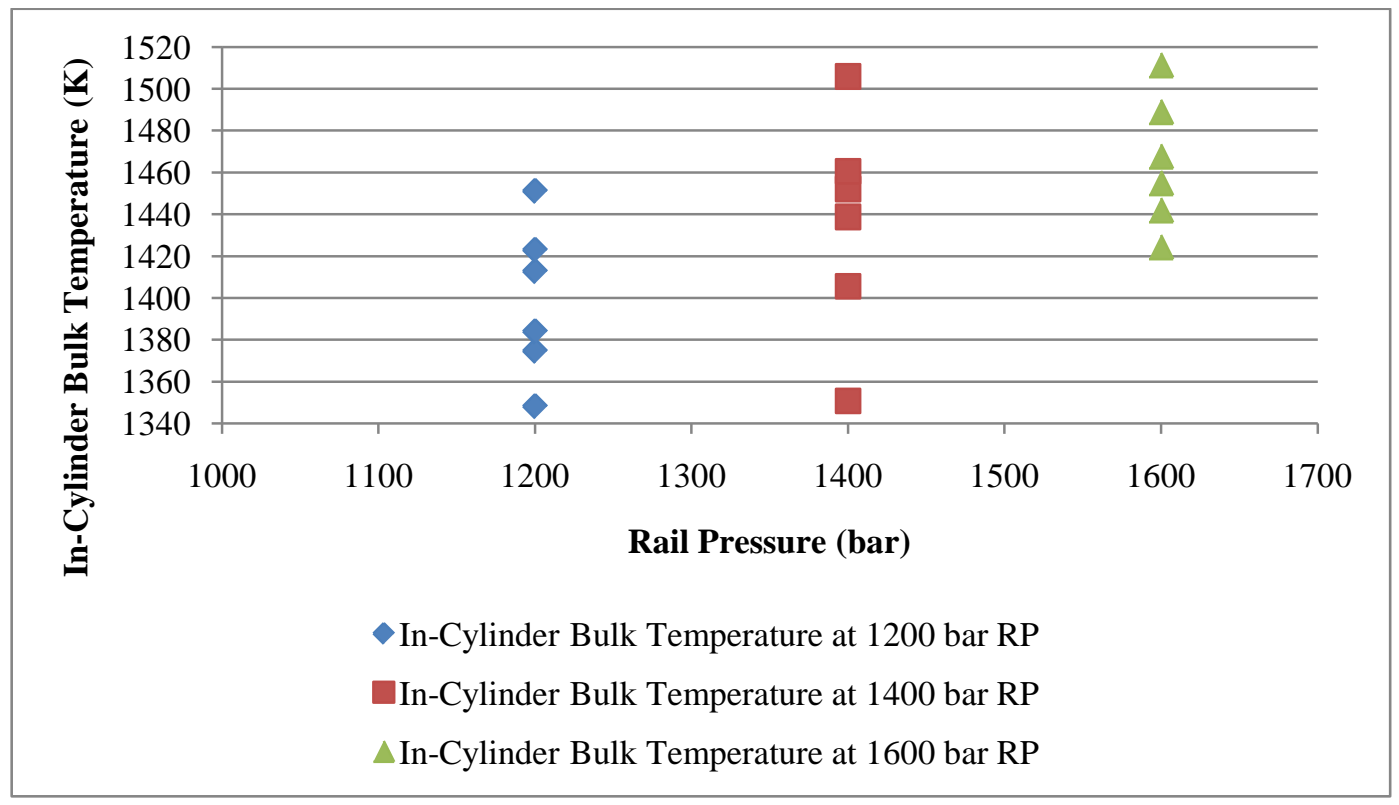

Figure 41: Effects of Rail Pressure on In-Cylinder Bulk Temperature 
As expected higher rail pressure increased the in-cylinder bulk temperature. This could be due to the fact that higher rail pressures contribute to better mixing of the fuel with air thus leading to an earlier start of combustion. Thus, a rail pressure of 1200 bar is optimum for a low bulk temperature which might have an inverse effect on PM formation.

\subsubsection{Strongest Parameters Influencing NOx and Particle CMD Emissions}

Main effects, such as SOI and EGR have a strong influence on NOx emissions while the former along with VGT had a strong influence on particle CMD. The following sections discuss individually the effects of the strong influences on NOx and particle CMD determined by ANOVA test over the 18 tests that were conducted.

\subsubsection{Effects of SOI on NOx Emissions}

Effects of SOI timing on NOx emissions is shown in Figure 42. Here, it can be observed that NOx decreases as SOI is advanced before TDC. However, from literature one would expect NOx decreasing with retarded injection due to decreased in-cylinder pressures. The early timing on the pilot SOI creates more mixing and therefore, more lean combustion producing lower NOx emissions.

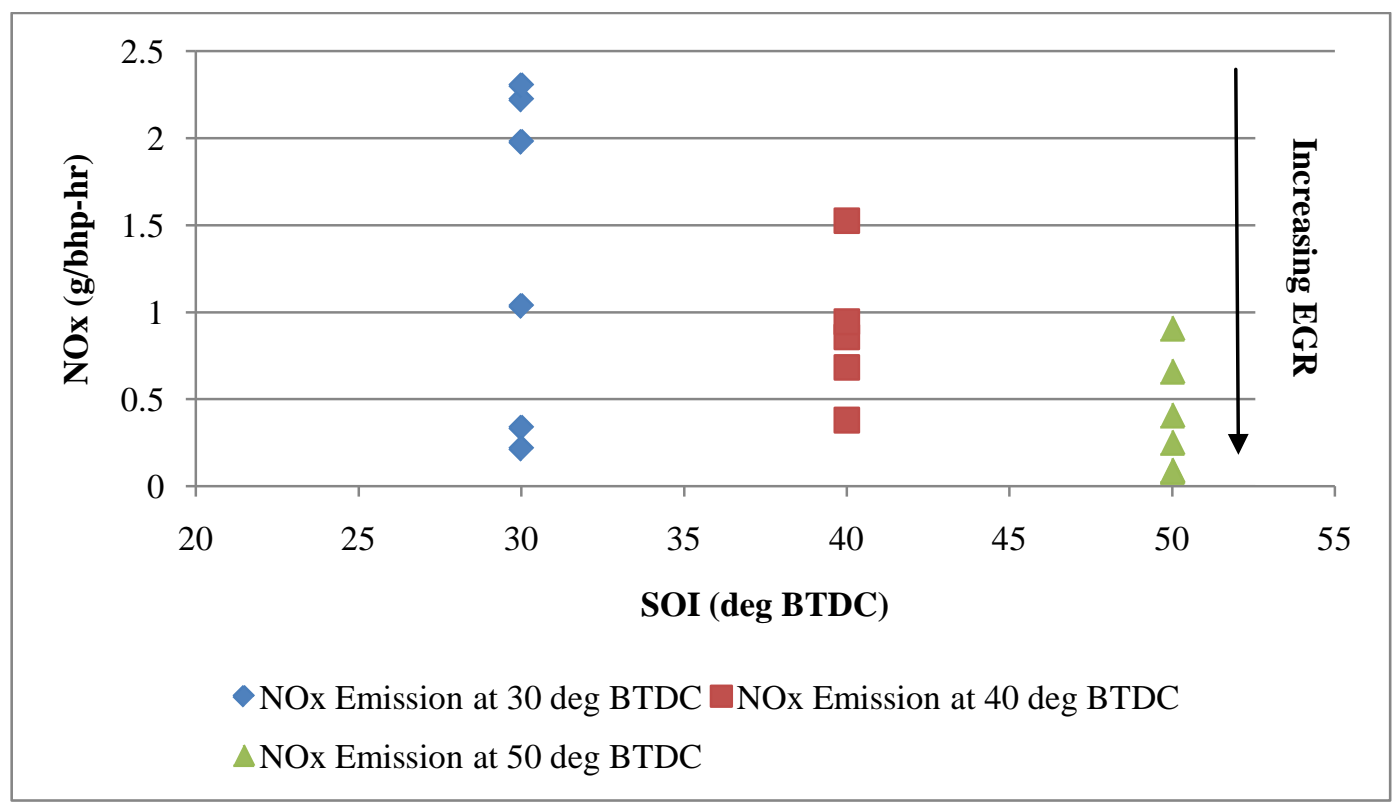

Figure 42: Effect of SOI Timing on NOx Emissions 


\subsubsection{Effect of EGR on NOx emissions}

Increase in EGR has the effect of reducing NOx emissions as expected while having an effect of increasing soot emissions, as shown in Figure 43. Thus an optimum strategy for EGR control is required along with other factors to reduce this trade-off.

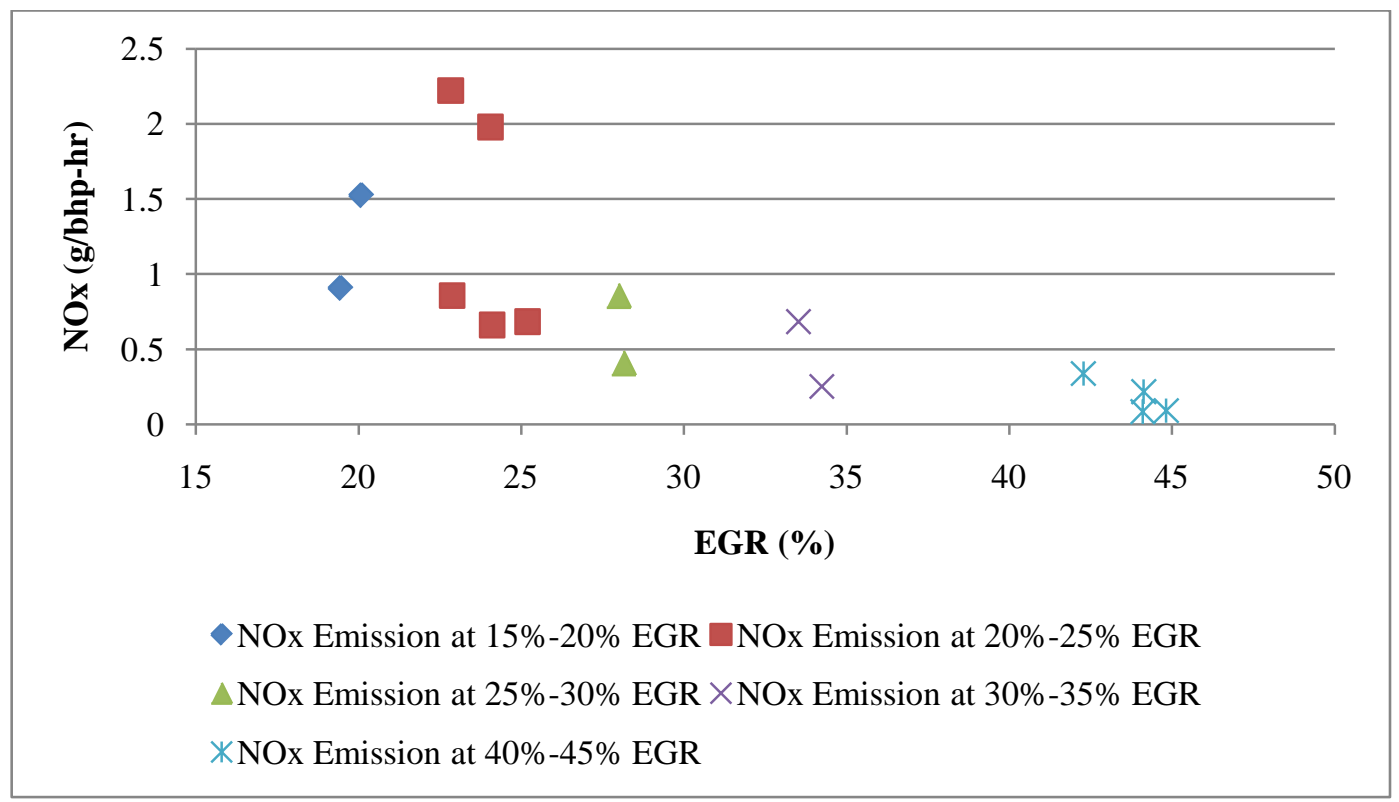

Figure 43: Effect of EGR on NOx Emissions

\subsubsection{Effect of SOI on PM Size Distribution}

Figure 44 shows the effect of pilot SOI on PM size distribution and concentration at a constant EGR rate. There is a shift towards smaller particles in the distribution with advanced SOI. At $40 \%-45 \%$ EGR, pilot SOI at $30^{\circ} \mathrm{BTDC}$, a CMD of $69.78 \mathrm{~nm}$ is observed in comparison to a $\mathrm{CMD}$ of $37.2 \mathrm{~nm}$ at $50^{\circ} \mathrm{BTDC}$. The decrease in the number concentration of accumulation mode particles at $50^{\circ} \mathrm{BTDC}$ has lead to a decrease in the soot emissions at this point compared to a retarded $30^{\circ} \mathrm{BTDC}$ injection. One attributes this trend due to better homogeneous like mixing at advanced SOI strategies. 


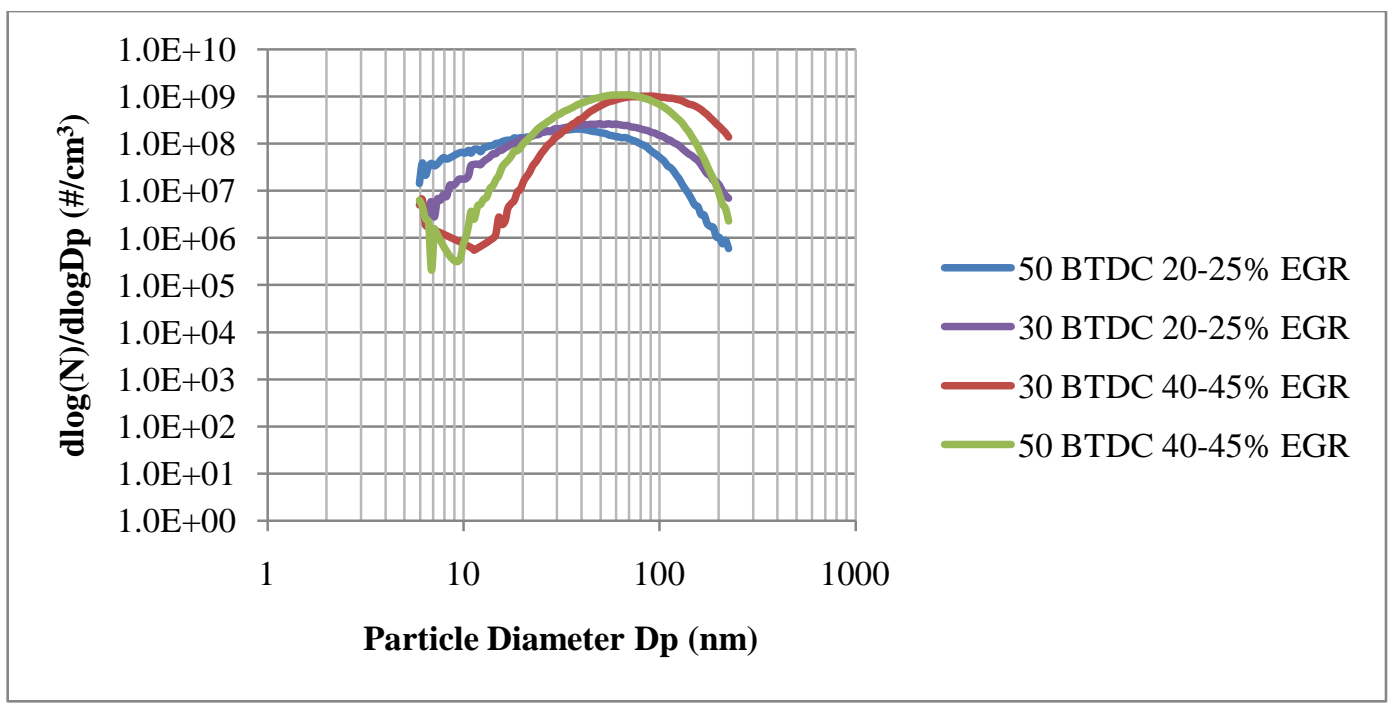

Figure 44: Effect of SOI on Size Distribution of PM

\subsubsection{Effect of SOI on Particle CMD}

Effect of SOI on particle CMD has been plotted for all 18 tests conducted and shown in Figure 45. Advancing SOI is observed to have the effect of decreasing particle count median diameter. This trend might be a result of better mixing at advanced SOI compared to retarded injections. With better mixing, the cylinder will contain fewer pockets of rich and lean mixtures; thus, contributing to lower particle CMD.

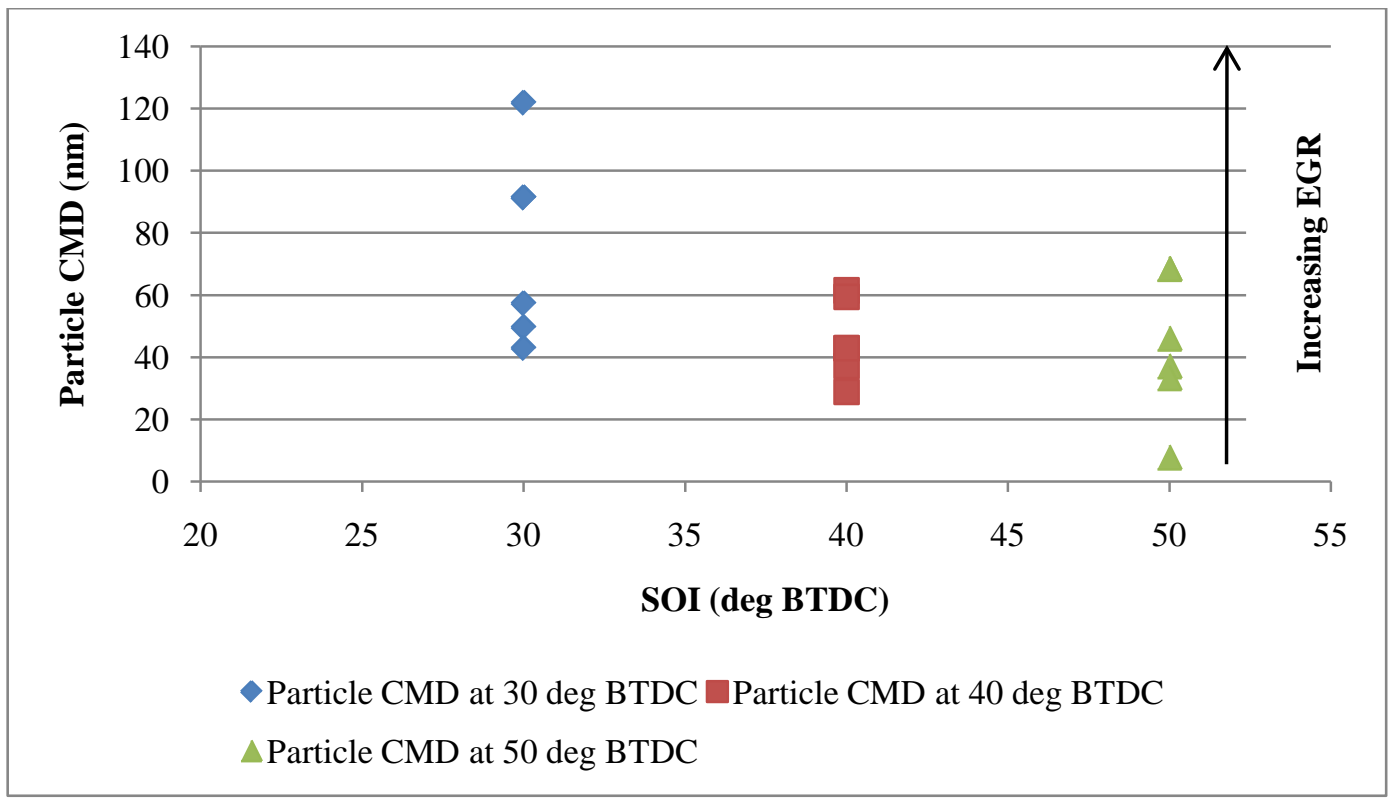

Figure 45: Effect of SOI on Particle CMD 


\subsubsection{Effect of EGR on PM Size Distribution}

Figure 46 shows the effect of EGR on particle size distributions and concentrations. Higher EGR rates leads to an increase in incomplete combustion and therefore an increase in the number concentration of accumulation mode particles. A decrease in the CMD from $91.4 \mathrm{~nm}$ at $40-45 \%$ EGR to $28.9 \mathrm{~nm}$ at $15-20 \%$ can be observed. Thus, an optimum EGR will tend to shift the PM CMD to a small diameter and lower particle concentrations.

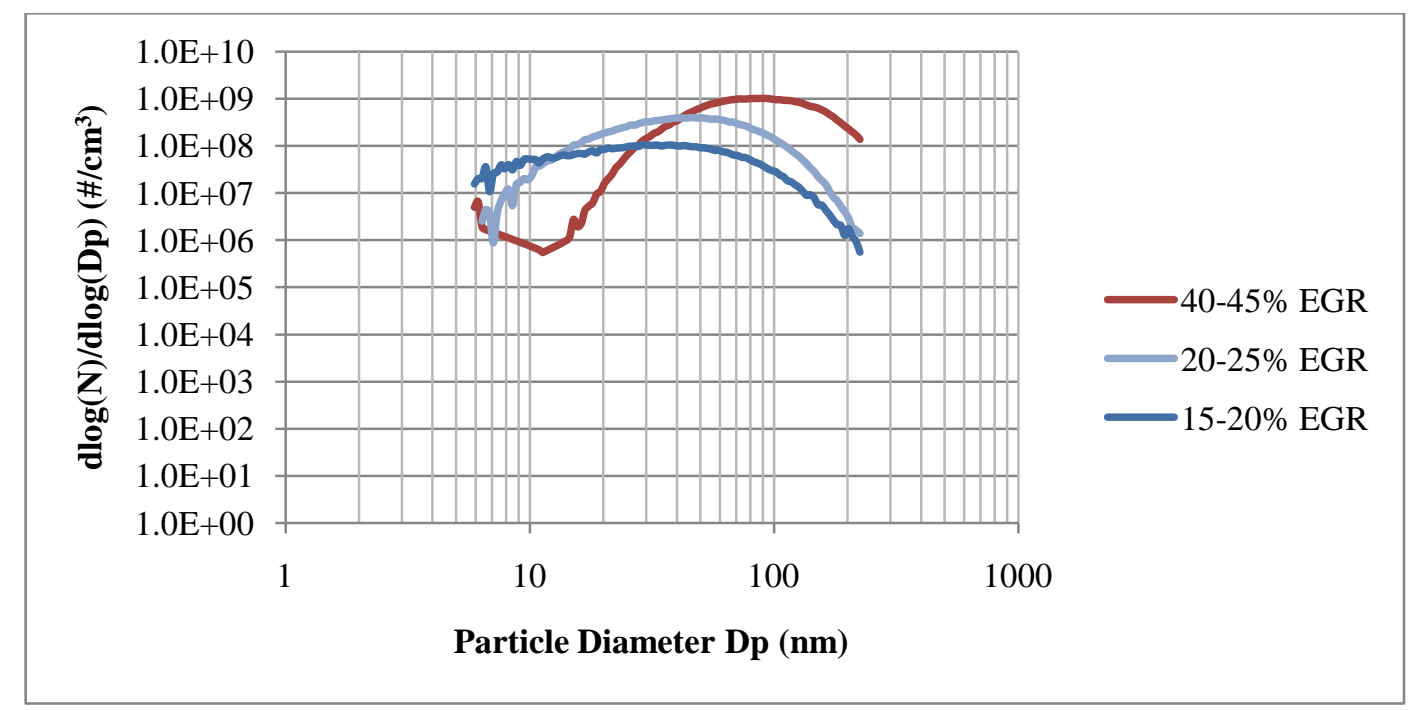

Figure 46: Effect of EGR on Particle Size Distribution

\subsubsection{Advancing SOI Effect on Particle CMD and NOx Emissions}

Figures 42 and 45 show that both NOx and particle CMD decrease as SOI timing is advanced. Thus, the highest level for SOI timing was selected as the setting for low NOx/low PM. Furthermore, Figure 47 shows no significant change in the total number concentration of PM particles for the 18 tests conducted. Thus, on advancing pilot SOI, a shift towards smaller count median diameters takes place without major change in the total number concentration of the PM particles. This proves the hypothesis that on advancing injection, an increase in the nuclei mode nano-particles might be observed. 


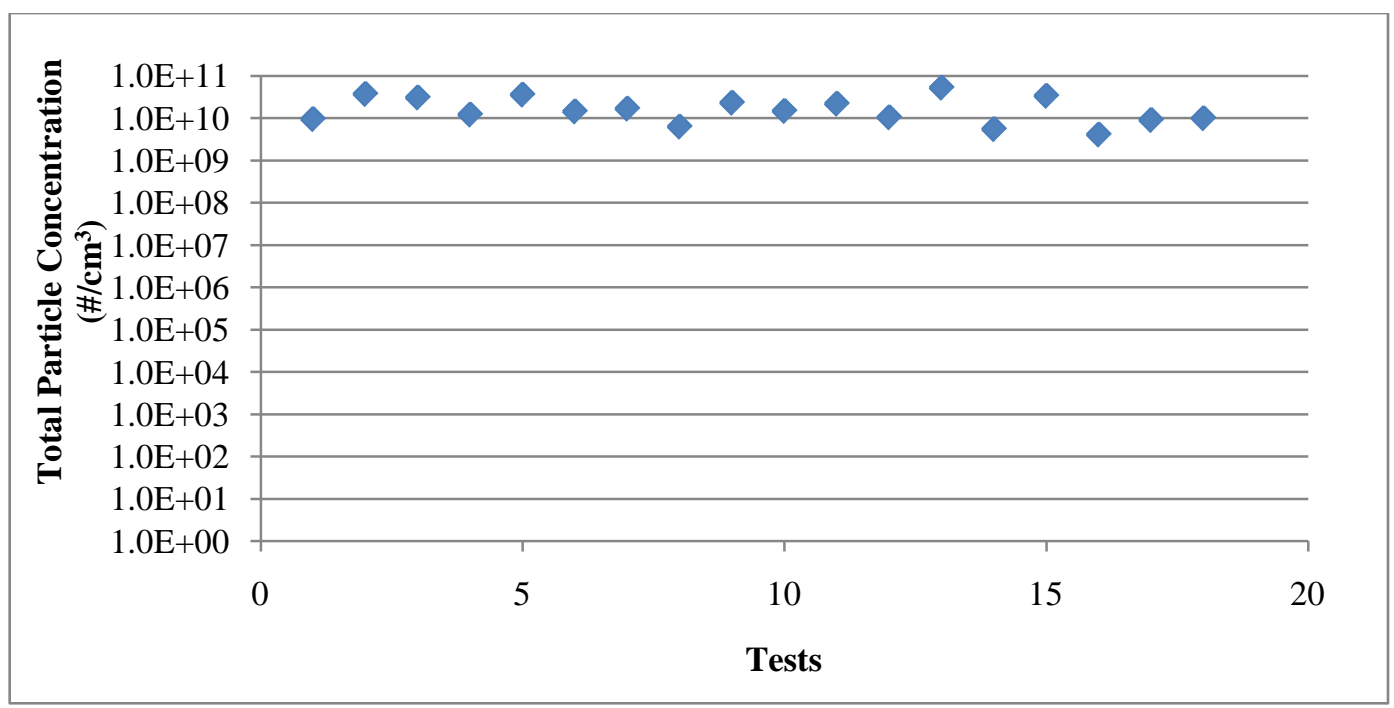

Figure 47: Total Number Concentration of PM Particles for 18 Tests Conducted

\subsubsection{Optimal Strategy for High Cetane Fuel}

$\mathrm{JMP}^{\circledR}$ prediction plot is a powerful tool to find the optimum responses for one or more responses. $\mathrm{JMP}^{\circledR}$ plots the response curve for the four chosen engine parameters. The first three rows of Figure 48 represent the optimal configurations for low in-cylinder bulk temperature, low NOx and low particle CMD, respectively. The last row represents the best settings for simultaneous low in-cylinder bulk temperature, low NOx and low particle CMD. The response curve points plotted in Figure 49 is derived from the difference between average of the response for the total tests and the average of the response at a particular level. 


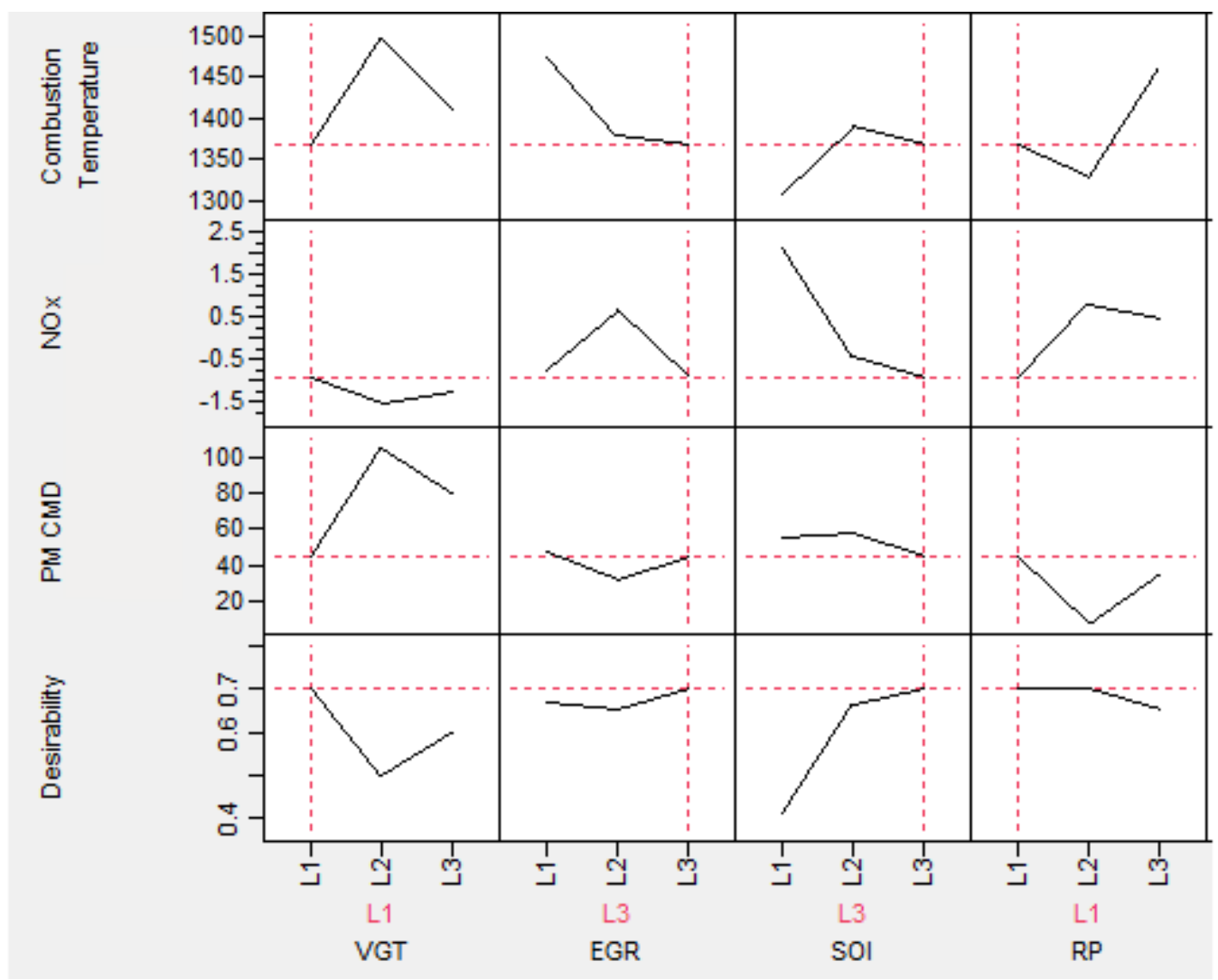

Figure 48: Response Curves for High Cetane Fuel

\subsubsection{Optimal Setting for High Cetane Fuel}

The optimal calibration settings achieving lowest in-cylinder bulk temperature along with low NOx emissions and particle CMD are given in Table 16.

Table 16: Optimal Parameter Setting for High Cetane Fuel

\begin{tabular}{|c|c|c|c|}
\hline \multicolumn{4}{|c|}{ Optimal Setting } \\
\hline \multicolumn{4}{|c|}{ Low NOx/Low CMD/Low CT } \\
\hline VGT & EGR & SOI & RP \\
\hline $45 \%$ & $25-30 \%$ & $50^{\circ}$ & $1200 \mathrm{bar}$ \\
\hline
\end{tabular}

$\mathrm{JMP}^{\circledR}$ uses the geometric mean of the responses at each level of a control parameter to determine the response curve for the optimal combination setting. Table 15 shows that the SOI timing chosen for optimal setting should be L3, which is reasonable since Figures 42 and 45 show decreasing trends in particle CMD and NOx emissions with advancing SOI. Once the optimum 
setting was determined the engine was tested at this setting to find out the reduction in NOx and soot emissions compared to baseline. Results at these optimum settings are shown in the following section. Figure 49 shows the plot between NOx and soot emissions for the optimum established (45\% VGT,25-30\% EGR, 50 SOI, 1400 bar RP) and the conventional baseline configuration. The baseline configuration refers to the engine running with an OEM ECU on commercially available ULSD fuel with cetane number of approximately 44. It was observed that the optimum strategy identified led to a reduction in soot and NOx emissions when compared to baseline configuration and therefore challenging the complex trade-off between NOx and PM emissions.

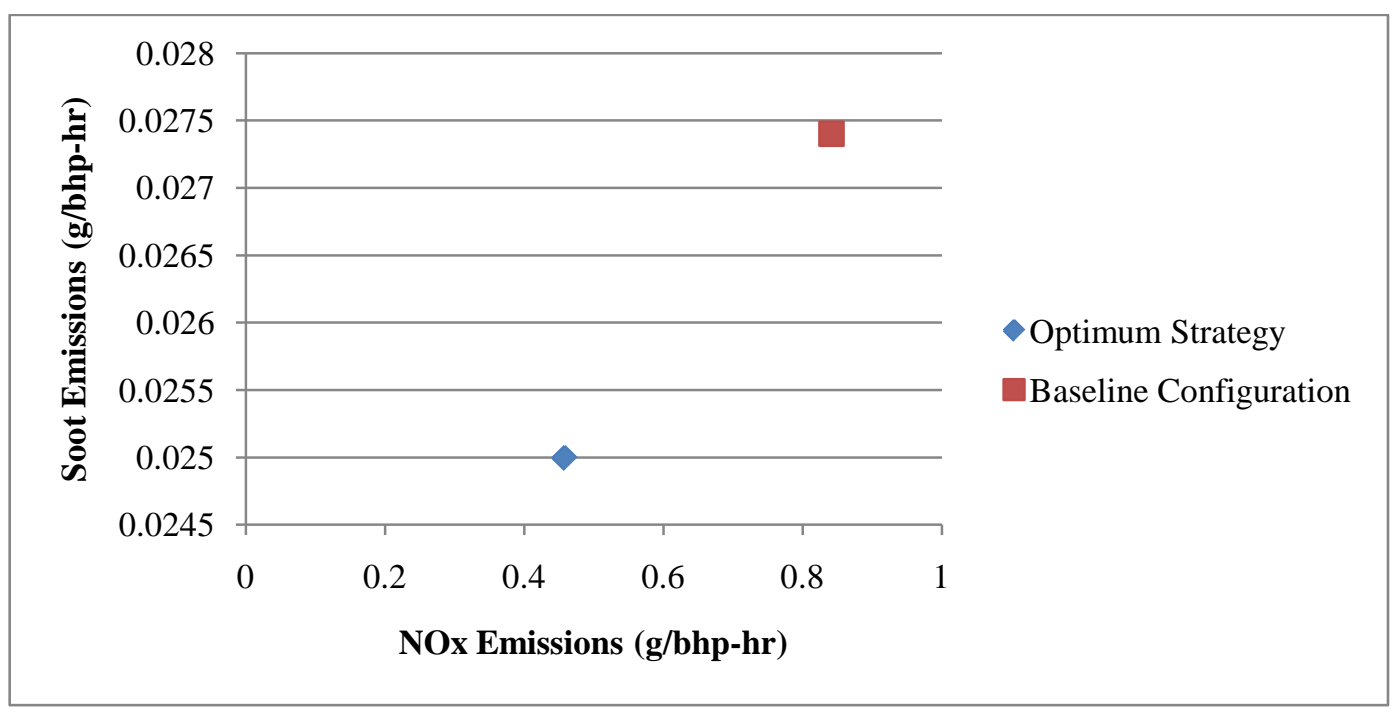

Figure 49: Comparison Between Baseline and optimum point for NOx and Soot

\subsubsection{Comparison in Emissions Between Baseline and Identified Optimum Strategy}

Figure 50 shows the comparison between the NOx, THC and soot emissions between baseline and the identified optimum strategy. As expected, there was an increase of about $46 \%$ on the total hydrocarbon emissions from the baseline while a decrease of $45 \%$ in $\mathrm{NOx}$ and $8 \%$ in soot emissions. 


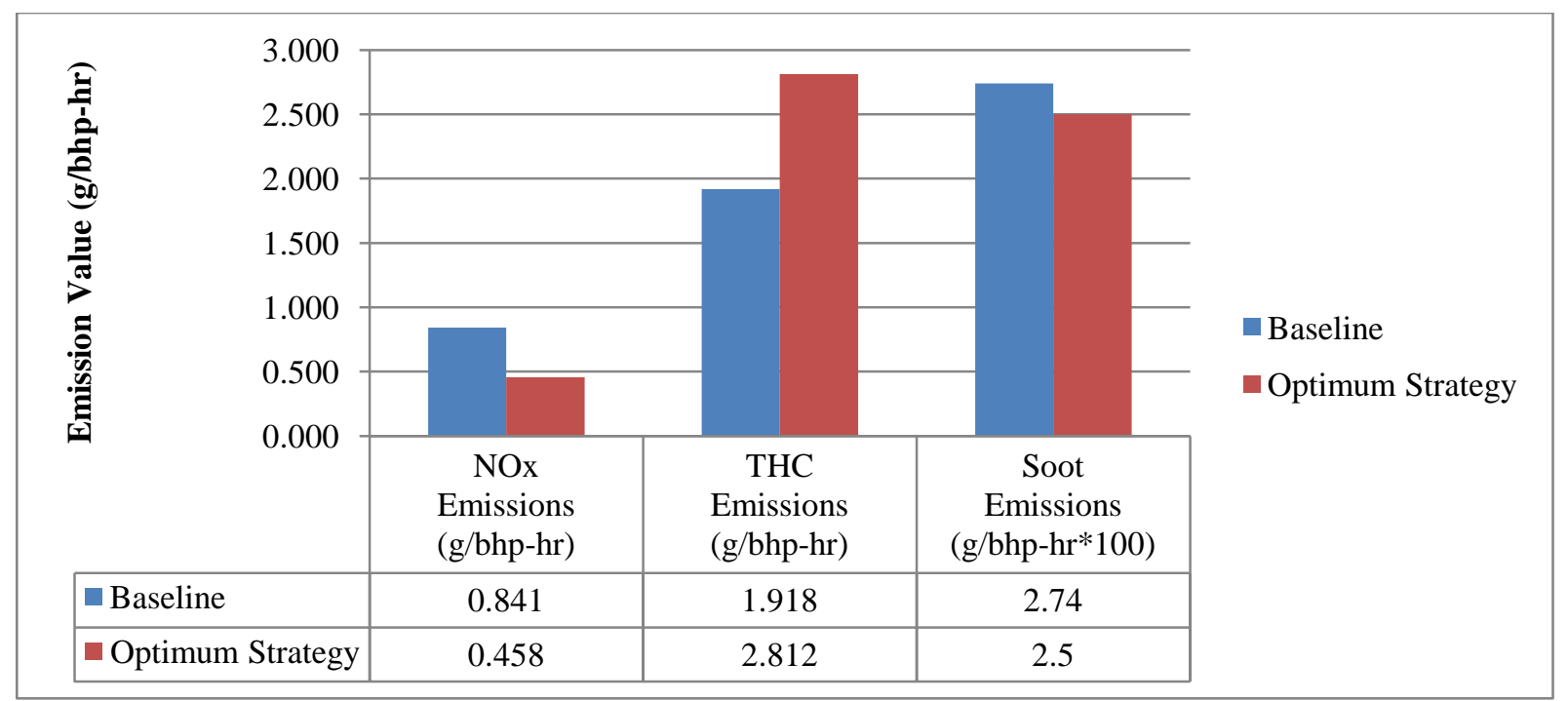

Figure 50: Comparison of Gaseous and Soot Emissions Between Baseline and Optimum Strategy

\subsubsection{PM Size Distribution Between Optimized Point and Low NOx Operating}

\section{Point}

A comparison between the PM size distribution during the optimized calibration setting and a low NOx calibration setting (identified from one of the tests during the implementation of the L18 test matrix) is shown in Figure 51. The particle CMD for the optimal strategy as compared to the low NOx strategy decreased from $91.4 \mathrm{~nm}$ to $38.5 \mathrm{~nm}$ along with a $35 \%$ penalty in NOx emissions. However, the optimal strategy still resulted in a 45\% NOx reduction from conventional combustion.

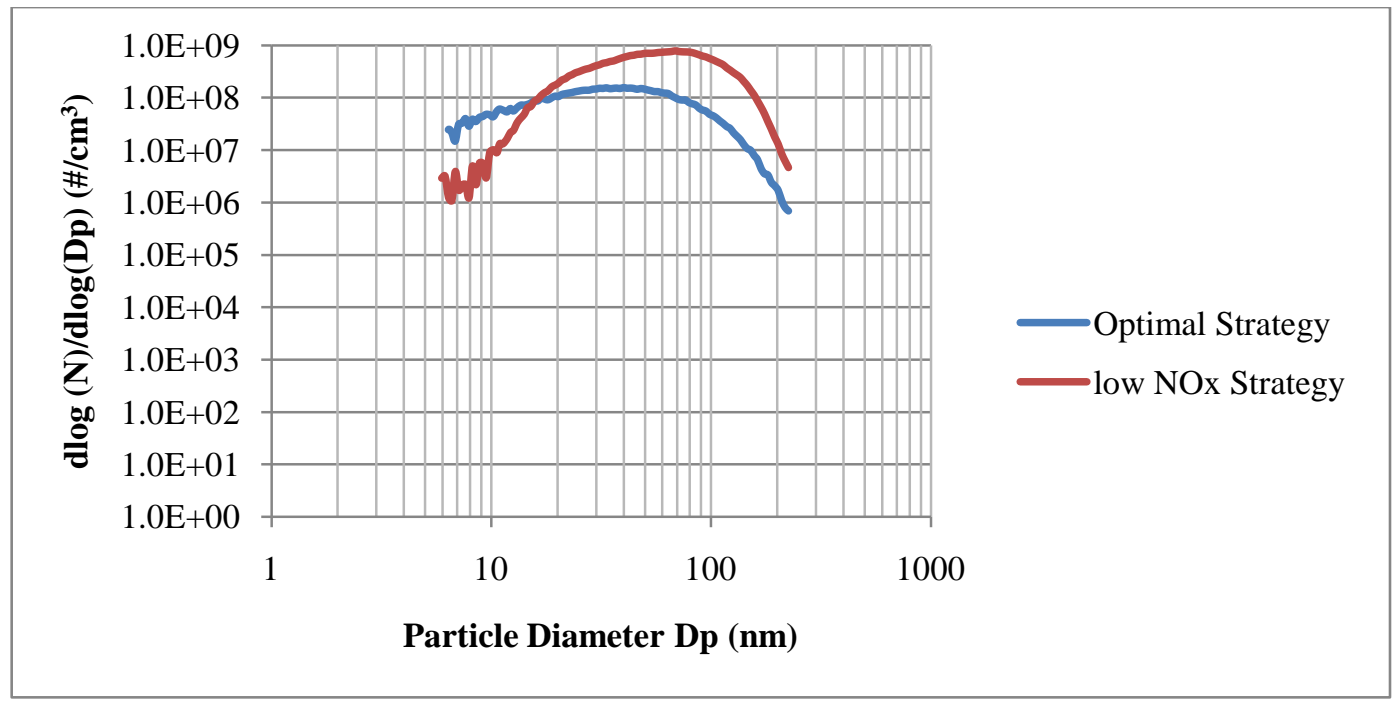


Figure 51: Comparison of particle size distribution Between identified optimal strategy and low NOx strategy

\subsubsection{PM Size Distribution Between Optimized Point and Low Soot Operating Point}

The size distribution between the optimized setting and low soot strategy (identified from one of the tests during the implementation of the L18 test matrix) is shown in Figure 52. It was observed that the optimal strategy has an increased accumulation mode particle count. The CMD shifted from $7.91 \mathrm{~nm}$ to $38.5 \mathrm{~nm}$ for the optimal configuration. However, the NOx at the identified optimal strategy decreased by little over $50 \%$.

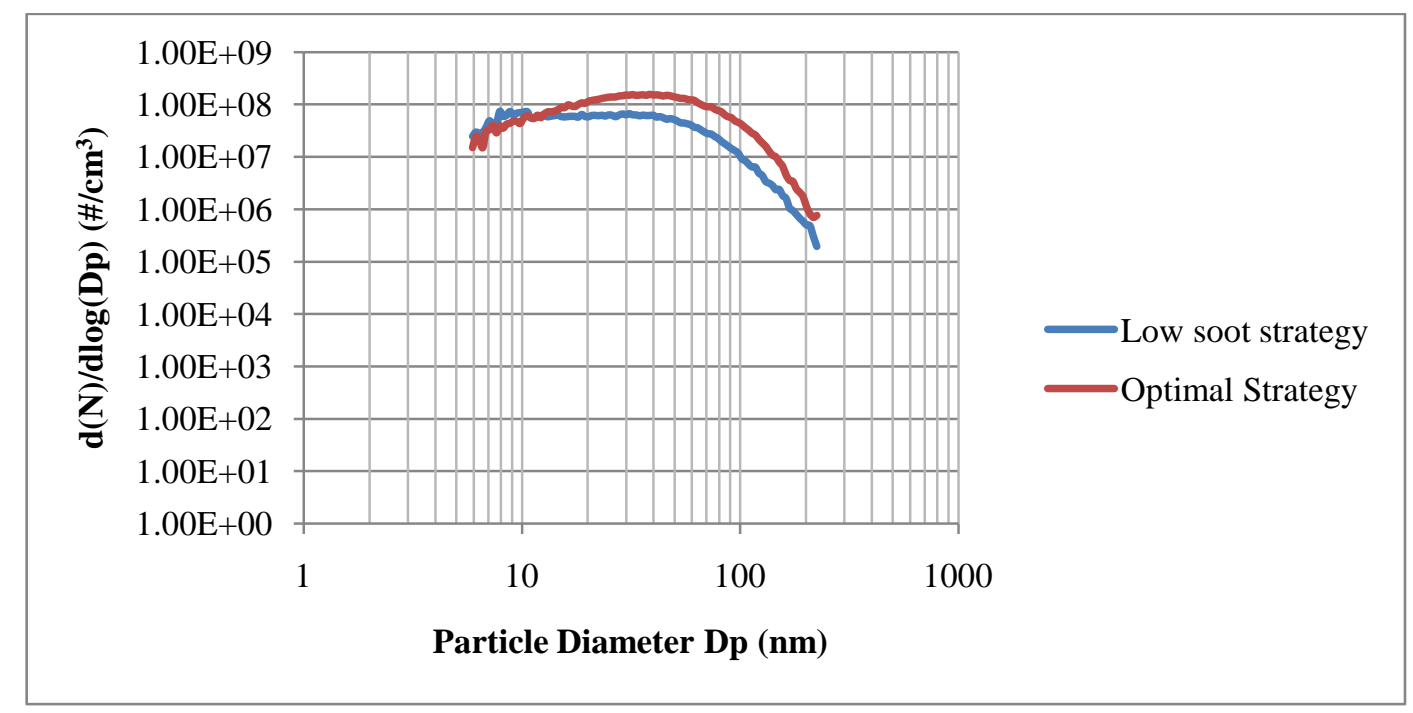

Figure 52: Comparison of PM Size Distribution Between Low Soot Strategy and Optimum Strategy

\subsection{Results for Low Cetane Fuel}

This section discusses the results established with the low cetane fuel whose properties are listed in Table 11. An identical L18, as implemented for the high CN fuel was repeated for the low CN fuel. However, the level assignment was different for the low cetane fuel as similar advanced pilot SOI settings along with high EGR rates led to misfiring with this fuel. The main SOI for low cetane was also advanced relative to that of high cetane fuel as retarded main injection led to misfire. Thus, for the low cetane fuel the main SOI timing was fixed at $5^{\circ}$ BTDC with a similar fuel split of 50\%. Again, the SOI timing selected was solely dependent on the fuel property. 


\section{5.1 Test Matrix for Low Cetane Fuel with Responses}

Table 17 shows the test matrix and the responses, namely in-cylinder bulk temperature, NOx emissions, particle CMD for low cetane fuel. Low cetane fuel indicates very low soot at most of the L18 set points. This trend may be attributed to the cetane property of the fuel. A low cetane fuel will have higher ignition delay, and thus will not combust immediately. This property will give more time for the air-fuel mixture to attain homogeneity thus avoiding rich and lean pockets of mixture ultimately leading to lower soot. A detailed comparison between both the fuels can be found in Section 5.6

Table 17: Test Matrix with Responses for the Low Cetane Fuel

\begin{tabular}{|c|c|c|c|c|c|c|c|}
\hline \multicolumn{8}{|c|}{ Test for the Low Cetane Fuel } \\
\hline Experiment & VGT & EGR & SOI & $\mathbf{R P}$ & CT & NOx & $\begin{array}{c}\text { Particle } \\
\text { CMD }\end{array}$ \\
\hline No & $\%$ & $\%$ & Deg & Bar & $\mathbf{K}$ & g/bhp-hr & $\mathrm{nm}$ \\
\hline 1 & L1 & L3 & L3 & L3 & 1505 & 0.995 & 9.47 \\
\hline 2 & L3 & L3 & L1 & L3 & 1483 & 0.091 & 30 \\
\hline 3 & L2 & L3 & L3 & L2 & 1383 & 0.244 & 20.9 \\
\hline 4 & $\mathrm{~L} 2$ & L1 & L1 & $\mathrm{L} 2$ & 1476 & 1.19 & 34.6 \\
\hline 5 & L3 & L3 & L3 & L3 & 1495 & 0.333 & 37.2 \\
\hline 6 & L3 & L1 & L1 & L1 & 1472 & 0.982 & 41.4 \\
\hline 7 & L3 & $\mathrm{L} 2$ & L3 & L1 & 1520 & 0.713 & 35.9 \\
\hline 8 & L1 & L2 & L3 & L1 & 1465 & 1.452 & 10.9 \\
\hline 9 & L3 & $\mathrm{L} 2$ & $\mathrm{~L} 2$ & L1 & 1506 & 0.45 & 32.2 \\
\hline 10 & L2 & L1 & $\mathrm{L} 2$ & L1 & 1496 & 1.271 & 32.2 \\
\hline 11 & $\mathrm{~L} 2$ & $\mathrm{~L} 2$ & $\mathrm{~L} 2$ & L2 & 1485 & 0.362 & 22.5 \\
\hline 12 & L1 & L3 & L2 & L3 & 1499 & 0.995 & 11.3 \\
\hline 13 & L2 & L3 & L1 & L2 & 1466 & 0.076 & 40 \\
\hline 14 & L1 & L1 & L2 & L2 & 1541 & 2.194 & 12.2 \\
\hline 15 & L2 & $\mathrm{L} 2$ & L1 & L1 & 1709 & 0.371 & 41.4 \\
\hline 16 & L1 & L1 & L3 & L2 & 1497 & 1.817 & 13.1 \\
\hline 17 & L1 & L2 & L1 & L3 & 1498 & 1.66 & 10.6 \\
\hline 18 & L3 & L1 & L2 & L3 & 1546 & 1.306 & 11.3 \\
\hline
\end{tabular}




\subsubsection{ANOVA Results for Low Cetane Fuel}

ANOVA table (see Table 17) was constructed for the low cetane fuel similar to that of the high cetane fuel to find the significant parameters on the responses. Table 17 shows the ANOVA table calculated by the $\mathrm{JMP}^{\circledR}$ from the experimental data provided.

\section{ANOVA Table}

Table 18 shows the generated ANOVA table for the low cetane fuel. The contribution of factors towards a response has been calculated from Table 18.

Table 18: ANOVA Table for Low Cetane Fuel

\begin{tabular}{|c|c|c|c|c|c|c|c|c|c|c|}
\hline \multicolumn{11}{|c|}{ ANOVA Table } \\
\hline \multirow[b]{3}{*}{ Parameters } & \multirow[b]{3}{*}{ DOF } & \multicolumn{3}{|c|}{ SS } & \multicolumn{3}{|c|}{ F value } & \multicolumn{3}{|c|}{$\mathrm{P}$ value } \\
\hline & & & & Particle & & & Particle & & & Particle \\
\hline & & CT & NOx & CMD & CT & NOx & CMD & CT & NOx & CMD \\
\hline VGT & 1 & 11536.9 & 1.67 & 533.94 & 3.12 & 2130.1 & 2.82 & 0.38 & 0.01 & 0.39 \\
\hline EGR & 2 & 12234.5 & 1.58 & 33.316 & 3.18 & 2031.2 & 0.18 & 0.37 & 0.02 & 0.86 \\
\hline SOI & 2 & 4564.89 & 0.03 & 331.32 & 1.19 & 40.312 & 1.75 & 0.54 & 0.11 & 0.47 \\
\hline $\mathrm{RP}$ & 2 & 19242.7 & 0.14 & 138.45 & 5.06 & 180.89 & 0.73 & 0.31 & 0.05 & 0.64 \\
\hline VGT*EGR & 4 & 28320.3 & 0.18 & 134.83 & 3.68 & 116.92 & 0.36 & 0.37 & 0.07 & 0.83 \\
\hline SOI*RP & 4 & 8713.89 & 0.12 & 120.52 & 1.13 & 78.219 & 0.32 & 0.56 & 0.08 & 0.85 \\
\hline Error & 1 & 1921.89 & 0.11 & 94.412 & & & & & & \\
\hline Total & & 86535.4 & 3.76 & 1386.8 & & & & & & \\
\hline
\end{tabular}

\subsubsection{Contribution of Factors towards Response}

Table 19 shows that the pilot SOI timing has an influence on particle CMD for low cetane fuel as it was for the high cetane fuel. Strong influence of SOI timing on both fuels is acceptable as change in SOI effects the combustion phasing and plays an important role in the mixing characteristics of the charge affecting the particle formation. Effects of VGT and EGR on NOx formation have been found to be statistically significant at $95 \%$ confidence level while rail pressure along with the interaction between VGT and EGR have been identified to be significant on in-cylinder bulk temperature. 
Table 19: Effects of Control Factors on Emissions Responses

\begin{tabular}{|c|c|c|c|c|}
\hline No. & Control & \multicolumn{3}{|c|}{ \% Contribution } \\
\hline & Factor & CT & NOx & PM CMD \\
\hline 1 & VGT & 13.4 & 44.6 & 38.5 \\
\hline 2 & EGR & 14.1 & 42.5 & 2.4 \\
\hline 3 & SOI & 5.28 & 0.85 & 23.9 \\
\hline 4 & RP & 22.2 & 3.79 & 9.98 \\
\hline 5 & VGT*EGR & 32.7 & 4.9 & 9.72 \\
\hline 6 & SOI*RP & 10.2 & 3.28 & 8.69 \\
\hline 7 & Error & 2.23 & 0 & 6.8 \\
\hline
\end{tabular}

Table 20 lists the strongest parameters for a given response for the low cetane fuel. This table has been created from the results established in Table 19.

Table 20: Strongest Parameters on Response for Low Cetane Fuel

\begin{tabular}{|c|c|c|}
\hline Response & $\begin{array}{c}\text { Strongest } \\
\text { Parameters }\end{array}$ & $\begin{array}{c}\text { Strongest } \\
\text { Interactions }\end{array}$ \\
\hline In-Cylinder Bulk Temperature & Rail Pressure & VGT*EGR \\
\hline Brake Specific NOx emissions & EGR, VGT & - \\
\hline Particle CMD & VGT, SOI & - \\
\hline
\end{tabular}

\subsubsection{Effect of Control Factors on In-Cylinder Bulk Temperature}

Rail pressure for low cetane fuel as in the case of high cetane fuel has been identified as a parameter that has a major influence on in-cylinder bulk temperature. Furthermore, the interaction between VGT and EGR has also been found to have an influence over bulk temperature for both fuels. Again, to obtain the optimum strategy only these significant factors have been considered. 


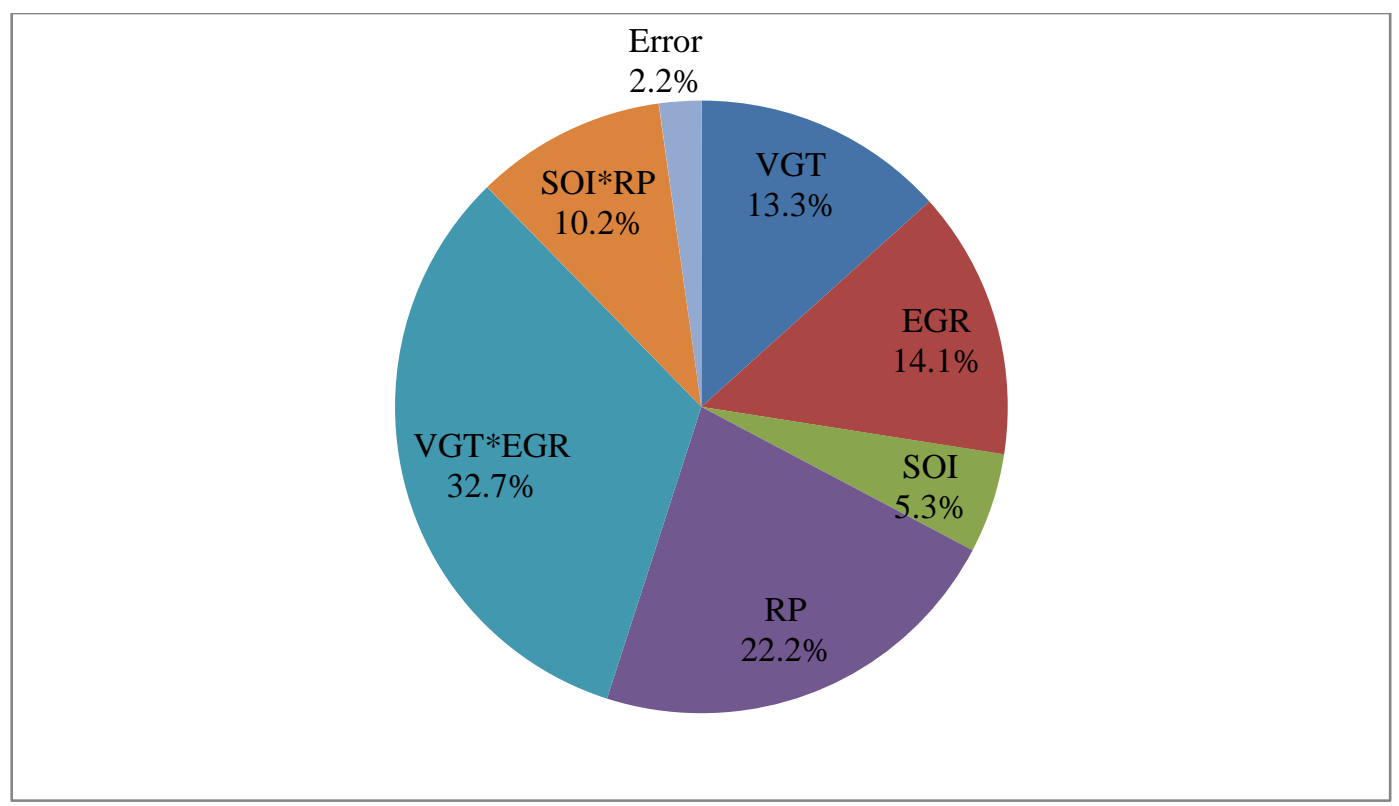

Figure 53: Effect of Control Factors on In-Cylinder Bulk Temperature

\subsubsection{Effect of Control Factors on NOx Emissions}

VGT and EGR were found to have a significant influence on the low cetane fuel. All the other parameters were not significant. Thus, to have the lowest NOx emissions VGT and EGR need to be optimized for perfomance.

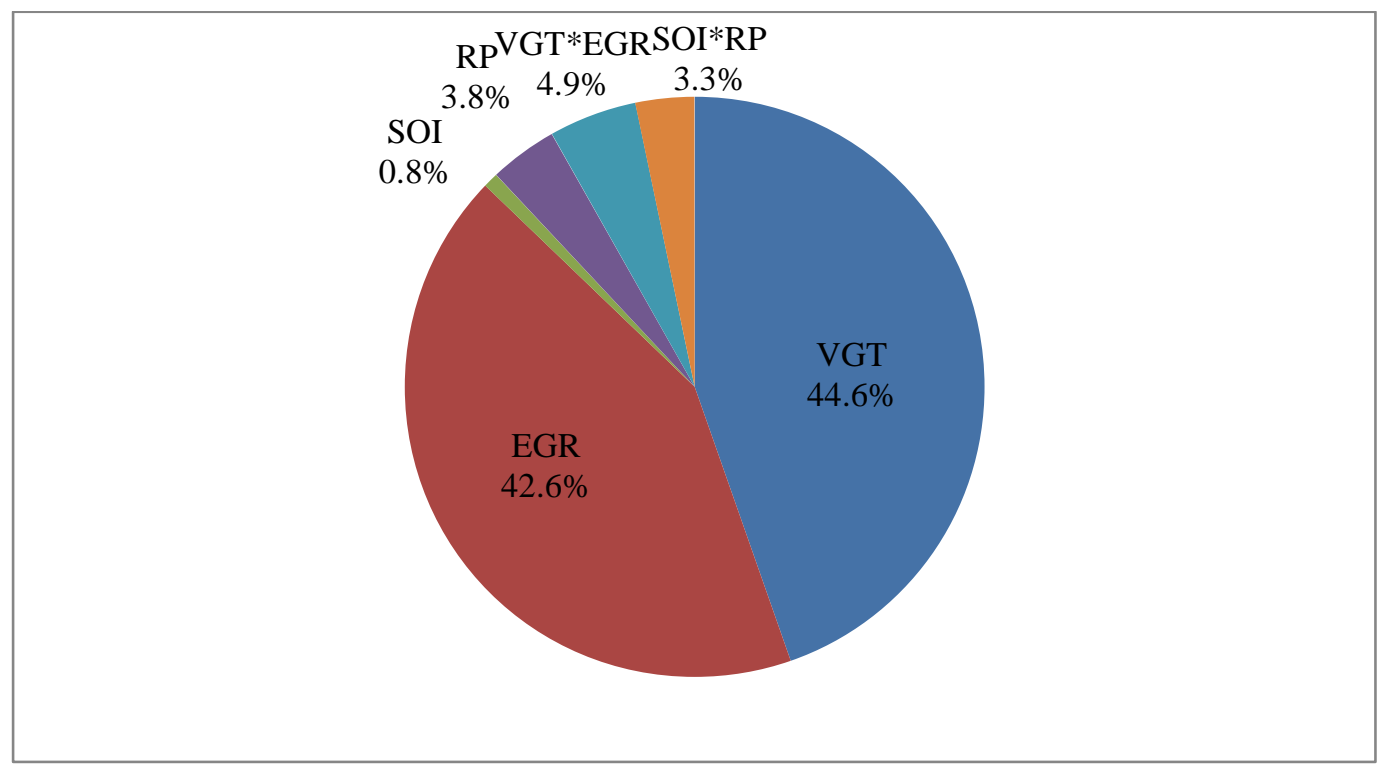

Figure 54: Effect of Control Factors on NOx Emissions 


\subsubsection{Effects of Control Factors on Particle Count Median Diameter}

Again, VGT and SOI have significant effects on particle CMD for both the fuels. An interesting fact here is that EGR does not have an influence on particle CMD. However, since VGT has an influence on particle CMD an indirect influence of EGR on particle CMD cannot be neglected.

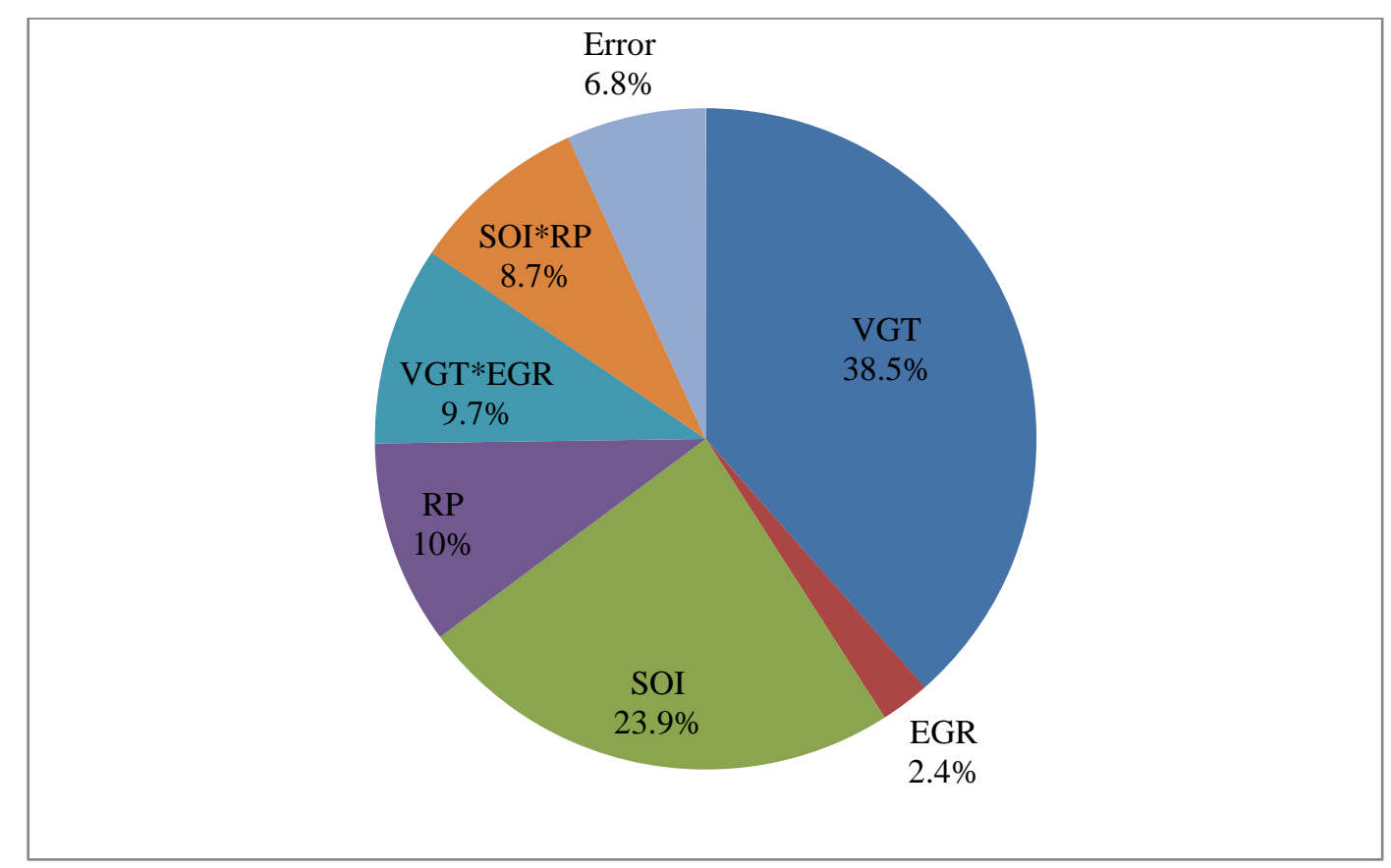

Figure 55: Effect of Control Factors on Particle CMD

\subsubsection{Effects of Significant Factors on In-Cylinder Bulk Temperature}

Effect of rail pressure on in-cylinder bulk temperature for low cetane fuel is seen in Figure 56. Increased rail pressure influences the combustion phasing, thus affecting the heat release rates and in-cylinder pressure. Ideally, during conventional combustion higher rail pressures should advance the combustion event causing an increase in heat release rates, in-cylinder pressures, and thus elevated NOx levels. However, Figure 56 shows increased rail pressures having a diminishing effect on the in-cylinder bulk temperature resulting in lower in-cylinder pressures. This trend may be because of the rail pressure having lesser influence on the combustion event as a whole when compared to EGR, VGT and SOI. Moreover, a split injection strategy initiated here which is not exactly conventional combustion might be another reason. 


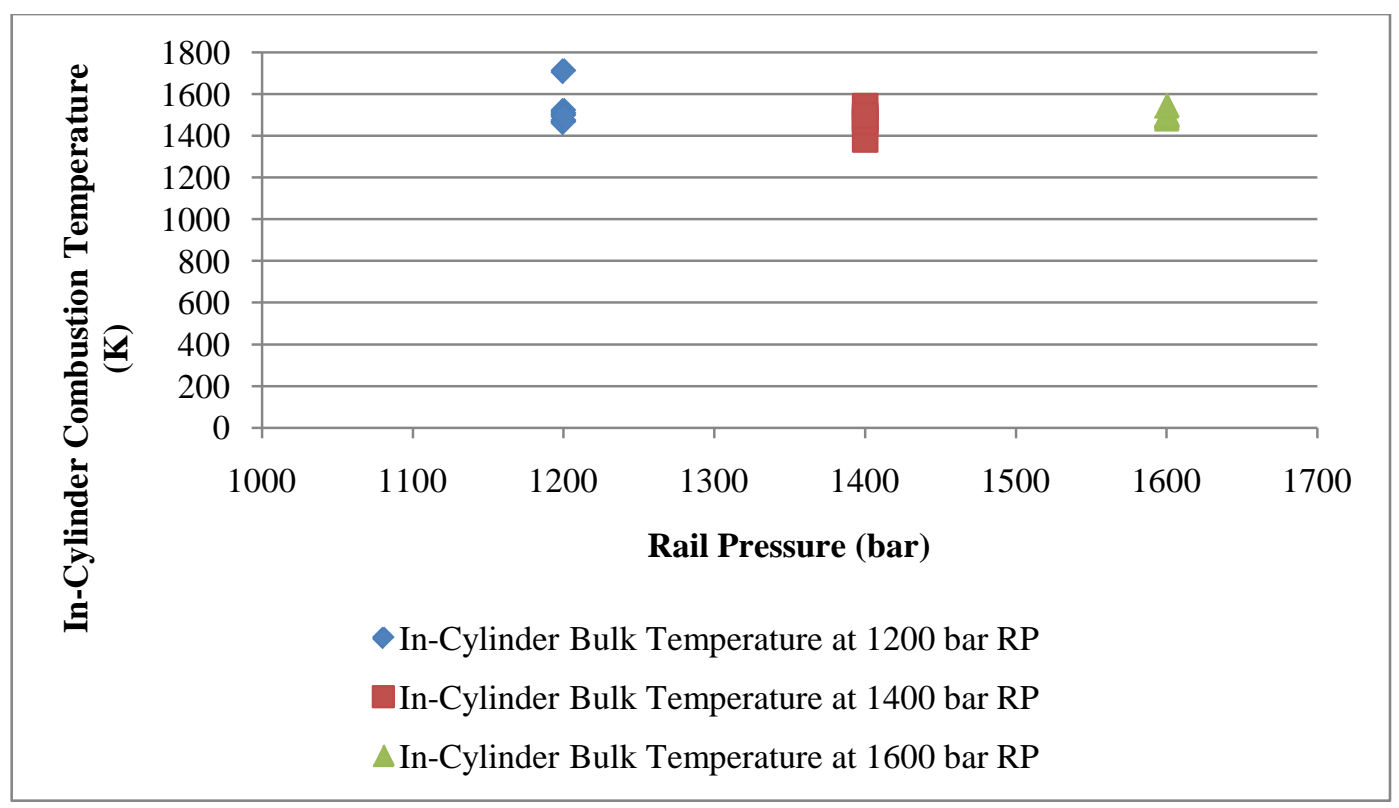

Figure 56: Effects of Rail Pressure on In-Cylinder Bulk Temperature

\subsubsection{Effects of Significant Factors on NOx Emissions}

The effects of significant factors on NOx emissions identified by the ANOVA test are discussed below.

\subsubsection{Effects of EGR on NOx Emissions}

As expected, increased EGR rates have a diminishing effect on the NOx emissions. Irrespective of the fuel used, EGR has a significant effect on NOx emissions. Figure 57 shows a clear trend in NOx emissions. However for the low cetane fuel, at $45^{\circ}$ BTDC SOI timing, the highest level of EGR (40-45\%) could not be attempted as it lead to misfire, thereby suggesting a strong influence of the cetane property of fuel on combustion. 


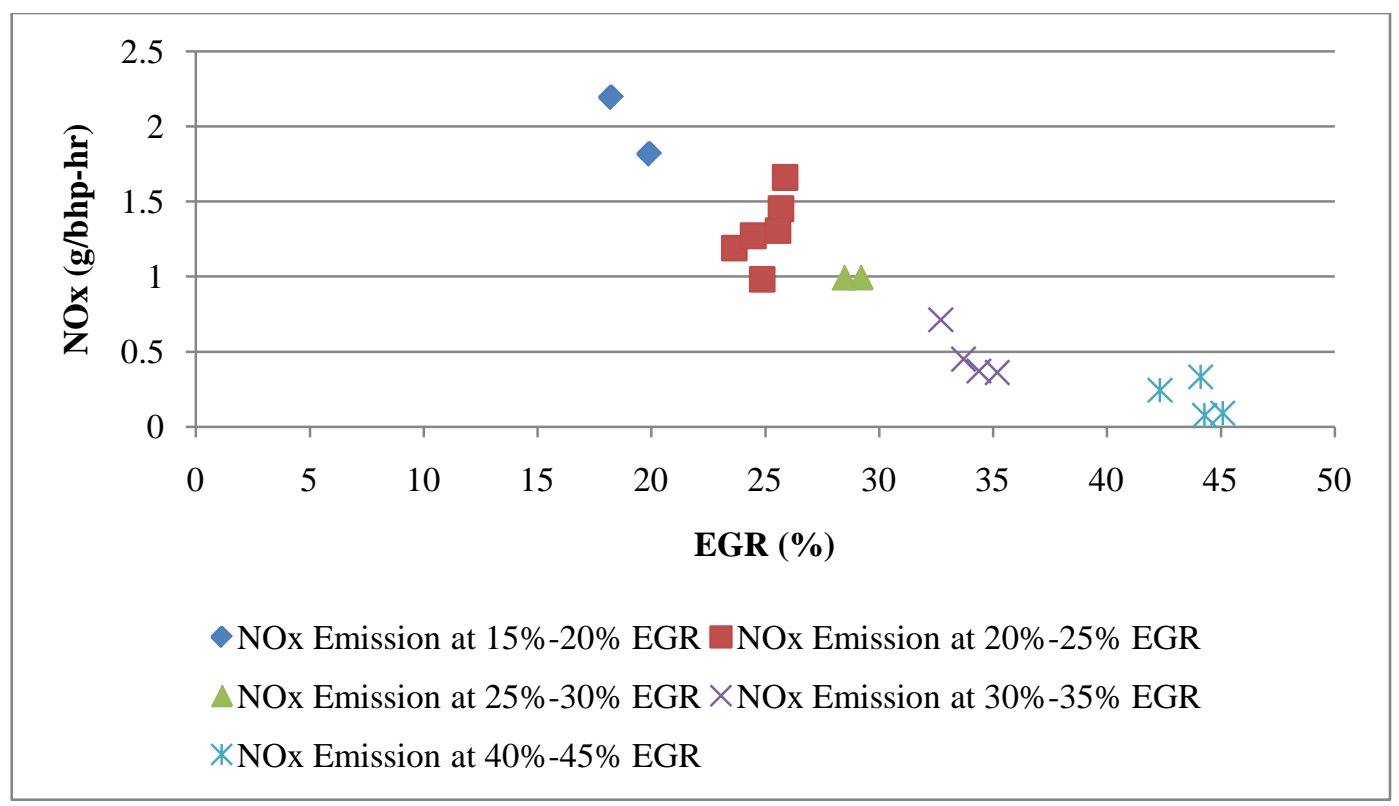

Figure 57: Effect of EGR Rate on NOx Emissions

\subsubsection{Effects of VGT on NOx Emissions}

Another significant influence on NOx emissions is the position of the VGT vane. Figure 58 shows a decreasing NOx emissions with an increase in boost. Higher boost essentially means higher $\mathrm{A} / \mathrm{F}$ ratio. Consequence of a high $\mathrm{A} / \mathrm{F}$ ratio is a leaner mixture which will avoid the high combustion temperature zones that produce NOx emissions. However more soot is produced as seen in Figure 59. Furthermore, high A/F ratio also improves the fuel economy.

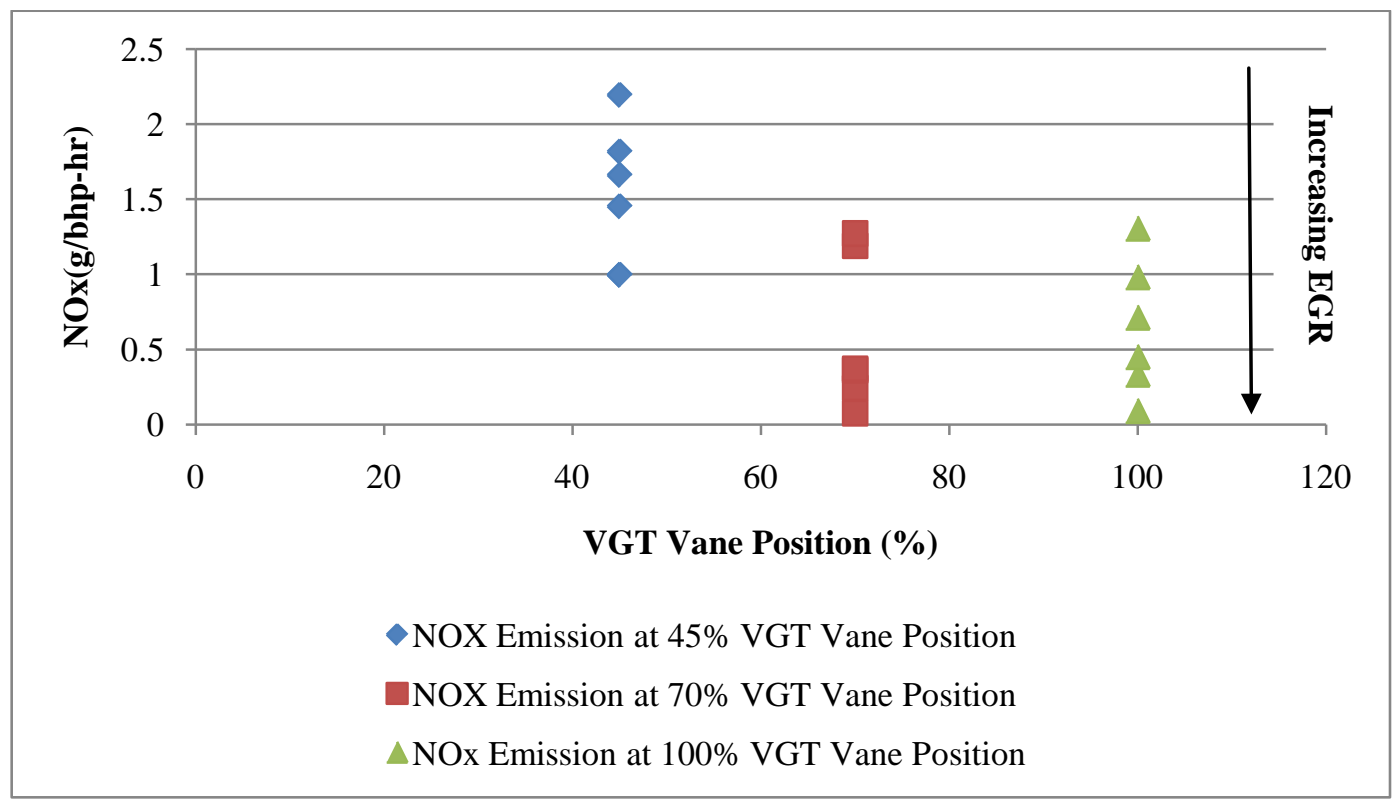

Figure 58: Effects of VGT Vane Position on NOx Emissions 


\subsubsection{Effects of Strongest Parameters on Particle CMD}

This section deals with the strongest parameters and their effects on particle CMD for low cetane fuel.

\subsubsection{Effects of VGT on Particle CMD}

As expected an inverse effect of VGT vane position is seen on particle CMD when compared to its effects on NOx formation. The PM CMD values increase as the VGT vane position (VGT \%) is increased. Again, as explained earlier this trend may be because of leaner mixtures at higher VGT vane positions.

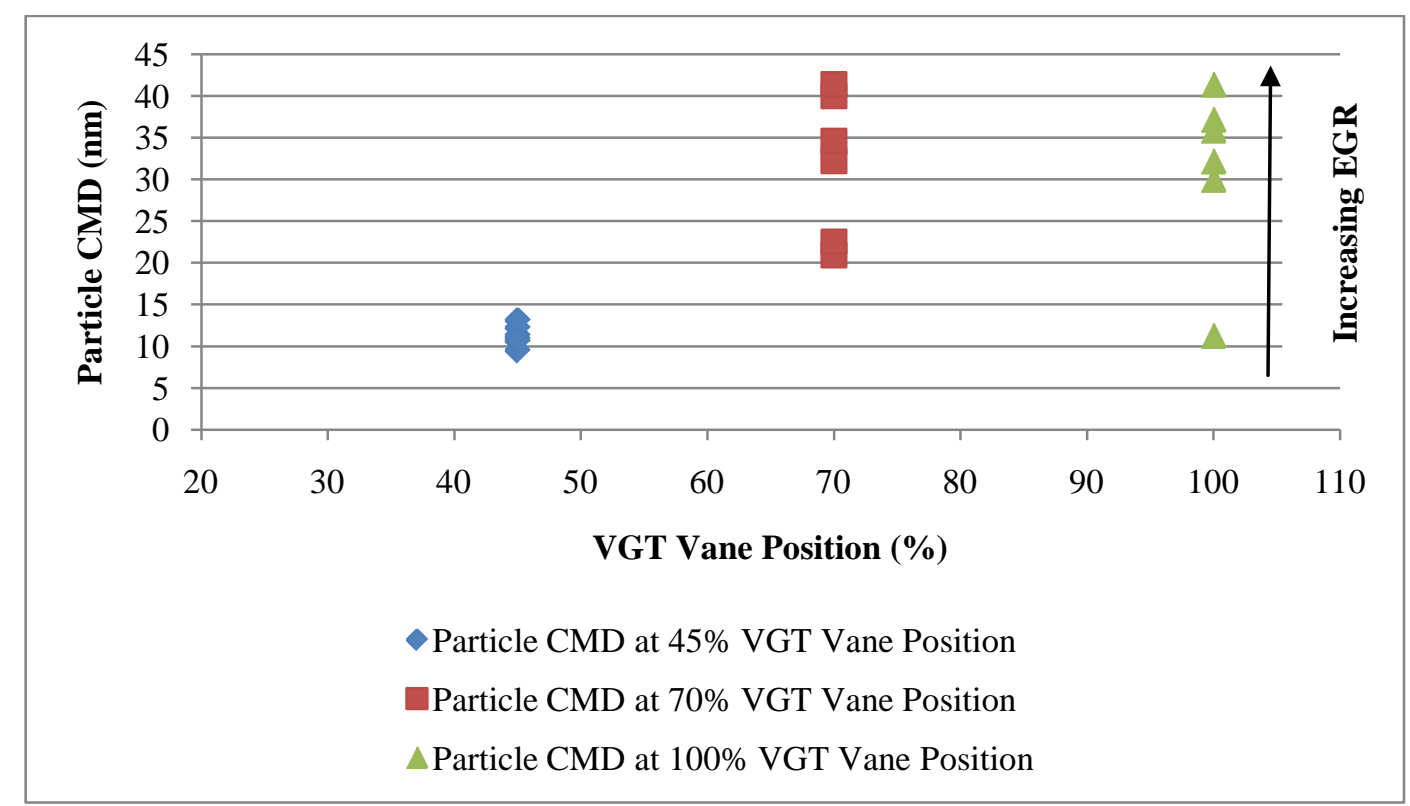

Figure 59: Effect of VGT Vane Position on Particle CMD at Same EGR Rate

\subsubsection{Effect of SOI Timing on Particle CMD}

The effect of SOI timing on low cetane fuel is similar to that of the high cetane fuel as it influences the mixing charecteristics of air-fuel mixture and thus particulate formation. 


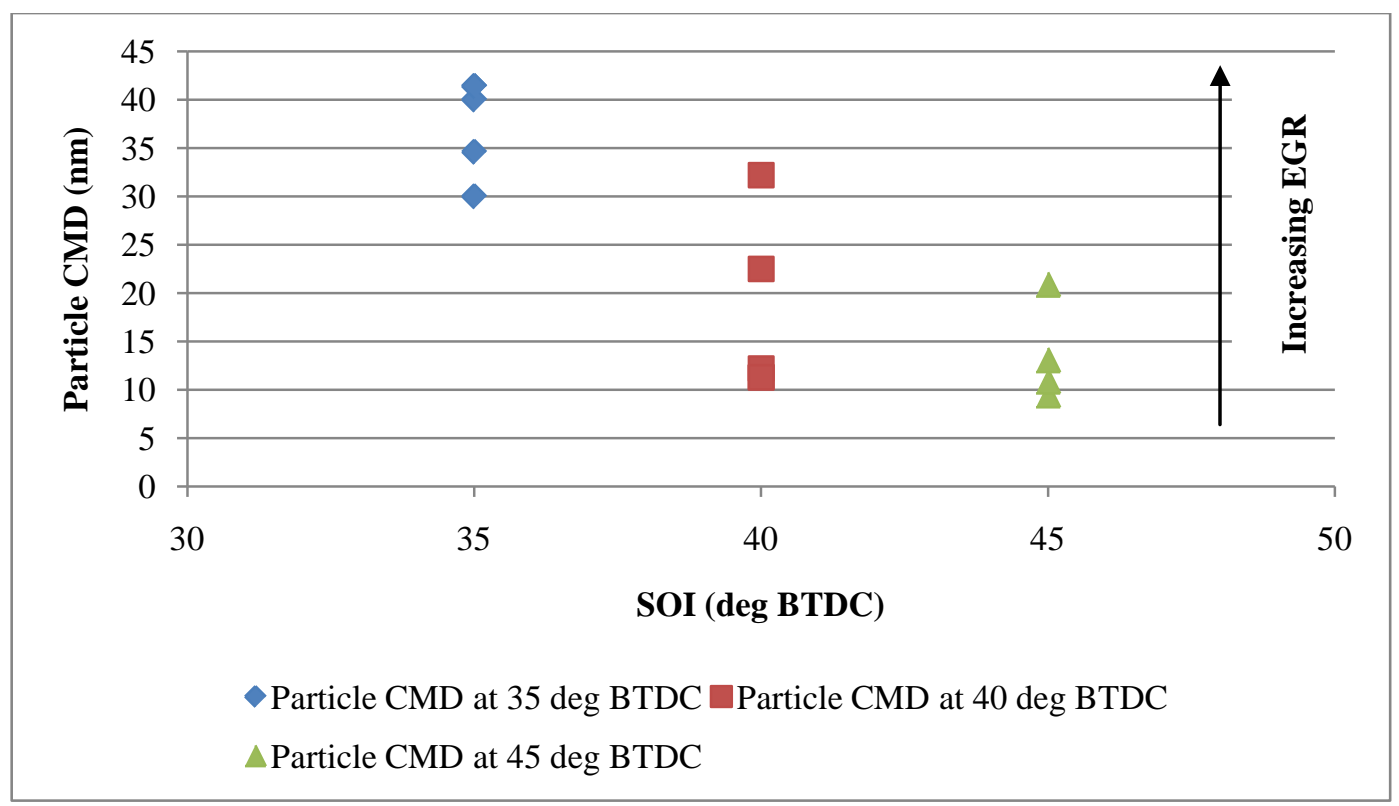

Figure 60: Effects of SOI Timing on Particle CMD

From the above figure advancing SOI leads to a decrease in particle CMD, and thus points towards a decrease in mass soot emissions.

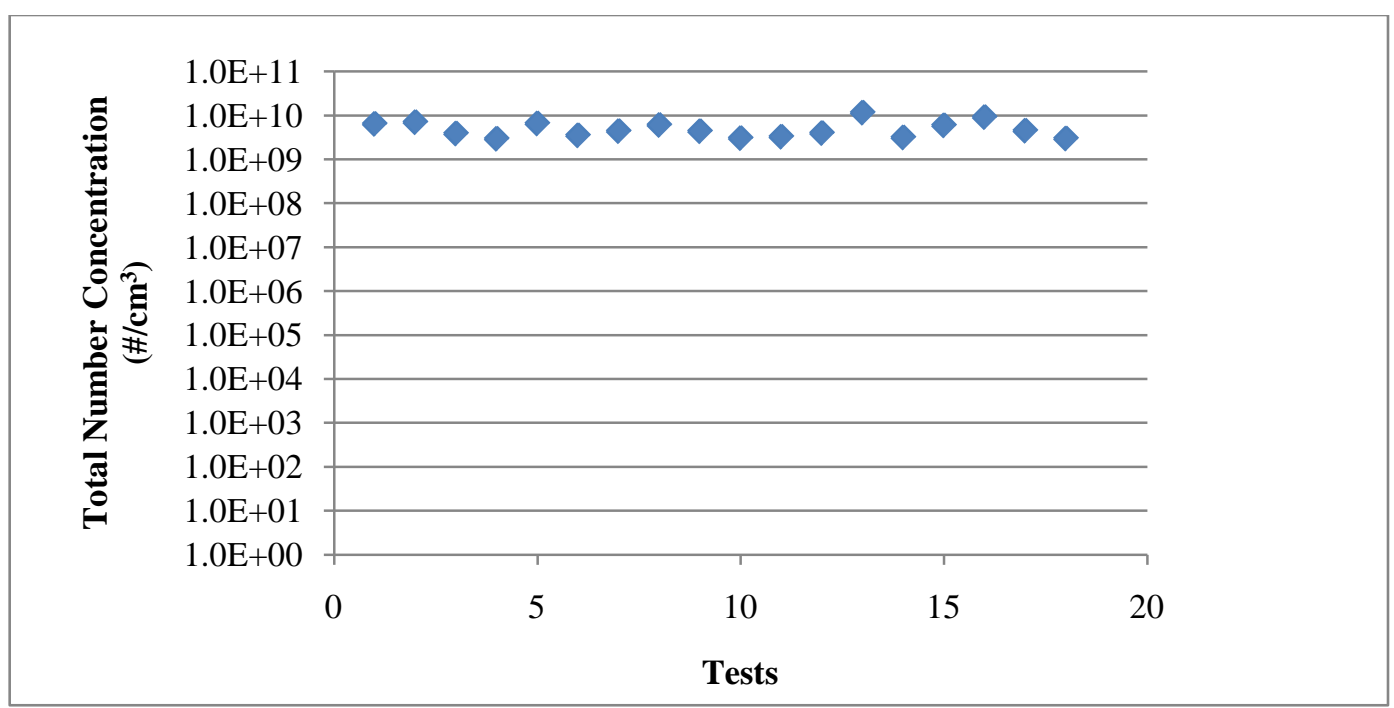

Figure 61: Total Number Concentration of PM Particles for the Tests

Similar to the high cetane fuel, the low cetane fuel also shows a diminishing particle CMD with increasing SOI along with no major change in the total concentration of the particles 
(see Figure 61). This again proves the hypothesis that advancing SOI will shift the particle CMD to lower values.

\subsubsection{Optimal Strategy for Low Cetane Fuel}

Similar to the high cetane fuel a response curve has been plotted for low cetane fuel as well. The desirability for low in-cylinder bulk temperature/low NOx/low particle CMD is show in Figure 62

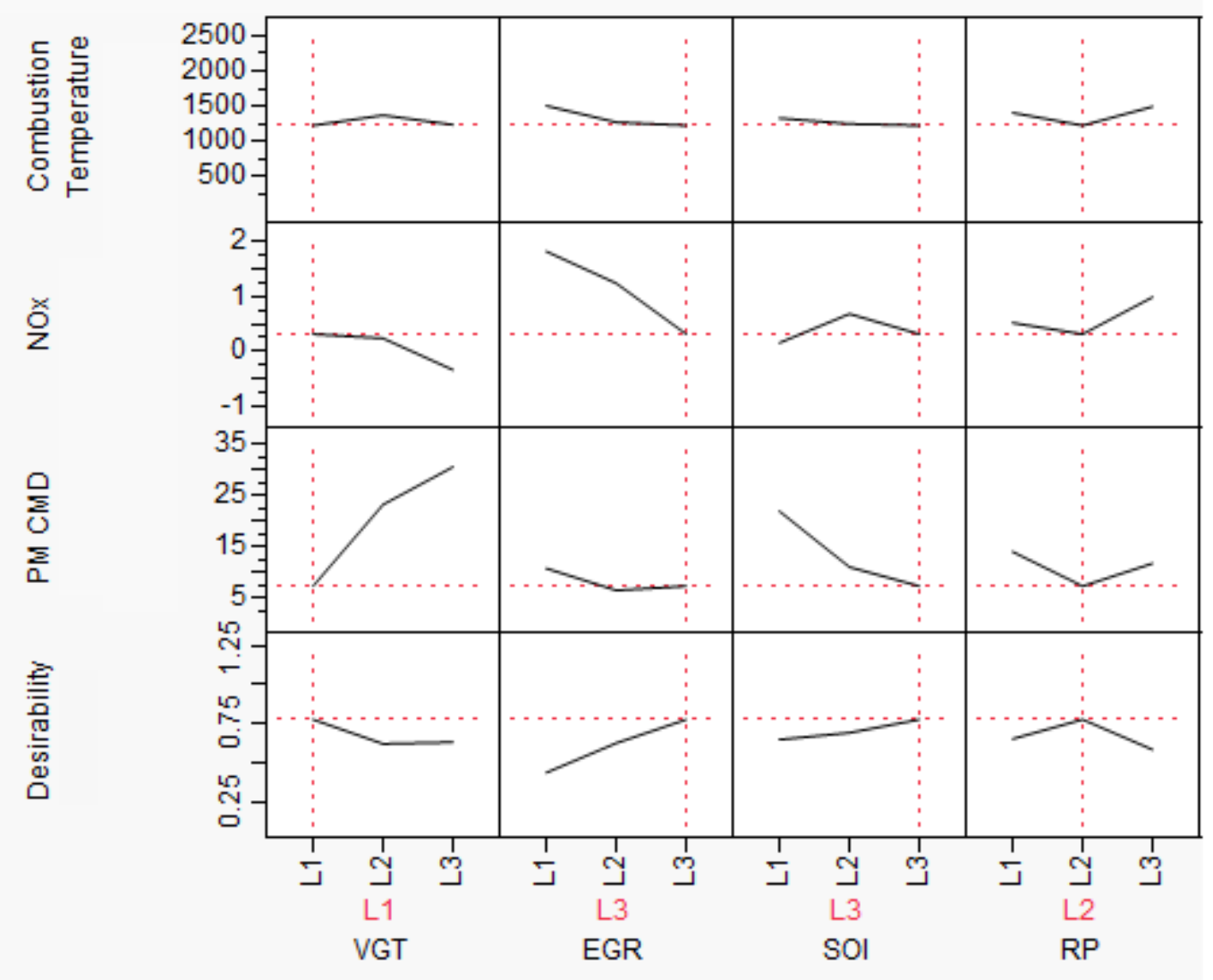

Figure 62: Response Curve for Low Cetane Fuel

The optimum strategy obtained in Figure 62 reflects the contribution from the strongest parameters identified by ANOVA. Having the lowest boost essentially should produce lower particle CMD and higher NOx emissions from Figures 58 and 59. Thus, the high NOx emissions because of low VGT vane position is compensated by having the highest setting for EGR rate while SOI has been advanced to the maximum extent possible to achieve a low particle CMD. Since, SOI timing has no significant effect on NOx emission, it was chosen in a way only to 
decrease the particle CMD. Having the second level for rail pressure would contribute to having the lowest in-cylinder bulk temperature possible.

\subsubsection{Optimum Setting for Low Cetane Fuel}

This section deals with the results obtained at the identified optimum strategy with the help of ANOVA and the response curve plotted. Table 21 shows the optimum parameter setting identified.

Table 21: Optimum Strategy for Low Cetane Fuel

\begin{tabular}{|c|c|c|c|}
\hline \multicolumn{4}{|c|}{ Optimal Setting } \\
\hline \multicolumn{4}{|c|}{ Low NOx/Low particle CMD/Low CT } \\
\hline VGT & EGR & SOI & RP \\
\hline $45 \%$ & $25-30 \%$ & 45 & 1400 \\
\hline
\end{tabular}

Figure 63 shows the results obtained at the identified optimum strategy for NOx and soot emissions. The baseline results here are from the engine running on a D2 diesel fuel having cetane number 44 with an OEM ECU.

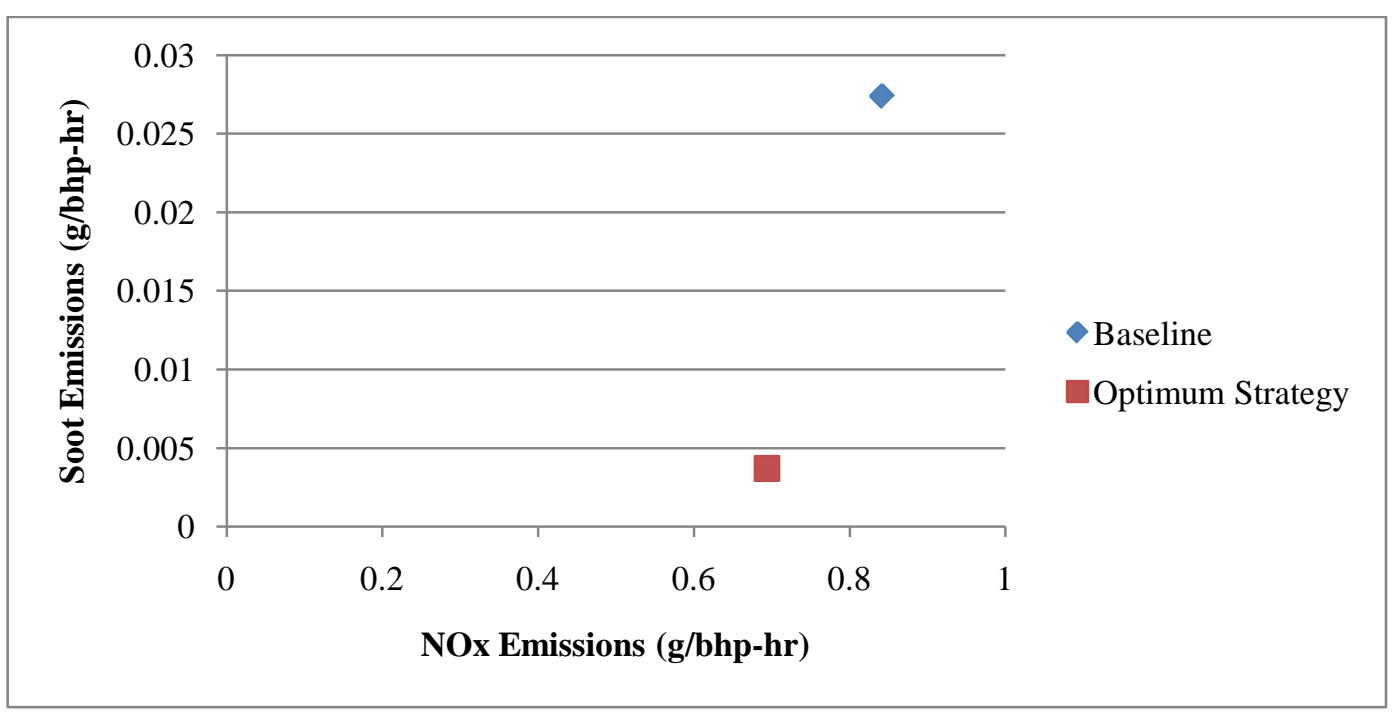

Figure 63: Comparison Between NOx and Soot Emissions during Baseline Operation and Optimum Strategy 
Results show simultaneous reduction in NOx and soot emissions compared to the baseline conventional combustion. Soot emissions are nearly zero for the low cetane fuel at optimum strategy. This result can be attributed directly to the property of the fuel. The low cetane fuel has a longer ignition delay when compared to a higher cetane fuel thus enhancing the mixing capabilities of the air-fuel mixture and avoiding the rich and lean pockets of the mixture.

\subsubsection{Comparison of Emissions Between Optimum Strategy and Baseline}

Figure 64 further shows the exact reduction in emissions during the optimum strategy for the low cetane fuel. A 17\% decrease in NOx emissions from baseline configuration is observed whereas the THC emissions have almost increased 2.5 times above the baseline value.

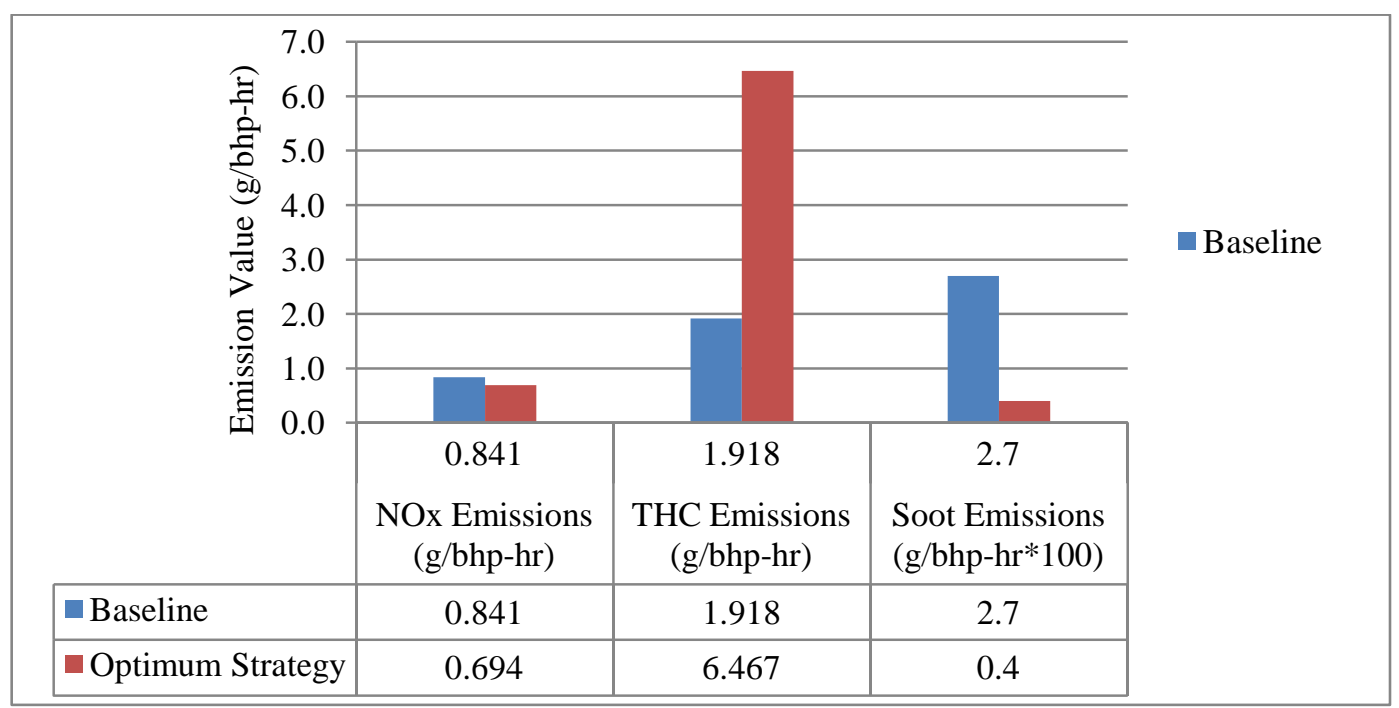

Figure 64: Comparison of Emissions Between Baseline and Optimum Strategy for Low Cetane Fuel

Soot emissions at optimum strategy in comparison with the baseline have reduced by $85 \%$. Decrease in the soot emissions is mainly due to the cetane property of the fuel, as discussed earlier. 


\subsubsection{PM Size Distribution Comparison Between Baseline and Optimum Strategy for Low Cetane Fuel}

Figure 65 shows the particle size distribution for the optimum strategy and the baseline. A clear shift towards the nucleation mode is seen during the optimum strategy when compared to the baseline. The shift in the particle CMD is from $30 \mathrm{~nm}$ to $12.2 \mathrm{~nm}$. The carbon particles generated during the optimum settings is small in size compared to the baseline due to the shift towards lower CMD and thus their contribution towards mass soot emissions is minimal.

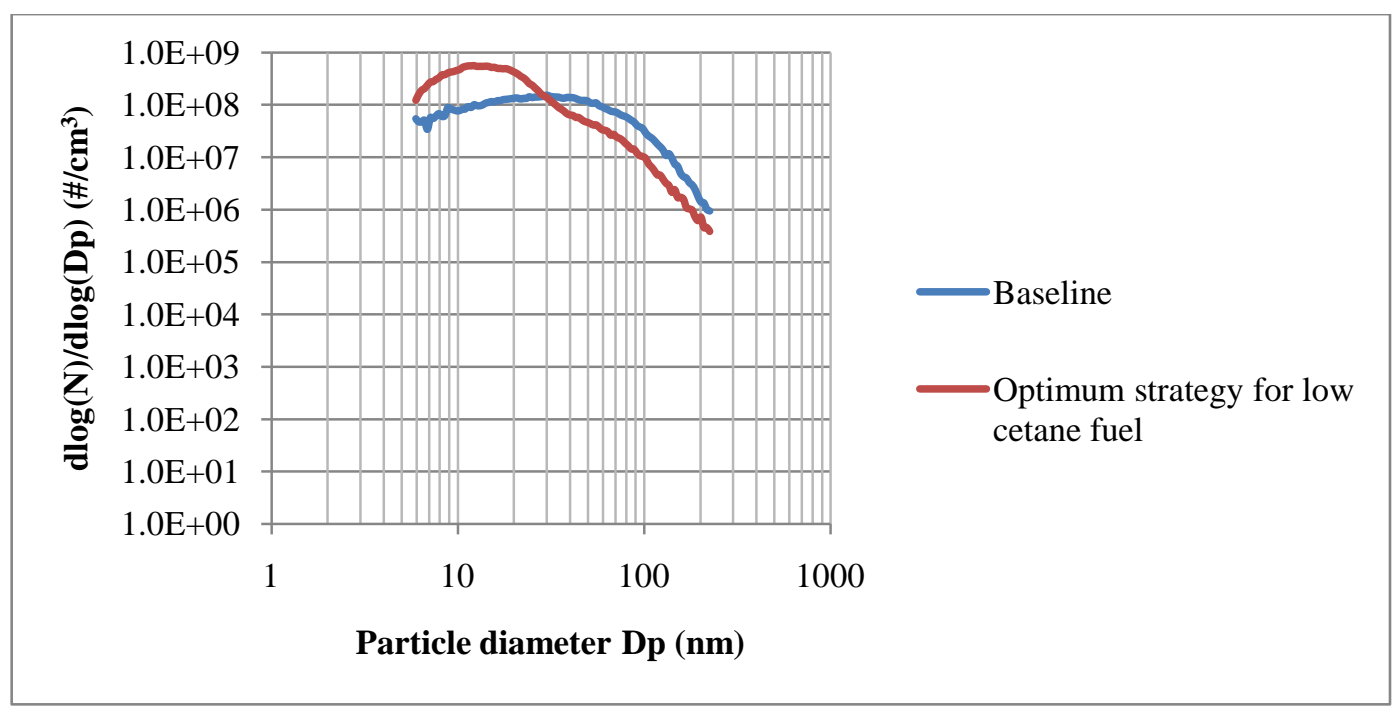

Figure 65: Comparison of PM Size Distribution Between Baseline and Optimum Strategy for Low Cetane Fuel

\subsection{Comparison Between Fuels}

This section discusses with the comparison between the gaseous emissions, soot emissions and particle size distributions for both fuels. Emissions characteristics of a fuel directly depend on its properties and this fact is clearly shown in the next section.

\subsubsection{Comparison Between Emissions}

A 51\% increase in the NOx emissions is seen in Figure 66 for the low cetane fuel compared to a high cetane fuel. This trend may be explained because of the 84\% soot reduction (see Figure 67) for low cetane fuel compared to the high cetane fuel. Thus, the NOx-PM trade-off is evident for the low cetane fuel. However, the NOx and soot emissions still remain below the baseline 
conventional combustion. The penalty for using the low cetane remains the THC emissions which is more than twice the amount of total hydrocarbons for high cetane fuel. Higher hydrocarbon emissions may be a result of wall wetting due to advanced pilot SOI timing. Wall wetting should be seen more with the low cetane fuel than the high cetane because of a prominent presence of ignition delay.

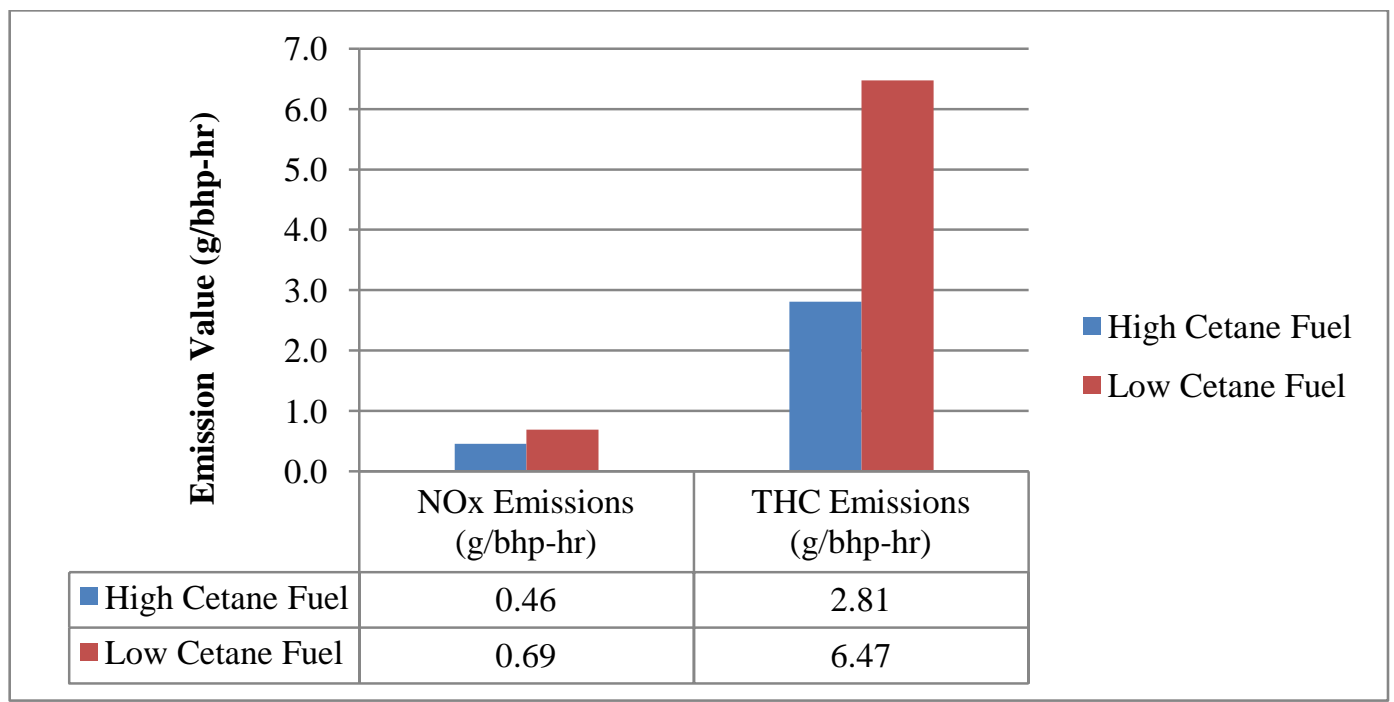

Figure 66: Comparison of gaseous emissions Between both the fuels

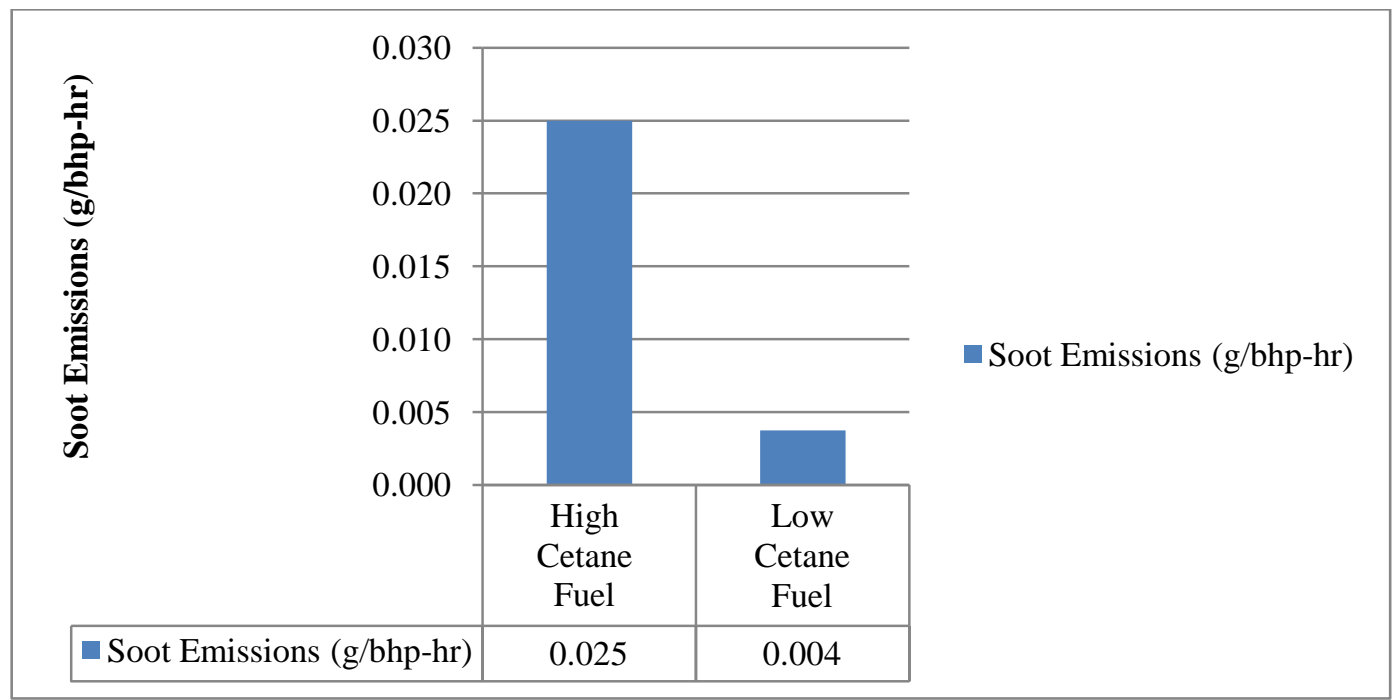

Figure 67: Comparison of Soot Emissions Between Fuels 


\subsubsection{Comparison of PM Size Distribution Between Optimum Strategies for Fuels}

Figure 68 shows the PM size distribution at the identified optimum strategy for both fuels. There is a clear shift towards nuclei particles for the low cetane fuel as compared to the high cetane fuel. A shift in CMD from 38.5nm to 12.2nm is seen. The low cetane fuel has a higher ignition delay compared to a high cetane fuel and thus achieves a better homogeneous like charge producing smaller carbon particles with a penalty in NOx.

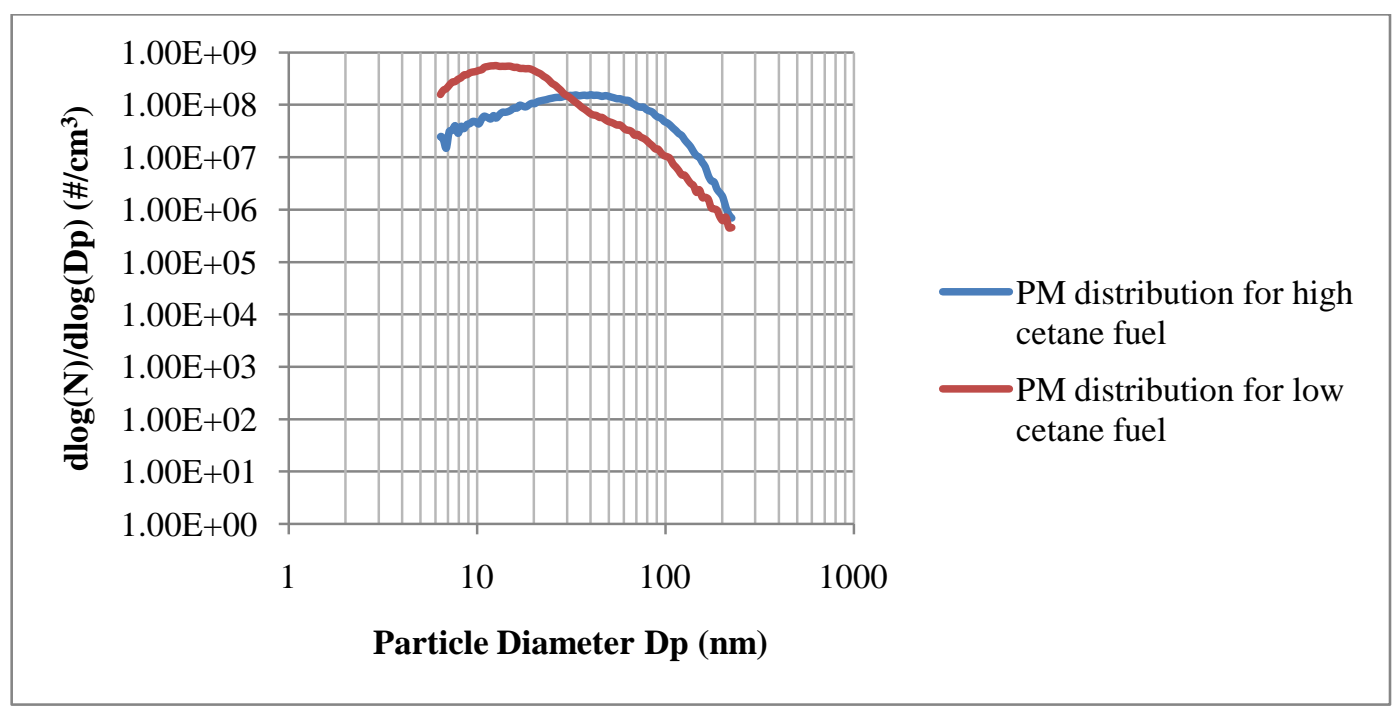

Figure 68: Comparison of PM Size Distribution Between Fuels

\subsubsection{Comparison Between Optimum Strategy for both Fuels for Particle CMD Based on Dilution Strategy}

A comparison in the particle CMD is shown in Table 22 between the two fuels using two different types of dilution strategies. An interesting fact here is the particle CMD obtained using a cold dilution for low cetane is higher than the CMD obtained for high cetane. It is understood that the presence of high voltaile fraction (a charecteristic of LTC) has contributed to larger particles and thus higher CMD.

Table 22: CMD comparison Between Fuels Based on the Dilution Strategy Used

\begin{tabular}{|c|c|c|}
\hline & \multicolumn{2}{|c|}{ Count Median Diameter (nm) } \\
\hline Fuel & Hot Dilution & Cold Dilution \\
\hline High Cetane & 38.5 & 69.8 \\
\hline Low Cetane & 12.2 & 107.4 \\
\hline
\end{tabular}




\section{CONCLUSIONS AND RECOMMENDATIONS}

\subsection{Conclusions}

The primary focus of this study was to characterize the size distributions and concentrations during LTC. In order to achieve LTC, optimization of four engine parameters namely VGT vane position, EGR rate, SOI timing and fuel injection rail pressure was carried out. Furthermore, the engine was operated on two fuels - one high cetane and the other low cetane to investigate their contribution towards regulated exhaust emissions.

The effect of SOI timing on particle CMD was found to be significant for both the low CN and high CN fuels. Advancing SOI results in a shift in PM size distribution towards nuclei mode for both fuels without a significant change in the total number concentration. However, contrary to the hypothesis an increase in rail pressures did not have an impact on the particle CMD. The rail pressure settings that were employed in this study were in a range that exceeded 1200 bar and the potential wall impingement at such high rail pressures did not impact PM size distribution.

Effects of fuel properties on emission characteristics, especially PM, were found to be more significant than actual engine parameters. However, engine settings were also strongly influenced by the fuel cetane number. As a result of that, identical level settings for engine parameters could not be achieved for the two different fuel studied.

PM size distributions at the optimized test set point (low in-cylinder bulk temperature, low NOx emissions and low particle CMD) for the high cetane fuel were similar to the baseline distribution. However a significant

- Decrease in the brake specific NOx emissions was observed when compared to the baseline strategy

- Increase in THC emissions was observed when compared to the baseline strategy

Also, the trade-off between NOx and PM does not exist for high cetane fuel while it was evident when the engine was operated on a low cetane fuel. 
A significant change in the particle size distribution at the optimized set point for LTC operation on low cetane fuel was observed in comparison to the baseline. The distribution showed a shift in particle count median diameter from 30nm in conventional combustion to $12.5 \mathrm{~nm}$ during optimized LTC.

Low cetane fuels may be preferred for LTC because of this combustion regime's zero soot characteristics, but not without a small penalty in NOx emissions and a relatively high penalty in THC emissions compared to high cetane fuels. However the NOx emissions still remain below the baseline conventional combustion.

Finally, use of cold dilution method to study the particle size distribution shows very high particle CMD for low cetane fuel probably because of the high volatile fraction that condensed on the smaller carbon particles. Thus, although the mass emissions of combustion generated particles are minimal during operation on low cetane fuel, effects of dilution strategy significantly affected the size distributions.

\subsection{Recommendations}

- L18 test matrix can be repeated to gain a better understanding of the emission responses of the engine at various settings. This will help in establishing more confidence in the responses recorded.

- Use of catalytic stripper to remove the volatile portion of the PM will result in a accurate study of the combustion generated particles. However, fuel sulfur could also induce $\mathrm{SO}_{3}$ formation and consequent sulfate formation.

- Split injection can be assumed as a control factor with three levels to study the influence of split injection strategies to achieve LTC. It is the author's belief that split injection strategy will have a significant impact achieving LTC regime.

- Effect of rail pressures on particle CMD has been found to be negligible. Lower rail pressures may be explored to study their effects on PM distribution. 


\section{REFERENCES}

[1] Juttu, S., Thipese, S.S., Marathe N.V. and Gajendra Babu, M.K., "Homogeneous Charge Compression Ignition (HCCI): A New Concept for Near Zero NOx and Particulate Matter (PM) from Diesel Engine Combustion," SAE Technical Paper 2007-26-020, 2007.

[2] Lilik, G.K., Herreros, J.M. and Boehman, A.L., "Advanced Combustion Operation in Compression Ignition Engine," Energy and Fuels, vol. 23, pp. 144-150, 2009.

[3] Dieselnet.com. [Online]. October 23, 2010.

Available: http://www.dieselnet.com/tech/engine_ltc.html

[4] GM Continues to Develop HCCI Platform, Demonstrates Gasoline HCCI at Idle. [Online]. 2008. Available: http://www.greencarcongress.com/2008/05/gm-continues-to.html

[5] Heywood, J.B., Internal Combustion Engines Fundementals: McGraw-Hill Book Co, 1988.

[6] Mathis, U., Mohr, M. and Forss, A.M., "Comprehensive Particulate Characterization of Modern Gasoline and Diesel Passenger Cars at Low Ambient Temperatures," Atmospheric Environment, vol. 39, pp. 107-117, 2005.

[7] Gordon, J. Variable Geometry Turbocharger. Motor Age, 2005.

[8] Rader, T. and Jung, R., "Effects of Variable Geometry Turbochargers in Increasing Effeciency and Reducing Lag,". [Online]. December 9, 2007.

Available: http://me1065.wikidot.com/variable-geometry-turbochargers

[9] Ryskamp, R.H., "Exploration of Injection Strategy and Fuel Property Effects on Advanced Combustion," Master's Dissertation, Department of Mechanical and Aerospace Engineering, West Virginia University, 2010.

[10] Simescu, S., Ryan, T.W., Neely, G.D., Matheaus, A.C. and Surampudi, B., "Partial Pre-mixed Combustion with Cooled and Uncooled EGR in a Heavy Duty Diesel Engine," SAE Technical Paper 2002-01-0963, 2002.

[11] Ghazikhani, M., Kalateh, M.R., Toroghi, Y.K. and Dehnavi, M., "An Experimental Study on the Effect of EGR and Engine Speed on CO and HC Emissions of Dual Fuel HCCI Engine," World Academy of Science, Engineering and Technology, vol. 52, 2009.

[12] Cho, K., Han, M., Sluder, C.S., Wagner, R.M. and Lilik, G.K., "Experimental Investigation of the Effects of Fuel Charecteristics on High Effeciency Clean Combustion in a Light-Duty Diesel Engine," SAE Technical Paper 2009-01-2669, 2009.

[13] Hasegawa, R. and Yanagihari, H., "HCCI combustion in DI Diesel Engine," SAE Technical Paper 2003-01-0745, 2003.

[14] Common Rail. [Online]. June 11, 2011.

Available: http://en.wikipedia.org/wiki/Common_rail 
[15] Mallamo, F., Badami, M. and Millo, F., "Effect of Compression Ratio and Injection Pressure on Emissions and Fuel Consumption of a Small Displacement Common-Rail Diesel Engine," SAE Technical Paper 2005-01-0379, 2005.

[16] Diesel Particulate Matter. [Online]. June 11, 2011.

Available: http://www.epa.gov/pm/

[17] Kittelson, D.B. and Khalek, I., "Formation of Nanoparticles During Exhaust Dilution," University of Minnesotta, January 20, 1999.

[18] Particulate Measurement Program- Heavy Duty Vehicle. [Online]. May. 2011.

Available: http://www.arb.ca.gov/research/veh-emissions/pmp-hd/pmp-hd.htm

[19] Health and Environment. [Online]. May 12, 2011.

Available: http://www.epa.gov/PM/health.html

[20] Oberdorster, G., Sharp, Z., Atudorei, V., Elder, A., Gelein, R., Kreyling, W. and Cox, C., "Translocation of Inhaled Ultrafine Particles to the Brain," Inhalation Toxicology, vol. 16, pp. 437-445, 2004.

[21] Flaim, K.C., "Study of the Variations in Continuous Diesel Particulate Matter Size Measurements and Effect of Fuel Properties on DPM Size," Master's Dissertation, Department of Mechanical and Aerospace Engineering, West Virginia University, 2008.

[22] "Toxological Profile For Sulfur Trioxide and Sulfuric Acid," U.S Department of Health and Human Services, 1998.

[23] Kittelson, D.B., "Engines and Nanoparticles: A Review," Journal of Aerosol Science, vol. 29, pp. 575-588, 1998.

[24] Storey, J., "Impacts of Advanced Combustion, Fuels and Aftertreatment Technologies on Diesel PM Emissions and Mobile Source Air Toxics: A Ten-Year Retrospective," in DEER, Sacremento, CA, 2009.

[25] Natti, K.C. and Henein, N.A., "Particulate Matter Charecterization Studies in a HSDI Diesel Engine Under Conventional and LTC Regime," SAE Technical Paper 2008-01-1086, 2008.

[26] ASTM D976-06 Standard Test Method for Calculated Cetane Index of Distillate Fuels. [Online], May 10, 2011. Available: http://www.astm.org/Standards/D976.htm

[27] ASTM D5186 - 03 Standard Test Method for Determination of Aromatic Content and Polynuclear Aromatic Content of Diesel Fuels and Aviation Turbine Fuels by Supercritical Fluid Chromatography. [Online]. 2009.

Available: http://www.astm.org/Standards/D5186.htm\#TOPOFPAGE

[28] "Increasing Diesel Fuel Volatility can Significantly Improve Effeciency and Emissions Under Early Direct-Injection, Low Temperature Combustion Conditions." Science and Technology for Energy and National Security, vol. 31, no. 1, February, 2009

Available: https://share.sandia.gov/crf/downloads/CRFV31N1.pdf

[29] Diesel Fuel Properties. [Online]. February 14, 2011.

Available: http://www.slideshare.net/biodieselautomotive/diesel-fuel-properties 
[30] Wu, Y., Carder, D., Shade, B., Atkinson, R., Clark, N. and Gautam, M., "A CFR 1065-

Compliant Transportable/On-Road Low Emissions Measurement Laboratory With Dual Primary

Full-Flow Dilution Tunnels," ASME Technical Paper ICES2009-76090, pp. 399-410, 2009.

[31] Air-Vac TD Series Data Sheet. [Online]. April 2, 2011.

Available: http://www.air-vac-eng.com/PDF\%20Files/td.pdf

[32] Air-Operated Vaccum Pumps Working. [Online]. April 12, 2011.

Available: http://www.airvacpumps.com/TDpump.htm

[33] Venkatasubramaniam, K.C., "Effect of Dilution Method on Diesel Exhaust Particulate Matter Concentrations and Size Distributions," Master's Dissertation, Department of Mecahnical and Aerospace Department, West Virginia University, 2007.

[34] "Model 3936 Scanning Mobility Particle Sizer Spectrometer Operation and Service Manual," ed, October 2006.

[35] "Model 3090 Engine Exhaust Particle Sizer Spectrometer Operation and Service Manual," ed, March 2006.

[36] "Model 3090 Engine Exhaust Particle Sizer Spectrometer," ed: TSI, 2005.

[37] AVL Micro Soot Sensor Working. [Online]. April 23,2011.

Available: https://www.avl.com/micro-soot-sensor

[38] Nuszkowski, J.P., "The Effects of Fuel Additives on Diesel Engine Emissions during Steady State and Transient Operation," Ph.D. Dissertation, Department of Mechanical and Aerospace Engineering, West Virginia University, 2010.

[39] Yamamoto, M., Yoneya, S., Matsuguchi, T. and Kumagai, Y., "Optimization of Heavy-Duty Diesel Engine Parameters for Low Exhaust Emissions Using Design of Experiments," SAE Technical Paper 2002-01-1148, 2002.

[40] Ardenese, M., "Simple Strategy-Based Technique to Reduce Emissions from SCR-Equipped Heavy Duty Diesel Engine Over Different Engine-Out Calibrations," Ph.D. Dissertation, Department of Mecahnical and Aerospace Engineering, 2008.

[41] Ice, J.D., "Investigation of EGR and Fuel Property Effects on Advanced Combustion Strategies Using In-Cylinder Combustion Analyses," Master's Dissertation, Department of Mechanical and Aerospace Engineering, 2010.

[42] Roy, R.K., Design of Experiments Using the Taguchi Method. New York: John Wiley \& Sons, January 2001.

[43] Moore, D.S. and Mccabe, G.B., Introduction to the Practice of Statistics. New York: W.H. Freeman and Company, 1989.

[44] Obermiller, D.J., "Multiple Response Optimization using JMP ${ }^{\circledR}$," The Dow Chemical Company, Midland, MI, May 2, 2011.

[45] Significance in Statistical Surveys. [Online]. March 10, 2011.

Available: http://www.surveysystem.com/signif.htm 


\section{APPENDICES}

Table 23: FACE Fuel Properties

\begin{tabular}{|c|c|c|}
\hline \multicolumn{3}{|c|}{ Analyses of FACE Diesel Fuels (Final 8/28/2008) } \\
\hline FACE Fuel \#: & 4 & 6 \\
\hline CPChem Designation: & FD-4-01 & FD-6-01 \\
\hline \multicolumn{3}{|c|}{ Design Variable Levels: } \\
\hline \multicolumn{3}{|c|}{ Cetane Number by Engine Method-ASTM D613 : } \\
\hline CPChem C of A & 28.44 & 53.3 \\
\hline ORNL/SwRI & 28.5 & 54.1 \\
\hline \multicolumn{3}{|c|}{ Distillation, T90 (F) - ASTM D86: } \\
\hline CPChem C of A & 639 & 646 \\
\hline ORNL/SwRI & 640 & 642 \\
\hline \multicolumn{3}{|c|}{ Hydrocarbons by FIA - ASTM D1319: } \\
\hline \multicolumn{3}{|c|}{ Aromatics, Volume \% (Reproducibility = 1.4-1.6 vol.\%): } \\
\hline -CPChem C of A & 46.6 & 21.3 \\
\hline ORNL/SwRI (\& repeat) & $51.2(49.1)$ & 22.5 \\
\hline NCUT (\& repeat) & $57.0(60.0)$ & 17.4 \\
\hline \multicolumn{3}{|c|}{ Olefins, Volume \% (Reproducibility = $1.7-5.1$ vol.\%): } \\
\hline CPChem C of A & 1.3 & 0.7 \\
\hline ORNL/SwRI (\& repeat) & $12.4(7.7)$ & 4.8 \\
\hline NCUT (\& repeat) & $3.6(3.8)$ & 4.1 \\
\hline \multicolumn{3}{|c|}{ Saturates, Volume \% (Reproducibility = 5.6-4.8 vol.\%): } \\
\hline CPChem C of A & 52.1 & 78 \\
\hline ORNL/SwRI (\& repeat) & $36.4(43.2)$ & 72.7 \\
\hline NCUT (\& repeat) & $39.4(36.2)$ & 78.5 \\
\hline \multicolumn{3}{|c|}{ Aromatics by SFC - ASTM D5186 (Reproducibility = 1.5-1.8 mass\%): } \\
\hline \multicolumn{3}{|c|}{ Total Aromatics, Mass \% } \\
\hline ORNL/SwRI & 40.7 & 21.1 \\
\hline NCUT & 40.6 & 21.9 \\
\hline \multicolumn{3}{|l|}{ Mono Aromatics, Mass \% } \\
\hline ORNL/SwRI & 38.8 & 17 \\
\hline NCUT & 38.7 & 17.2 \\
\hline \multicolumn{3}{|c|}{ Polynuclear Aromatics, Mass \% } \\
\hline ORNL/SwRI & 2 & 4.1 \\
\hline NCUT & 1.9 & 4.7 \\
\hline \multicolumn{3}{|c|}{ Hydrocarbon Types by Mass Spectrometry, Volume \% - ASTM D2425 (ORNL/SwRI): } \\
\hline Paraffins (Reproducibility $=4.0 \%$ ) & 39.7 & 42.1 \\
\hline Monocycloparaffins (Reproducibility $=5.2 \%$ ) & 22.8 & 21.9 \\
\hline Dicycloparaffins (Reproducibility $=4.4 \%$ ) & 0 & 10.6 \\
\hline Tricycloparaffins (Reproducibility $=2.0 \%$ ) & 0 & 5.4 \\
\hline Total Napthenes & 22.8 & 37.9 \\
\hline Total Saturates & 62.5 & 80 \\
\hline Alkylbenzenes (Reproducibility = 1.4\%) & 35.2 & 8.2 \\
\hline Indans/Tetralins (Reproducibility $=0.5 \%$ ) & 0.6 & 6 \\
\hline Indenes (CnH2n-10) & 0 & 1.3 \\
\hline
\end{tabular}




\begin{tabular}{|c|c|c|}
\hline FACE Fuel \#: & 4 & 6 \\
\hline Napthalene (Reproducibility = 1.0\%) & 0.5 & 0.6 \\
\hline Alkylnapthalenes & 0.9 & 1.6 \\
\hline Acenapthenes $(\mathrm{CnH2n}-14)$ (Reproducibility $=0.9 \%)$ & 0.1 & 1.6 \\
\hline Acenapthylenes $(\mathrm{CnH} 2 \mathrm{n}-16)($ Reproducibility $=0.7 \%)$ & 0.2 & 0.8 \\
\hline Tricyclic Aromatics $(\mathrm{CnH} 2 \mathrm{n}-18)($ Reproducibility $=0.4 \%)$ & 0 & 0 \\
\hline Total PNAs & 1.7 & 4.6 \\
\hline Total Aromatics & 37.5 & 20.1 \\
\hline \multicolumn{3}{|c|}{ Net Heat of Combustion (BTU/lb) -ASTM D240 (Reproducibility = $0.40 \mathrm{MJ} / \mathrm{kg}=172 \mathrm{Btu} / \mathrm{lb}$ ): } \\
\hline ORNL/SwRI & 18269.4 & 18399.4 \\
\hline \multicolumn{3}{|c|}{ API Gravity - ASTM D4052: } \\
\hline ORNL/SwRI & 37.8 & 36.7 \\
\hline \multicolumn{3}{|c|}{ Specific Gravity (Reproducibility $=0.0005 \mathrm{~g} / \mathrm{ml}$ ) : } \\
\hline CPChem C of A & 0.8355 & 0.8411 \\
\hline ORNL/SwRI & 0.8359 & 0.8412 \\
\hline NCUT & 0.8352 & 0.8401 \\
\hline \multicolumn{3}{|c|}{ Elemental Analysis - ASTM D5291: } \\
\hline \multicolumn{3}{|c|}{ Carbon, wt\% (Reproducibility = $($ Mean Value +48.48$) * 0.018):$} \\
\hline ORNL/SwRI & & 86.22 \\
\hline NCUT & & 86.28 \\
\hline \multicolumn{3}{|c|}{ Hydrogen, wt \% (Reproducibility $\left.=0.2314^{*}(\text { Mean Value })^{\wedge} 0.5\right)$ : } \\
\hline ORNL/SwRI & 12.77 & 13.66 \\
\hline NCUT & 13.23 & 13.55 \\
\hline Bromine Number (g Br/100g) -ASTM D1159-NCUT: & 0.29 & 0.23 \\
\hline \multicolumn{3}{|c|}{ Cloud Point $\left({ }^{\circ} \mathrm{C}\right)$ - ASTM D2500: } \\
\hline ORNL/SwRI & -50 & -25 \\
\hline NCUT & -59 & -28 \\
\hline \multicolumn{3}{|c|}{ Kinematic Viscosity at $40^{\circ} \mathrm{C}(\mathrm{cSt})$ - ASTM D445 (Reproducibility = $0.8 \%$ ): } \\
\hline CPChem C of A & - & 3.09 \\
\hline ORNL/SwRI & 1.785 & 3.097 \\
\hline NCUT & 1.781 & 3.099 \\
\hline \multicolumn{3}{|c|}{ Sulfur by UV Fluorescence (PPM) - ASTM D5453 : } \\
\hline CPChem C of A & 0.1 & 13.6 \\
\hline ORNL/SwRI & $<1$ & 2.8 \\
\hline Sulfur (PPM) -ASTM D5623 -NCUT: & $<0.5$ & 2 \\
\hline Nitrogen (mg/L) - ASTM D4629 - NCUT: & 0.87 & 2.3 \\
\hline \multicolumn{3}{|c|}{ Cetane Number by Engine Method -ASTM D613: } \\
\hline CPChem C of A & 28.4 & 53.3 \\
\hline ORNL/SwRI & 28.5 & 54.1 \\
\hline \multicolumn{3}{|c|}{ Cetane Index (calculated) - ASTM D976: } \\
\hline ORNL/SwRI & 40.7 & 52.1 \\
\hline \multicolumn{3}{|c|}{ Flash Point by Closed Cup $\left({ }^{\circ}\right.$ F) - ASTM D93: } \\
\hline CPChem C of A & 130.4 & - \\
\hline ORNL/SwRI & 139 & 166 \\
\hline \multicolumn{3}{|c|}{ Distillation $\left({ }^{\circ}\right.$ F) - ASTM D86 (Reproducibility dependent on apparatus and setup used): } \\
\hline \multicolumn{3}{|c|}{ CPChem C of A } \\
\hline IBP & 331.7 & 364.3 \\
\hline $5 \%$ & 345.6 & 414.3 \\
\hline $10 \%$ & 350.1 & 440.6 \\
\hline
\end{tabular}




\begin{tabular}{|c|c|c|}
\hline FACE Fuel \#: & 4 & 6 \\
\hline $20 \%$ & 360.7 & 471.4 \\
\hline $30 \%$ & 376.7 & 494.1 \\
\hline $40 \%$ & 400.5 & 512.8 \\
\hline $50 \%$ & 437.5 & 530.2 \\
\hline $60 \%$ & 477.9 & 550.9 \\
\hline $70 \%$ & 518.4 & 575.2 \\
\hline $80 \%$ & 574.7 & 607.3 \\
\hline $90 \%$ & 639 & 645.8 \\
\hline $95 \%$ & 664 & 667.4 \\
\hline FBP & 675.1 & 674.4 \\
\hline Recovered (mL) & 98.5 & 97.6 \\
\hline Residue (mL) & 1 & 0.8 \\
\hline Loss (mL) & 0.5 & 1.6 \\
\hline \multicolumn{3}{|c|}{ ORNL/SwRI } \\
\hline IBP & 324 & 369 \\
\hline $5 \%$ & 342 & 405 \\
\hline $10 \%$ & 348 & 433 \\
\hline $15 \%$ & 353 & 450 \\
\hline $20 \%$ & 359 & 466 \\
\hline $30 \%$ & 376 & 489 \\
\hline $40 \%$ & 400 & 508 \\
\hline $50 \%$ & 433 & 527 \\
\hline $60 \%$ & 474 & 547 \\
\hline $70 \%$ & 513 & 569 \\
\hline $80 \%$ & 571 & 601 \\
\hline $90 \%$ & 640 & 642 \\
\hline $95 \%$ & 664 & 663 \\
\hline FBP & 674 & 673 \\
\hline Recovered (mL) & 97.7 & 97.5 \\
\hline Residue (mL) & 1.4 & 1.7 \\
\hline Loss (mL) & 0.9 & 0.8 \\
\hline \multicolumn{3}{|c|}{$\begin{array}{c}\text { Simulated Distillation }\left({ }^{\circ} \text { F) - mass \% - ASTM D2887 - NCUT (Reproducibility - 1.4 F @ 10\%; } 2.2\right. \\
\text { F @ 95\%; 5.8 F @ FBP): }\end{array}$} \\
\hline $0.50 \%$ & 283.3 & 253.8 \\
\hline $5 \%$ & 298.4 & 357.1 \\
\hline $10 \%$ & 326.1 & 402.1 \\
\hline $15 \%$ & 328.6 & 433.0 \\
\hline $20 \%$ & 338.7 & 456.1 \\
\hline $30 \%$ & 359.6 & 488.8 \\
\hline $40 \%$ & 397.0 & 516.2 \\
\hline $50 \%$ & 442.8 & 541.0 \\
\hline $60 \%$ & 475.5 & 565.2 \\
\hline $70 \%$ & 522.0 & 594.0 \\
\hline $80 \%$ & 584.6 & 643.3 \\
\hline $90 \%$ & 677.5 & 690.4 \\
\hline $95 \%$ & 703.4 & 710.2 \\
\hline
\end{tabular}

